\title{
Revision of Trechus Clairville, 1806 of the Bale Mountains and adjacent volcanos, Ethiopia (Coleoptera, Carabidae, Trechini)
}

\author{
Joachim SCHMIDT ${ }^{1} \&$ Arnaud FAILLE ${ }^{2, *}$ \\ ${ }^{1}$ University of Rostock, Institute of Biosciences, General and Systematic Zoology, \\ Universitätsplatz 2, 18055 Rostock, Germany. \\ ${ }^{1}$ University of Marburg, Fb. 17 - Biologie, Karl-von-Frisch-Straße 8, 35043 Marburg, Germany. \\ ${ }^{2}$ Institute of Evolutionary Biology (CSIC-Universitat Pompeu Fabra), \\ Passeig Maritim de la Barceloneta 37, 08003 Barcelona, Spain. \\ ${ }^{2}$ MECADEV - UMR 7179 MNHN/CNRS, Paris, France. \\ ${ }^{*}$ Corresponding author: arnaud1140@yahoo.fr \\ ${ }^{1}$ Email: schmidt@agonum.de
}

\begin{abstract}
${ }^{1}$ urn:1sid:zoobank.org:author:10E53423-2414-4280-9558-A8806A7D4531
${ }^{2}$ urn:lsid:zoobank.org:author:34F015D0-0840-478A-BFE2-AA2B1F6D05D5
\end{abstract}

\begin{abstract}
Based on a study of 2150 specimens of the genus Trechus Clairville, 1806 from the Bale Mts, Mount Chillalo, and Mount Enkuolo, southern Ethiopia, the current knowledge regarding systematics and distribution of the genus in the area is summarized. Twenty-six new species are described and figured in detail: Trechus abalkhasimi sp. nov. (southeastern slope of Bale Mts, below Mt Abalkhasim); T. adaba sp. nov. (western Bale Mts, above Adaba); T. angavoensis sp. nov. (western Bale Mts, above Dodola); T. balesilvestris sp. nov. (western Bale Mts, above Adaba); T. bombi sp. nov. (southern escarpment of Bale Mts, Harenna Forest); T. colobus sp. nov. (western Bale Mts); T. depressipennis sp. nov. (northeastern margin of Sanetti Plateau, Bale Mts); T. dodola sp. nov. (western Bale Mts, above Dodola); T. fisehai sp. nov. (northern slope of Bale Mts, above Goba); T. grandipennis sp. nov. and T. hagenia sp. nov. (southern escarpment of Bale Mts, Harenna Forest); T. haggei sp. nov. (northeastern margin of Sanetti Plateau); T. harenna sp. nov. and T. harryi sp. nov. (southern escarpment of Bale Mts, Harenna Forest); T. iridescens sp. nov. (southeastern slope of Bale Mts, below Mt Abalk-hasim); T. mattisi sp. nov. (southern escarpment of Bale Mts, Harenna Forest); T. mekbibi sp. nov. (southern and western part of Bale Mts); T. minitrechus sp. nov. (northeastern slope of Mt Enkuolo); T. nanulus sp. nov. (southern escarpment of Bale Mts, Harenna Forest); T. nigrifemoralis sp. nov. and T. oppositus sp. nov. (western Bale Mts, above Dodola); T. rira sp. nov. (southern escarpment of Bale Mts, upper Rira Valley); T. sanettii sp. nov. (southeastern slope of Sanetti Plateau, Bale Mts); T. tragelaphus sp. nov. (western Bale Mts, above Dodola); T. transversicollis sp. nov. (southern escarpment of Bale Mts, Harenna Forest); T. wiersbowskyi sp. nov. (southern escarpment of Bale Mts, upper Rira Valley). New distributional data are provided for T. baleensis (Basilewsky, 1974), T. bastianinii Magrini \& Sciaky, 2006, T. batuensis Magrini \& Sciaky, 2006, T. chillalicus Jeannel, 1936, T. clarkeianus (Basilewsky, 1974), T. culminicola Jeannel, 1936, T. ericalis Magrini, Quéinnec \& Vigna Taglianti, 2013, T. gallorites Jeannel, 1936, T. gypaeti Vigna Taglianti \& Magrini, 2010, T. oromiensis Magrini, Quéinnec \& Vigna Taglianti, 2012, T. relictus Magrini, Quéinnec \& Vigna Taglianti, 2012 and T. rotundicollis (Basilewsky,
\end{abstract}


1974). Cothresia robini Basilewsky, 1974 is considered a junior synonym of T. chillalicus Jeannel, 1936. A key to all species known to occur in the Bale Mts and adjacent volcanos is presented.

Keywords. Ground beetles, new species, new synonymy, key to species, local endemism, Africa.

Schmidt J. \& Faille A. 2018. Revision of Trechus Clairville, 1806 of the Bale Mts and adjacent volcanos, Ethiopia (Coleoptera, Carabidae, Trechini). European Journal of Taxonomy 446: 1-82. https://doi.org/10.5852/ejt.2018.446

\section{Introduction}

Occurrences of ground beetles (Carabidae) of the genus Trechus Clairville, 1806 in Central Africa are restricted to the high altitudes. The Trechus fauna of the Ethiopian highlands was identified as being particularly diverse with 35 species described until now (e.g., Pawłowski 2003; Geginat 2008; Ortuño \& Novoa 2011; Magrini et al. 2013). Distribution of each of these species seems to be restricted to one of the many volcanic massifs of the country. Most of the Trechus species, namely ten, were described from the Simien Mts in north western Ethiopia (Jeannel 1954; Basilewsky 1975; Magrini \& Sciaky 2006). These rugged mountains represent the remains of the oldest shield volcano of northern Ethiopia, where the age of the most ancient lava flows is about $30 \mathrm{Ma}$ (Williams 2016), and are well-known for their abundant natural resources. The Bale Mts in southeastern Ethiopia also represent another very large shield volcano with a similar geological age. This massif is internationally renowned for its rich and endemic biota, and large parts of the area are thus under national and regional protection (Bale Mts and Arsi Mts National Parks). Most information regarding its faunal content, however, is documented for vertebrates, while our knowledge on megadiverse insect groups such as ground beetles is low. Although a high degree of endemism can be expected, particularly in the beetle family Carabidae, a more profound investigation of this area is lacking, as is a review of the taxonomical and biogeographical knowledge on this interesting species group.

Eight endemic Trechus species are known to occur in the Bale Mts (Magrini \& Sciaky 2006; Geginat 2008; Magrini et al. 2012, 2013). Additional local endemic species were described from the much younger and smaller northerly adjacent volcanos Mt Enkuolo (one species, Vigna Taglianti \& Magrini 2010), Mt Badda (one species, Basilewsky 1974, see Geginat 2008), and Mt Chillalo (five species, Jeannel 1936, 1960). The development of the latter volcanos goes back to the Late Pliocene/ Early Quaternary (Williams 2016). Although each of them represents a very impressive high-rising landmark on the southern margin of the Rift Valley, these volcanos are connected which each other and with the Bale Mts by rather highly elevated flat ridges of $2600 \mathrm{~m}$ a.s.l and above. These ridges are situated in the elevational zone of the mesophilic montane forests (Knapp 1973). Occurrences of montane Trechus species in areas between the volcanic peaks can thus be assumed at least for pre-anthropogenic times, e.g., the mesophilic forest floor species Trechus oromiensis Magrini, Quéinnec \& Vigna Taglianti, 2012. However, the countryside between the volcanic peaks today is completely deforested (apart from some Eucalyptus plantations) and changed into an agrarian steppe characterized by intense heat during day and exceptionally dry weather conditions during winter season, without the presence of Trechus habitats. The latter may only occur relictually along brooks and canyons on the steeper slopes of the volcanic peaks.

In the present paper we summarize the current knowledge regarding systematics and distribution of Trechus species of the Bale Mts and adjacent volcanos. This study is mainly based on a large number of specimens collected in this area by several researchers during the last decade. It includes newly collected material from the type localities of previously known species, but also from hitherto uninvestigated areas. New species are described and figured in detail, and a key to all species known to occur in the Bale Mts and adjacent volcanos is presented. 


\section{Material and methods}

This study is based on about 2150 specimens of the genus Trechus from the Bale Mts, Mt Chillalo, and Mt Enkuolo. Newly collected material from the type localities of all but one species (T. scotti Jeannel, 1936) was available and was thus used for species identification. Institutional acronyms used in the taxonomic treatment are as follows:

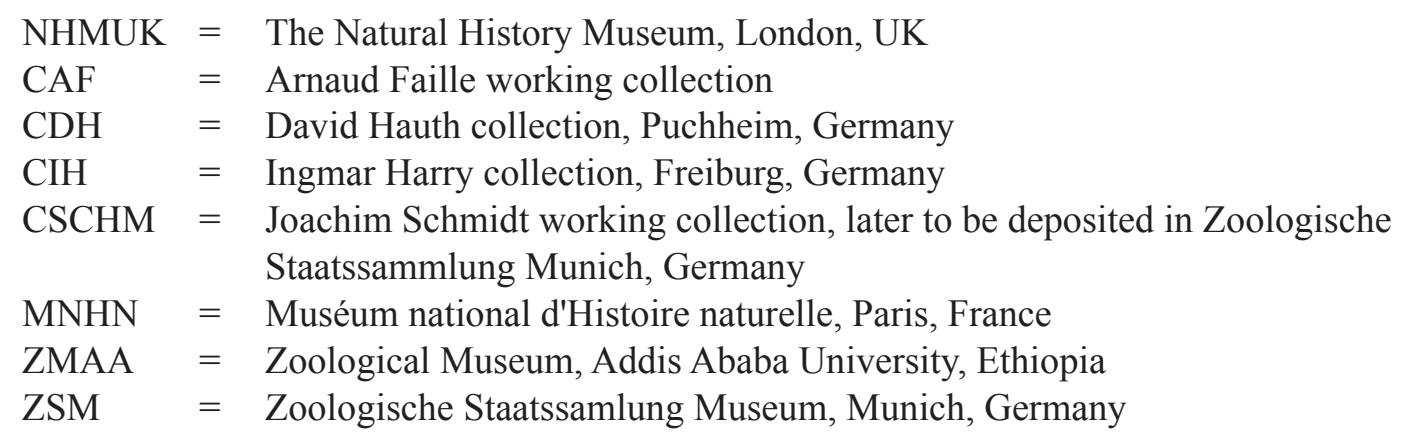

Specimens were examined by stereo microscope Leica M205-C. The photographs were taken with a Leica DFC450 digital camera using a motorized focussing drive, light base Leica TL5000 Ergo, diffused light with Leica hood LED5000 HDI, subsequently processed with Leica LAS application software, and enhanced with CorelDRAW Graphics Suite X5.

The description of the patterns of microsculpture refers to the dorsal surface of the body and was studied by magnification of $\times 80$. Description of the internal structures of the aedeagal median lobe is based on the normal position of the internal sac (not inflated).

Body size was measured from the tip of mandibles in closed position to the apex of elytra. The width of the head was measured across the widest portion including compound eyes. The width of the pronotum and elytra were measured at their widest points. The length of the pronotum was measured along the median line. The width of the pronotal base was measured between the tips of the hind angles. The length of the elytra was measured from the most advanced point of the humerus to the apex of the longer elytron. The length of aedeagal median lobe was measured across the longest distance without consideration of the basal bulb velum. The following abbreviations are used in the species descriptions:

$\mathrm{AL}=$ Length of aedeagal median lobe
$\mathrm{EL}=$ Length of elytra
$\mathrm{EW}=$ Width of elytra
$\mathrm{HW}=$ Width of head
$\mathrm{PBW}=$ Width of pronotal base
$\mathrm{PL}=$ Length of pronotum
$\mathrm{PW}=$ Width of pronotum

\section{Results}

The systematic position of the Ethiopian species within Trechus sensu lato is widely unknown. Some of the species were assigned to the subgenus Trechus sensu stricto (e.g., Pawłowski 2003; Magrini et al. 2012, 2013). Jeannel (1954) proposed the T. sublaevis group for species characterized by an unusual position of the elytral dorsal setae adjoining the fourth stria. Pawłowski (2001) defined the T. chokensis group based on three species from Mt Choke in northern Ethiopia, characterized by a pubescence on the dorsal surface of the head, pronotum and elytra. Two years later, Pawłowski (2003) announced the description of a new subgenus with nine new species from northern Ethiopia, characterized by the 
presence of only one dilated basal protarsomere in males. However, this description was not published until January 2018. Within his undescribed subgenus as well as within Trechus s. str., Pawłowski (2003) identified eight species groups alongside two additional incertae sedis groups without giving diagnostic information. Vigna Taglianti \& Magrini (2010) described the monotypic subgenus Minitrechus (type species: Trechus gypaeti Vigna Taglianti \& Magrini, 2010, from Mt Enkuolo), and Magrini et al. (2012) the monotypic subgenus Archeotrechus (type species: Trechus relictus Magrini, Quéinnec \& Vigna Taglianti, 2012, from Mt Batu in the Bale Mts), both are characterized by presence of only one dilated basal protarsomere in males. Archeotrechus is additionally distinguished by presence of almost complete dorsal separation of the lateral walls of the aedeagal median lobe (Magrini et al. 2012). However, Casale (2011) already pointed out that the presence of only one dilated male basal protarsomere "seems not a valid characteristic able to distinguish just one group within Trechus in the widest sense". In their review of the Ethiopian Trechus species, Ortuño \& Novoa (2011) came to the same conclusion and stated "that before proposing new taxonomic groups it would be best to have at our disposal information regarding all Ethiopian species to be able to place future discoveries in their correct places within this genus". Following these opinions, the newly described subgenera Minitrechus Vigna Taglianti \& Magrini, 2010, and Archeotrechus Magrini, Quéinnec \& Vigna Taglianti, 2012, should considered synonyms of Trechus Clairville, 1806. At the present time, however, no taxonomic revision exists that includes species of these subgenera and therefore, their respective systematic position remains uncertain. In addition, the phylogenetic position of all the Ethiopian Trechus lineages within Trechina is likewise widely unknown. For example, it is unclear whether the Ethiopian Highlands have been multiply colonized by representatives of different lineages of Trechina during Cenozoic times, or, whether the high diversity of Trechus is based on a single event of long-distance dispersal. Consequently, at the current state, nomenclatural acts can only be made with great uncertainty. It is reasonable to be particularly prudent because previous molecular phylogenetic analyses have shown that Trechus in the widest sense is a polyphyletic assembly (Faille et al. 2010, 2013). To ensure nomenclatural stability a sufficient number of Ethiopian Trechus species with representatives of the previously proposed species groups of Jeannel (1954), Pawłowski (2001, 2003), Vigna Taglianti \& Magrini (2010), and Magrini, Quéinnec \& Vigna Taglianti (2012), should therefore be included in the phylogenetic studies before new nomenclatural acts are proposed. Consequently, given that the present study does not aim to provide new insights into the phylogeny of Ethiopian Trechina, the synonymy of Minitrechus and Archeotrechus will be discussed no further herein. Instead, we follow the proposals of Casale (2011) and Ortuño \& Novoa (2011) and deal with all species of the study area under Trechus in the widest sense. Phylogeny and phylogeography of the Ethiopian Trechina are, however, the subject of a subsequent molecular genetic study (currently in progress).

The Trechus species of the study area share the following characters, which are therefore not repeatedly mentioned in the description chapters of the new species:

- Mandibles with dentition pattern as in Trechus s. str.

- Labrum with six setae near apical margin.

- Clypeus with two pairs of setae.

- Two supraorbital setae each side in normal position for Trechus s. str.

- Pronotum with lateral seta located near or slightly before the widest point of pronotum.

- Dorsum glabrous, without pilosity.

- Proepisternum glabrous and smooth.

- Parascutellar setiferous pore present.

- Elytral dorsal setae each adjoining the third stria.

- Metepisternum very short, glabrous and smooth, with outer margin as long as anterior margin.

- Dilated male basal protarsomere(s) dentoid at the inner apical border. 


\section{Taxonomy}

Class Hexapoda Blainville, 1816

Order Coleoptera Linnaeus, 1758

Family Carabidae Latreille, 1802

Subfamily Trechinae Bonelli, 1810

Tribe Trechini Bonelli, 1810

Genus Trechus Clairville, 1806

Trechus mattisi sp. nov.

urn:1sid:zoobank.org:act:DDAE320F-8BA5-4C34-8DB7-E0C12CB021F9

Figs 1, 5, 9, 37-38

\section{Diagnosis}

Within the Ethiopian fauna this species is easily recognized based on a combination of the following characters: (1) body length below $3.5 \mathrm{~mm}$, (2) only the first basal protarsomere of male dilated, (3) mandibles and antennae rather slender, (4) apical margin of labrum moderately emarginated, (5) tempora smooth, (6) pronotum with laterobasal angles markedly developed, slightly obtuse and sharp on tip, (7) internal striae on elytra distinct, (8) elytral preapical seta absent. Trechus mattisi sp. nov. has characters (1)-(5) and (7)-(8) in common with the below described T. transversicollis sp. nov. from the same mountain area, however, it is easily distinguished by darker body colour, pronotum with larger and sharper laterobasal angles and much larger laterobasal foveae, and elytra with two discal setae developed. For additional distinguishing features see diagnosis of the latter species below.

\section{Etymology}

This new species is dedicated to Mattis Berndt, youngest son of one of the authors (JS), and helpful companion during the 2017 field work of JS in the Bale Mts.

\section{Material examined}

Holotype

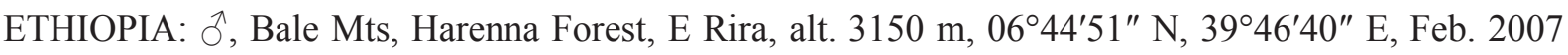
(CSCHM, registration number ZSM_COL_2018_001).

\section{Paratypes}

ETHIOPIA: $10 \widehat{\partial}, 5$ qq , same data as for holotype (CAF, CSCHM); $4 \hat{\partial}, 4 q q$, Harenna Forest, E Rira, alt. 3050-3150 m, 06 44'59" N, 3947'36" E, 12 Feb. 2017 (CAF, CSCHM); 1 ô, same data as

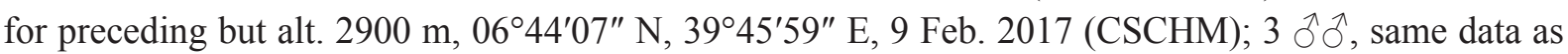

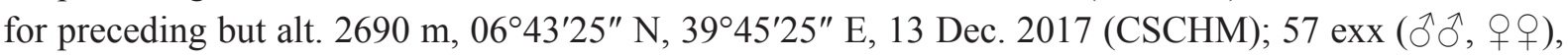
Harenna Forest W Rira, alt. 3000 m, 06²45'57" N, 3941'47" E, 14 Dec. 2017 (NHMUK, CAF, CDH, CSCHM, MNHN, ZMAA).

\section{Description}

Body Length. 3.0-3.4 mm $(\varnothing=3.12 \mathrm{~mm}, \mathrm{n}=12)$.

Proportions $(\mathrm{n}=10) . \mathrm{PW} / \mathrm{HW}=1.46-1.52(\varnothing=1.48) ; \mathrm{PW} / \mathrm{PL}=1.50-1.61(\varnothing=1.55) ; \mathrm{PW} / \mathrm{PBW}=$ $1.24-1.32(\varnothing=1.27) ; \mathrm{EW} / \mathrm{PW}=1.49-1.63(\varnothing=1.55) ; \mathrm{EL} / \mathrm{EW}=1.14-1.24(\varnothing=1.20)$. 


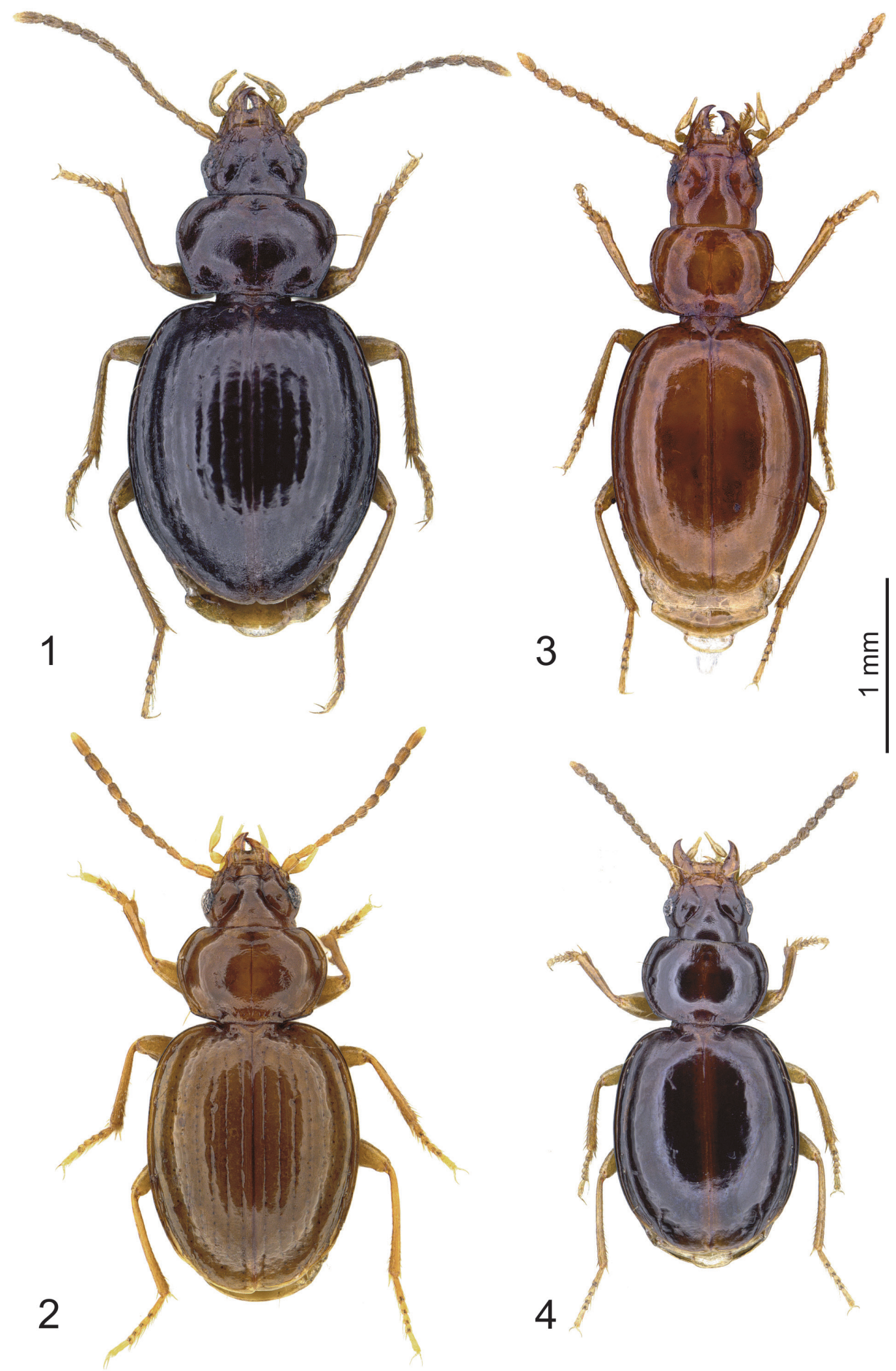

Figs 1-4. Trechus spp., habitus. 1. T. mattisi sp. nov., paratype, đ̊. 2. T. transversicollis sp. nov., holotype. 3. T. minitrechus sp. nov., paratype, $\widehat{\partial}$. 4. T. nanulus sp. nov., paratype, $\widehat{\partial}$. 
CoLour. Head and pronotum brown or dark brown, elytra blackish brown, markedly shiny, elytra slightly iridescent. Clypeus and labrum light brown, palpi, antennal base and legs yellowish; antennae distally indistinctly darkened beginning from distal half of third antennomere.

MicrosCulPtURE. Same in males and females. Head with comparatively large, almost isodiametric meshes on disc and supraorbital area, and smaller meshes on clypeus. Pronotum with somewhat irregularly formed $+/$ - marked transverse meshes, which are deeper engraved near base. Elytra with very finely engraved very narrow transverse meshes.

HEAD. Comparatively robust. Mandibles moderately slender. Labrum with apical margin moderately emarginated. Eyes moderately small, distinctly convexly protruded. Tempora convex, markedly wrinkled to the neck, $0.5-0.6$ times as long as eyes, smooth. Frons and supraorbital area strongly convex, with supraorbital furrows almost uniformly bent on disc, deep throughout. Antennae rather slender, proportions of the first four antennomeres as follows: 1/0.93/1/0.87.

Prothorax. Pronotum large, markedly transverse, broadest portion distinctly before middle, more markedly narrowed towards apex, base distinctly wider than apical margin. Disc markedly convex. Anterior margin slightly concave with anterior angles broadly rounded and slightly protruded. Lateral margin rounded in anterior $2 / 3$ and straight towards laterobasal angles, latter slightly obtuse, sharp at tip, +/- protruded laterally. Marginal gutter narrow in anterior half, distinctly widened towards base. Base straight in middle, very faintly sinusoidal at outer quarter with laterobasal angles sometimes slightly shifted posteriad. Median longitudinal impression fine but distinct, disappearing at apex and base; anterior and posterior transverse impressions shallow and smooth; laterobasal foveae large and smooth, internally distinctly sloped, externally coalescing with the lateral gutter. Pronotum with laterobasal setae present.

PTEROTHORAX. Elytra markedly convex on disc, in dorsal view markedly short and broad, broadest in midlength, with shoulders fully rounded; broadly rounded at apex. Striae indistinctly punctate, parascutellar stria very short or moderately long, striae 1-4 (5) finely or moderately impressed, external stria finer, often indistinct, stria 8 finely impressed at level of the middle group and deeply impressed at level of the subapical group of marginal umbilicate pores. Internal intervals slightly convex. Recurrent preapical stria deep, moderately short, curved in front, directed to the fifth stria. Third stria with two setiferous dorsal pores, the anterior one at anterior elytral quarter, the posterior one at middle; preapical seta absent (but in one specimen present!). Number and positions of the setae of the marginal umbilicate series as in Trechus s. str. (Fig. 9).

LEGS. Short and comparatively thin; protibia slightly dilated towards apex, straight, finely grooved on external surface. Only one basal protarsomere of male dilated.

Male genitalia. EL/AL $=4.24-4.45(\varnothing=4.36, \mathrm{n}=7)$. Aedeagal median lobe very small, stout, rather weekly sclerotized, in lateral view almost evenly bent throughout; apical lamella short, broadly rounded at tip; basal bulb moderately large, sagittal aileron small and transparent. Endophallus with copulatory piece very weakly sclerotized, in lateral view bag-like, narrowed towards apex.

\section{Distribution}

Until now, only found on the southern slope of the Bale Mts east of Rira village at altitudes of 2900$3150 \mathrm{~m}$. 


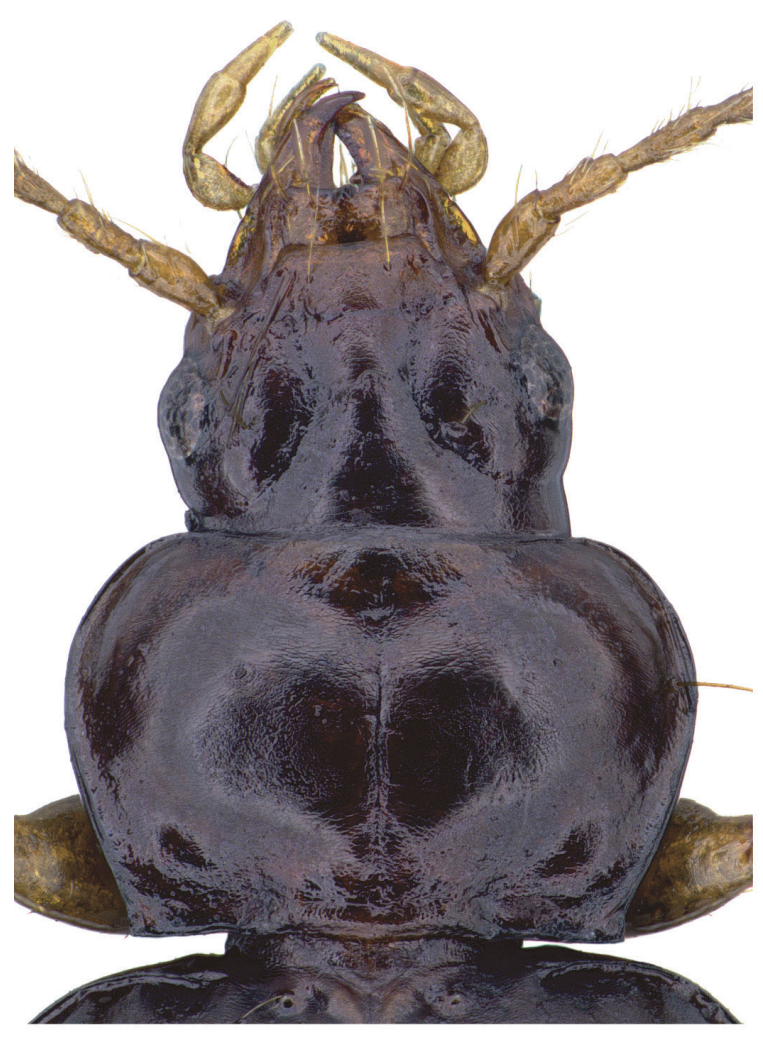

5

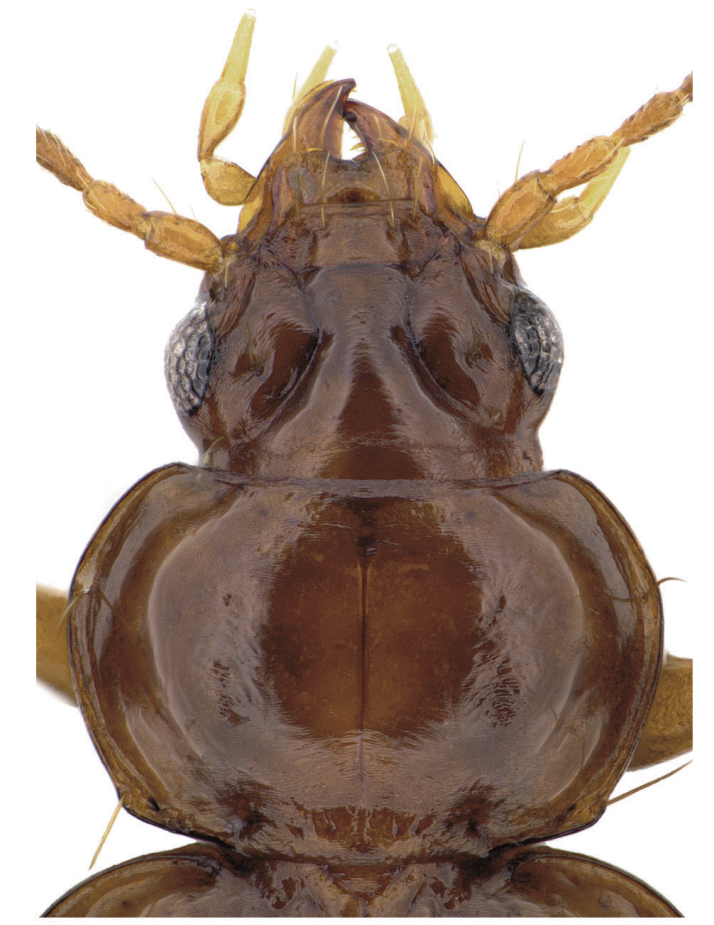

6

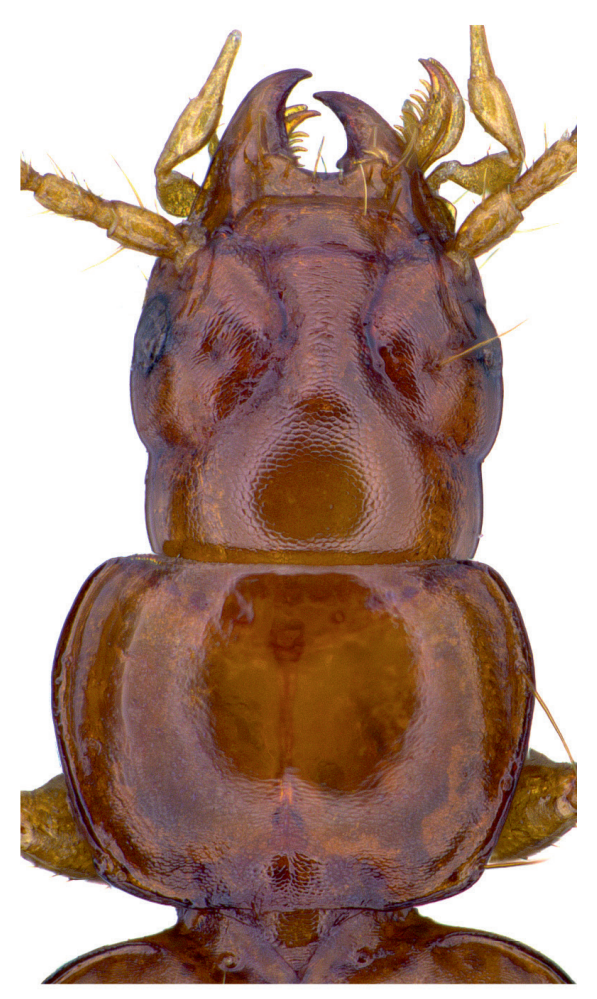

7

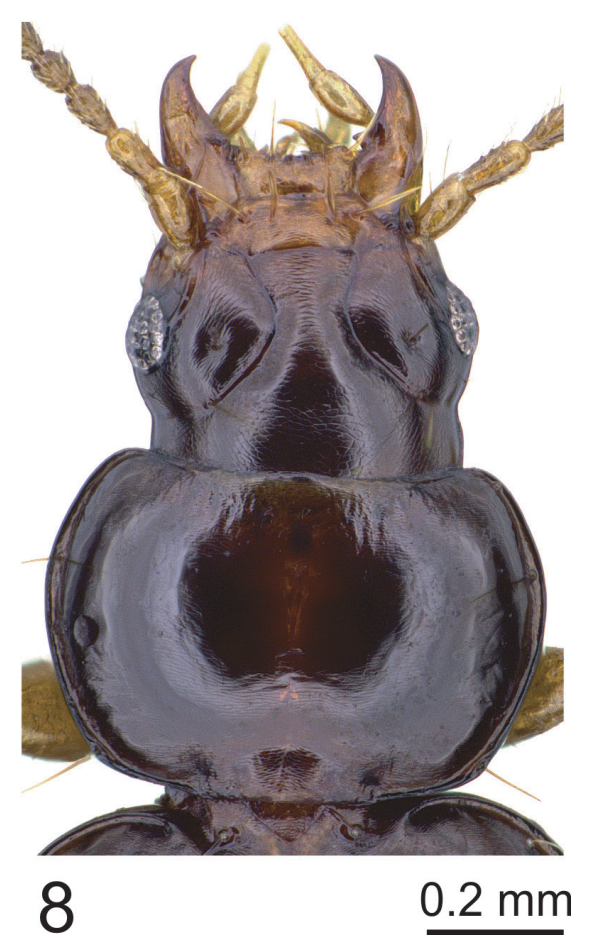

Figs 5-8. Trechus spp., head, pronotum. 5. T. mattisi sp. nov., paratype, đิ. 6. T. transversicollis sp. nov., holotype. 7. T. minitrechus sp. nov., paratype, §. 8 . T. nanulus sp. nov., paratype, $\widehat{\partial}$. 
Trechus transversicollis sp. nov. urn:lsid:zoobank.org:act:8C43D55B-FF22-4CDE-A836-DC3EAABC6574

Figs 2, 6, 10, 39

\section{Diagnosis}

This new species has more diagnostic characters in common with the above described T. mattisi sp. nov. (for details see above) than with any other species of the Ethiopian fauna. It is easily distinguished from the latter by the lighter colour of body, narrower meshes of pronotal microsculpture, larger eyes, pronotum with much more obtuse laterobasal angles, with basal margin laterally shifted anteriad, and with much smaller laterobasal foveae, and by the elytra with a single dorsal seta.

\section{Etymology}

The specific epithet refers to the markedly transverse pronotum of the new species.

\section{Material examined}

\section{Holotype}

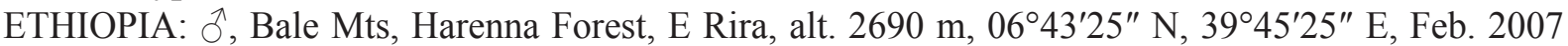
(CSCHM, registration number ZSM_COL_2018_002).

\section{Paratypes}

ETHIOPIA: $1 \hat{\jmath}$, same data as for holotype (CAF); $21 \hat{\delta} \hat{\delta}, 18 q+$, same data as for preceding but 13 Dec. 2017 (NHMUK, CAF, CDH, CSCHM, MNHN, ZMAA).

\section{Description}

BODY LENGTH. $2.65 \mathrm{~mm}$.

Proportions. $\mathrm{PW} / \mathrm{HW}=1.50 ; \mathrm{PW} / \mathrm{PL}=1.59 ; \mathrm{PW} / \mathrm{PBW}=1.24 ; \mathrm{EW} / \mathrm{PW}=1.41 ; \mathrm{EL} / \mathrm{EW}=1.29$.

Colour. Head, pronotum, and elytra light brown, very shiny, appendages yellowish, but antennae distally indistinctly darkened beginning from third antennomere.

Microsculpture (male). Very slightly engraved on whole body surface. Head with comparatively large, almost isodiametric meshes on disc and supraorbital area, and smaller meshes on clypeus. Pronotum with very narrow, elytra with extremely narrow (hardly visible) transverse meshes.

Head. Comparatively robust. Mandibles moderately slender. Labrum with apical margin moderately emarginated. Eyes moderately small, distinctly convexly protruded. Tempora convex, markedly wrinkled to the neck, 0.35 times as long as eyes, smooth. Clypeus, frons and supraorbital area very markedly convex; supraorbital furrows uniformly bent on disc, very deep throughout, foveate on level of supraorbital setae. Antennae rather slender, proportions of the first four antennomeres as follows: $1 / 1 / 1 / 0.75$.

Prothorax. Pronotum large, markedly transverse, broadest portion slightly before middle, more markedly narrowed towards apex, base distinctly wider than apical margin. Disc markedly convex. Anterior margin slightly concave with anterior angles moderately protruded. Lateral margin rounded throughout, laterobasal angles obtuse, blunt at tip. Marginal gutter narrow throughout. Base slightly convex in middle, distinctly shifted anteriorly at outer quarter. Median longitudinal impression fine but distinct, disappearing at apex and base; anterior transverse impression indistinct, smooth, posterior transverse impression broad but shallow in middle, slightly rugose towards base; laterobasal foveae very small, pit-like. Pronotum with laterobasal setae present. 

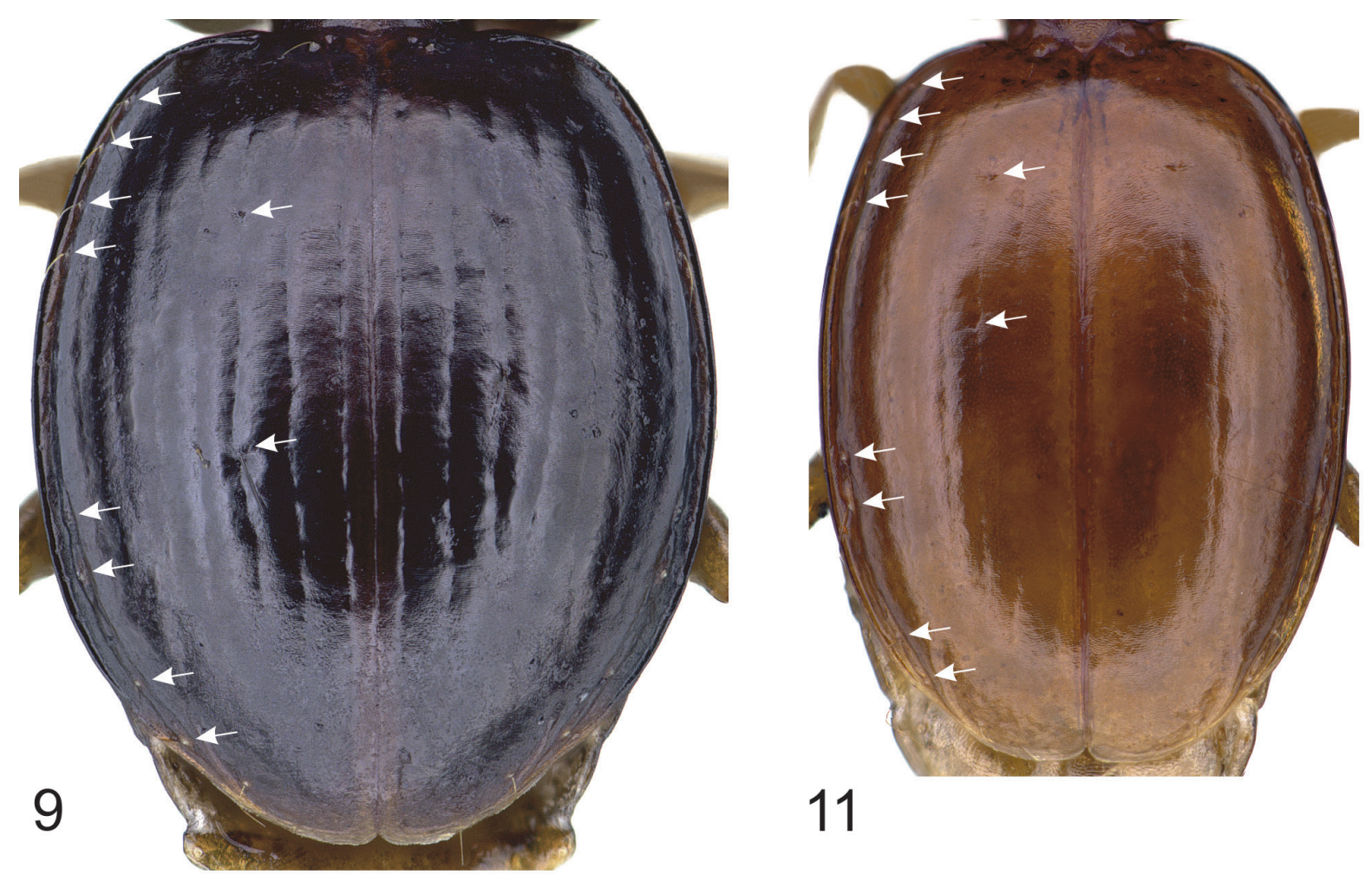

11
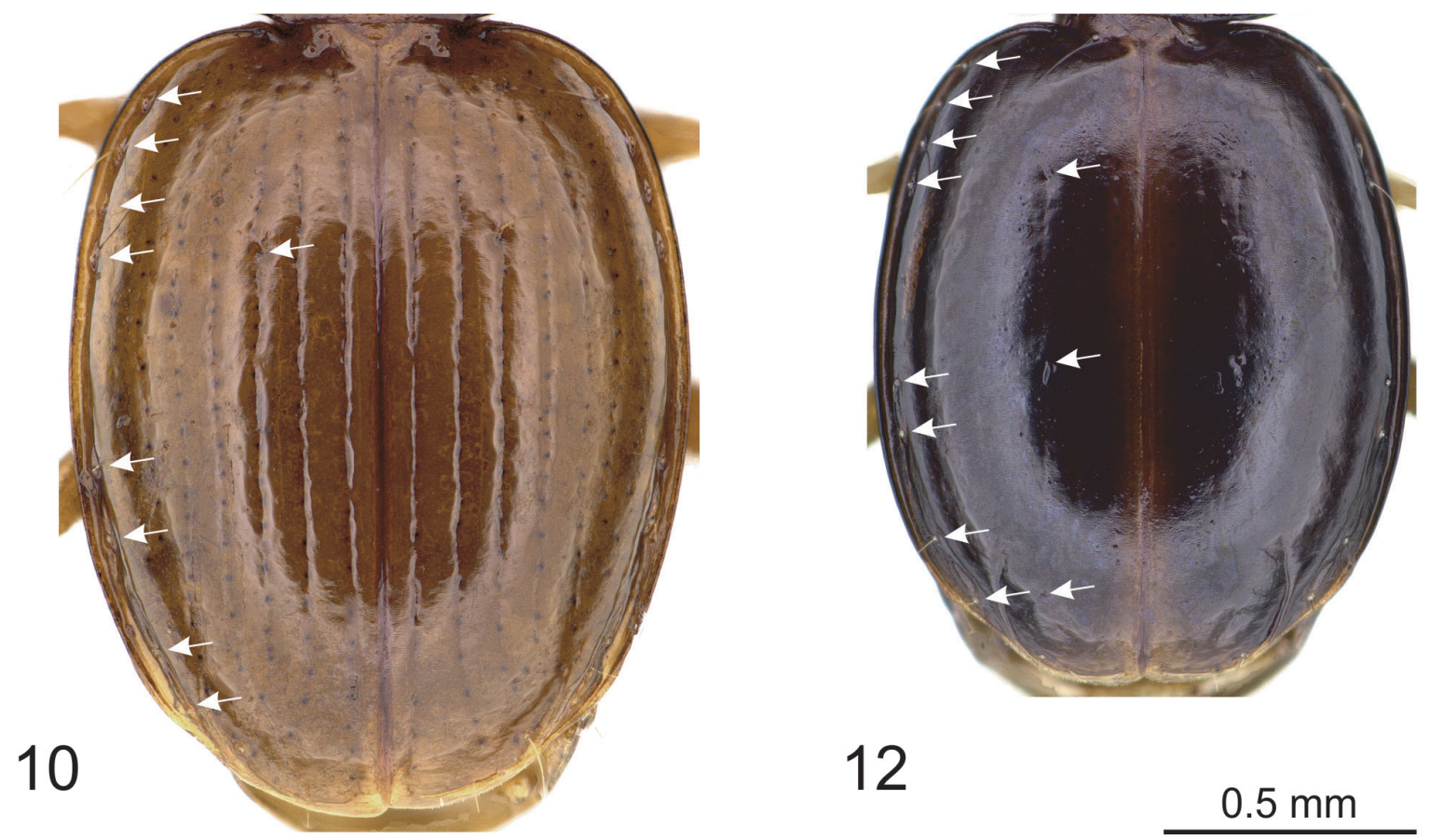

Figs 9-12. Trechus spp., elytra. 9. T. mattisi sp. nov., paratype, đ. 10. T. transversicollis sp. nov., holotype. 11. T. minitrechus sp. nov., paratype, $\widehat{\partial}$. 12. T. nanulus sp. nov., paratype, $\widehat{\partial}$. The arrows point to the insertions of the discal setae, preapical seta (if present), and setae of the umbilical series. 
Pterothorax. Elytra markedly convex on disc, in dorsal view short and broad, broadest in mid-length, with shoulders fully rounded; broadly rounded at apex. Striae finely punctate, parascutellar stria short, striae 1-4 moderately impressed, stria 5 finer, 6-7 indistinct, 8 moderately impressed from level of the middle group of the subapical group of marginal umbilicate pores towards apex. Internal intervals slightly convex. Recurrent preapical stria deep, moderately short, curved in front, directed to the fifth stria. Third stria with a single setiferous dorsal pore at anterior elytral quarter; posterior dorsal seta and preapical seta absent. Number and positions of the setae of the marginal umbilicate series as in Trechus s. str. (Fig. 10).

Legs. As described in T. mattisi sp. nov.

Male Genitalia. EL/AL $=5.16$. Aedeagal median lobe markedly small, stout, weakly sclerotized, in lateral view almost evenly bent throughout; apex very broad, rounded; basal bulb and saggital aileron rather small; endophallic copulatory piece very weakly sclerotized, sack-like shaped.

\section{Distribution}

Known only from the southern slope of the Bale Mts, east of Rira village, at an altitude of $2690 \mathrm{~m}$.

Trechus gypaeti Vigna Taglianti \& Magrini, 2010

Trechus (Minitrechus) gypaeti Vigna Taglianti \& Magrini, 2010: 72; locus typicus: Ethiopia, Oromia, top of Mt Enkuolo, above Timbite village, near Bekoji, lat. 7.37, long. 39.35, approx. $3800 \mathrm{~m}$.

\section{Type material}

Not studied. Identification is based on the very detailed description and figuring of habitus and genital characters as well as on additional material collected close to the type locality.

\section{Type locality}

Vigna Taglianti \& Magrini (2010) noted an altitude of $4000 \mathrm{~m}$ for the type locality, and 7.36 and 39.35 for latitude and longitude, respectively. However, the maximum height of Mt Enkuolo reaches slightly more than $3800 \mathrm{~m}$, and the top ridge above Timbite village lies at lat. 7.37, long. 39.35.

\section{Material examined}

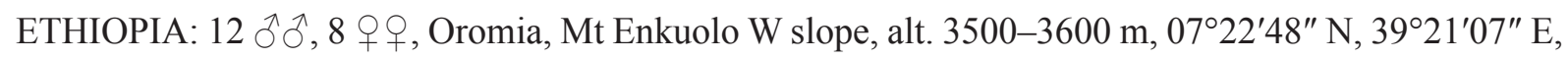

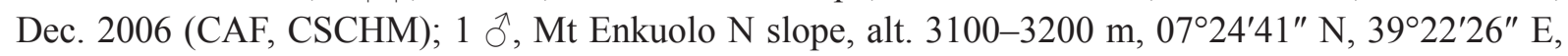
5-7 Dec. 2016 (CSCHM).

\section{Description}

See key to species and description of T. minitrechus sp. nov.

\section{Distribution}

Locally endemic of the northern and western slopes of Mt Enkuolo; the holotype was collected on top of the mountain (Vigna Taglianti \& Magrini 2010). The vertical distribution of the species ranges from approximately $3100 \mathrm{~m}$ to $3800 \mathrm{~m}$. 


\section{Trechus minitrechus sp. nov. urn:1sid:zoobank.org:act:43FA1539-70DB-4B0E-947C-E48876836DA4}

Figs 3, 7, 11, 40, 41

\section{Diagnosis}

Given the overall similarity of $T$. minitrechus sp. nov. with $T$. gypaeti of the same volcanic mountain, these species are doubtless allopatric sister species. T. minitrechus sp. nov. is easily recognized from the latter by the lack of the posterior elytral dorsal seta. In addition, in the new species the copulatory piece of the aedeagus is distinctly more strongly sclerotized on the dorsal side than in T. gypaeti.

\section{Etymology}

The specific epithet refers to both the very small body length of the species, and to the species group Minitrechus, to which it belongs.

\section{Material examined}

\section{Holotype}

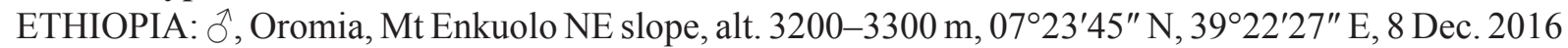
(CSCHM, registration number ZSM_COL_2018_003).

\section{Paratypes}

ETHIOPIA: $19 \precsim \hat{\jmath}, 16$ +q , same data as for holotype (CAF, CSCHM).

\section{Description}

Body LeNGTH. 2.4-2.6 mm (Ø $=2.52 \mathrm{~mm}, \mathrm{n}=20)$.

Proportions $(\mathrm{n}=10)$. PW/HW $=1.25-1.34(\varnothing=1.31) ; \mathrm{PW} / \mathrm{PL}=1.40-1.48(\varnothing=1.45) ; \mathrm{PW} / \mathrm{PBW}=$ $1.26-1.35(\varnothing=1.30) ; \mathrm{EW} / \mathrm{PW}=1.48-1.60(\varnothing=1.54) ; \mathrm{EL} / \mathrm{EW}=1.30-1.43(\varnothing=1.37)$.

Colour. Head, pronotum and elytra light brown, moderately shiny, not iridescent; clypeus, labrum, palpi, antennae, and legs yellowish.

Microsculpture. Same in males and females. Head with comparatively large, almost isodiametric meshes on disc and supraorbital area, and smaller meshes on clypeus. Pronotum with slightly smaller, slightly transverse meshes, which are more markedly engraved near base than on disc. Elytra with very narrow but distinct, transverse meshes.

HeAd. Comparatively robust. Mandibles short. Labrum with apical margin widely emarginated. Eyes markedly small and flat. Tempora convex, markedly wrinkled to the neck, 1.3-1.4 times as long as eyes, smooth or, in some specimens, with few very fine and very short hairs. Frons and supraorbital area strongly convex, with supraorbital furrows almost uniformly bent on disc, deep throughout. Antennae short, proportions of the first four antennomeres as follows: $1 / 1 / 0.9 / 0.75$; antennomeres $7-9$ only slightly longer than broad.

Prothorax. Pronotum moderately large, transverse, broadest portion distinctly before middle, base as wide as apical margin. Disc markedly convex. Anterior margin straight or very slightly concave with anterior angles rounded, not or very slightly protruded. Sides rounded in anterior $3 / 4,+/-$ straight just anteriad of laterobasal angles; latter slightly obtuse, blunt at apex. Marginal gutter very narrow, slightly widened near laterobasal angles. Base straight in middle, distinctly bent anteriorly at outer quarter. Median longitudinal impression fine but distinct, not deepened near base, disappearing at apex; anterior transverse impression very shallow, smooth; posterior transverse impression shallow in middle, slightly 
deepened towards laterobasal foveae, latter very small, notch-like, smooth. Pronotum with laterobasal setae present.

Pterothorax. Elytra convex on disc, in dorsal view moderately short and broad, broadest in midlength or slightly before, with shoulders fully rounded; broadly rounded at apex. Striae impunctate, parascutellar stria and first stria absent, latter sometimes finely impressed near apex, striae $2-5$ indistinct but present, striae 6-7 usually absent, stria 8 moderately impressed from level of the middle group of the marginal umbilicate pores towards apex. All intervals flat. Recurrent preapical stria deep, curved in front, directed to the fifth stria. Third stria with a single setiferous dorsal pore near the end of anterior elytral quarter; preapical seta lacking. Number and positions of the setae of the marginal umbilicate series as in Trechus s. str. (Fig. 11).

LEGS. Short and comparatively thin; protibia slightly dilated towards apex, hardly bowed, finely but distinctly grooved on external surface. Only one basal protarsomere of male dilated.

MALE GENITALIA. EL/AL $=3.88-4.01(\varnothing=3.96, \mathrm{n}=6)$. Aedeagal median lobe small, moderately stout, in lateral view almost evenly bent towards apex; apical lamella very short with apex rounded; dimensions of basal bulb and sagittal aileron average. Endophallus with copulatory piece bag-like, triangular in lateral view, arcuate towards apex, very slightly sclerotized with exception of the dorsal side, which is covered with more strongly sclerotized scales.

\section{Distribution}

Known only from the type locality, along a brook valley on the northeastern slope of Mt Enkuolo, at altitudes of $3200-3300 \mathrm{~m}$.

Trechus nanulus sp. nov. urn:1sid:zoobank.org:act:6C2C58F5-6A6D-4FA3-B32B-486736DFBD91

Figs 4, 8, 12, 42-43

\section{Diagnosis}

Habitus and male genital characters very similar to T. gypaeti and T. minitrechus sp. nov. from Mt Enkuolo, but slightly smaller, colour of body distinctly darker brown and shinier with elytra iridescent, pronotum and elytra with meshes of microsculpture less deeply engraved, eyes larger and more protruded, pronotum more transverse, elytra broader and shorter with preapical seta developed, and aedeagal median lobe stouter. Trechus nanulus sp. nov. is also very similar to T. rira sp. nov. but readily distinguished by larger eyes and stouter aedeagal median lobe (see below for details). Compared to all other Trechus species of the Ethiopian fauna, the new species differs by the combination of the following characters: body length below $2.5 \mathrm{~mm}$, only one protarsomere of male dilated, elytral striae indistinctly impressed on disc; aedeagal median lobe apex simply tapered.

\section{Etymology}

The specific epithet refers to the very small body length of the species and particularly to the fact that it represents the smallest Trechus species known from Ethiopia.

\section{Material examined}

\section{Holotype}

ETHIOPIA: ${ }^{\wedge}$, Oromia, S slope Bale Mts below Rira, alt. 2380 m, 06² 43'17" N, 3943'14" E, Dec. 2006 (CSCHM, registration number ZSM_COL_2018_004). 


\section{Paratypes}

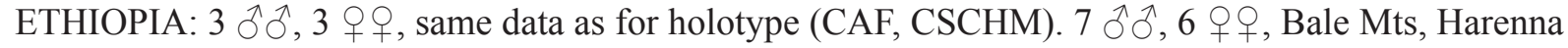

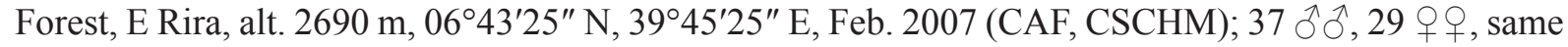

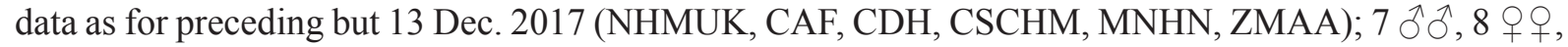
Harenna Forest, W Rira, alt. 3000 m, 06²45'57" N, 3941'47" E, 14 Dec. 2017 (CSCHM).

\section{Description}

Body LENGTH. 2.2-2.4 mm (Ø $=2.29 \mathrm{~mm}, \mathrm{n}=20)$.

Proportions $(\mathrm{n}=10): \mathrm{PW} / \mathrm{HW}=1.35-1.42(\varnothing=1.38) ; \mathrm{PW} / \mathrm{PL}=1.50-1.60(\varnothing=1.56) ; \mathrm{PW} / \mathrm{PBW}=$ $1.22-1.30(\varnothing=1.25) ; \mathrm{EW} / \mathrm{PW}=1.41-1.51(\varnothing=1.46) ; \mathrm{EL} / \mathrm{EW}=1.24-1.31(\varnothing=1.28)$.

Colour. Head, pronotum and elytra dark brown, markedly shiny, elytra slightly iridescent. Clypeus, labrum, palpi, antennal base and legs yellowish; antennae distally darkened beginning from third antennomere.

Microsculpture. Same in males and females. Head with comparatively large, almost isodiametric meshes on disc and supraorbital area, and smaller meshes on clypeus. Pronotum and elytra with slightly engraved narrow transverse meshes, which are narrower on elytra than on pronotum.

HeAD. Comparatively robust. Mandibles short. Labrum with apical margin widely emarginated. Eyes moderately small, distinctly convexly protruded. Tempora convex, markedly wrinkled to the neck, 0.9 times as long as eyes, very finely and sparsely pubescent. Frons and supraorbital area strongly convex, with supraorbital furrows almost uniformly bent on disc, deep throughout. Antennae short, proportions of the first four antennomeres as follows: 1/1/0.9/0.7; antennomeres $7-9$ only slightly longer than broad.

Prothorax. Pronotum large, markedly transverse, broadest portion slightly before middle, base as wide as apical margin. Disc markedly convex. Anterior margin slightly concave with anterior angles slightly protruded. Sides almost evenly rounded throughout. Laterobasal angles very obtuse, blunt at apex. Marginal gutter very narrow, not widened near laterobasal angles. Base straight in middle, distinctly bent anteriorly at outer quarter. Median longitudinal impression fine but distinct, not deepened near base, disappearing at apex; anterior transverse impression very shallow, smooth; posterior transverse impression shallow, laterobasal foveae very small, notch-like, smooth. Pronotum with laterobasal setae present.

Pterothorax. Elytra convex on disc, in dorsal view markedly short and broad, broadest in mid-length, with shoulders fully rounded; broadly rounded at apex. Striae impunctate, parascutellar stria and first stria absent, latter sometimes finely impressed near apex, striae 2-5 indistinct but present, striae 6-7 usually absent, stria 8 impressed only at levels of the middle and subapical groups of the marginal umbilicate pores. All intervals flat. Recurrent preapical stria deep, curved in front, directed to the fifth stria. Third stria with two setiferous dorsal pores, the anterior one slightly behind the anterior elytral quarter, the posterior one slightly behind middle (except in one specimen without posterior discal seta!), and with preapical seta which is situated at the apical anastomosis of second and third striae slightly closer to the elytral apex than to the suture. Number and positions of the setae of the marginal umbilicate series as in Trechus s. str. (Fig. 12).

Legs. Short and comparatively thin; protibia slightly dilated towards apex, hardly bowed, finely but distinctly grooved on external surface. Only one basal protarsomere of male dilated.

Male Genitalia. EL/AL $=4.00-4.28(\varnothing=4.13, \mathrm{n}=6)$. Aedeagal median lobe small and stout, in lateral view with ventral margin slightly bent near base and apex, straight in middle; apical lamella moderately 
short with apex simply tapered; basal bulb moderately large, sagittal aileron average. Endophallus with copulatory piece bag-like, triangular in lateral view, arcuate towards apex, very slightly sclerotized.

\section{Distribution}

Known only from Harenna Forest on the southern slope of the Bale Mts, below Rira village, at altitudes of $2380-2690 \mathrm{~m}$.

Trechus rira sp. nov.

urn:1sid:zoobank.org:act:C77BCBF5-16DC-40A4-AD08-2403F17A0463

Figs 13, 17, 21, 44

\section{Diagnosis}

Very similar to the above-described T. nanulus sp. nov. from the same mountain area, but slightly larger, with eyes smaller, pronotum less transverse, laterobasal area of pronotum more depressed, aedeagal median lobe more elongated. For differentiation from the other rather tiny species of Trechus from the Bale Mts, see key to species and the diagnosis for the respective species below.

\section{Etymology}

The specific epithet refers to the village Rira, close to the type locality of the new species.

\section{Material examined}

\section{Holotype}

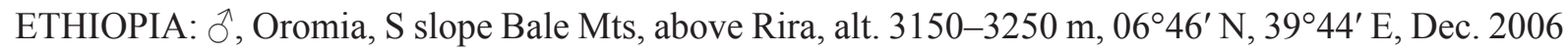
(CSCHM, registration number ZSM_COL_2018_005).

\section{Paratype}

ETHIOPIA: $1 \hat{\jmath}$, same data as for holotype (CSCHM); $11 \hat{\jmath} \hat{\partial}, 10$ 우, Oromia, Bale Mts, S slope above Rira, alt. 3240 m, 0646'39" N, 3944'52" E, 15 Dec. 2017 (CAF, CSCHM, ZMAA).

\section{Description}

Body LENGTH. $2.6 \mathrm{~mm}(\mathrm{n}=2)$.

Proportions $(\mathrm{n}=2) . \mathrm{PW} / \mathrm{HW}=1.35-1.37 ; \mathrm{PW} / \mathrm{PL}=1.39-1.41 ; \mathrm{PW} / \mathrm{PBW}=1.23-1.24 ; \mathrm{EW} / \mathrm{PW}=$ $1.55-1.60 ; \mathrm{EL} / \mathrm{EW}=1.30-1.36$.

Colour AND microsculpture. As described in T. nanulus sp. nov.

Head. Eyes small, tempora 1.1 times as long as eyes. Proportions of the first four antennomeres as follows: 1/1/0.9/0.8. In all other characters as described in T. nanulus sp. nov.

Prothorax. Pronotum moderately large, transverse, broadest portion distinctly before middle, base as wide as apical margin. Disc markedly convex. Anterior margin slightly concave with anterior angles rounded, slightly protruded. Sides rounded throughout but less markedly towards base. Laterobasal angles very obtuse, blunt at apex. Marginal gutter very narrow, slightly widened near laterobasal angles. Base straight in middle, distinctly bent anteriorly at outer quarter. Median longitudinal impression fine but distinct, not deepened near base, disappearing at apex; anterior transverse impression indistinct, smooth; posterior transverse impression very shallow, laterobasal foveae diffuse limited towards disc and sides, moderately small, smooth. Pronotum with laterobasal setae present. 

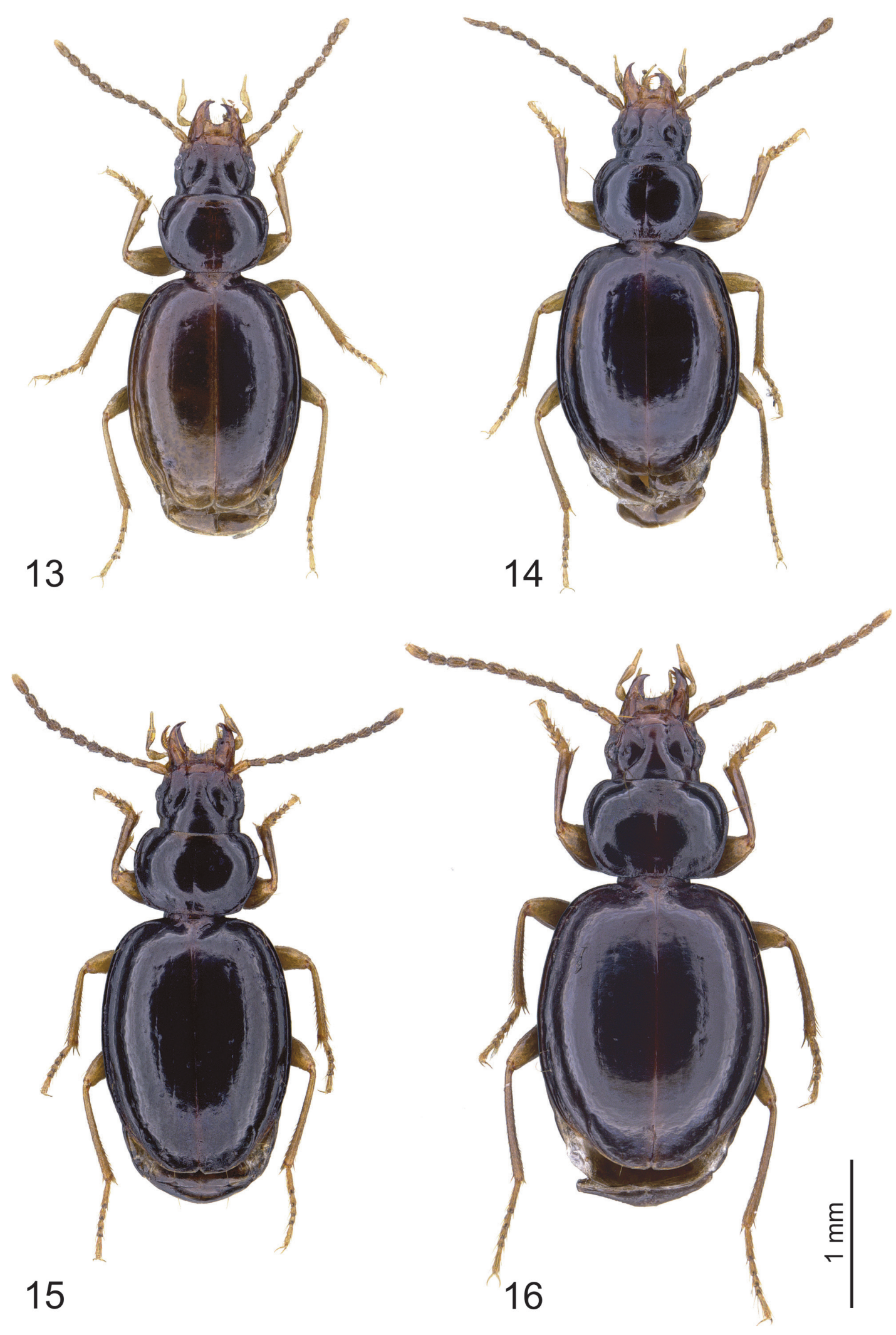

Figs 13-16. Trechus spp., habitus. 13. T. rira sp. nov., holotype. 14. T. iridescens sp. nov., holotype. 15. T. oppositus sp. nov., paratype, $\overbrace{}^{\lambda}$ 16. T. bombi sp. nov., holotype. 
Pterothorax. Elytra convex on disc, in dorsal view moderately short and broad, broadest in midlength or slightly before, with shoulders fully rounded; broadly rounded at apex. Striae impunctate, parascutellar stria absent, striae 1-5 indistinct (stria 1 absent in the paratype specimen), striae 6-7 absent, stria 8 moderately impressed from level of the middle group of the marginal umbilicate pores towards apex. All intervals flat. Recurrent preapical stria deep, curved in front, directed to the fifth stria. Third stria with two setiferous dorsal pores, the anterior one between anterior elytral fifth and quarter, the posterior one in middle, and with preapical seta situated at the apical anastomosis of second and third striae, slightly closer to the elytral apex than to the suture. Number and positions of the setae of the marginal umbilicate series as in Trechus s. str.

Legs. As described in T. nanulus sp. nov.

Male genitalia. EL/AL = 3.28-3.29 $(\mathrm{n}=2)$. Aedeagal median lobe small, moderately elongated, in lateral view almost evenly bent throughout; apical lamella moderately long with apex roundly delimited; basal bulb and sagittal aileron average. Endophallus with copulatory piece narrowly triangular, arcuate towards apex, in lateral view more strongly sclerotized on dorsal side.

\section{Distribution}

Known only from the southern slope of the Bale Mts, above Rira village, at an altitude of approx. $3200 \mathrm{~m}$.

Trechus relictus Magrini, Quéinnec \& Vigna Taglianti, 2012

Fig. 47

Trechus (Archeotrechus) relictus Magrini, Quéinnec \& Vigna Taglianti, 2012: 20; locus typicus: Oromia Province, Bale massif, Goba, Mt Sgona (Mt Batu), alt. about 3800 m.

\section{Diagnosis}

This species is easily recognizable based on the combination of the following characters: body length below $3 \mathrm{~mm}$ (maximum body length $3.02 \mathrm{~mm}$ : Magrini et al. 2012), only one protarsomere of male dilated, elytra with striae indistinctly impressed on disc, not iridescent, aedeagal median lobe elongated with ventral margin sinusoidal and with apical capitulum markedly button-like delimited.

\section{Type material}

Not studied. Identification is based on the very detailed description and figuring of habitus and genital characters as well as on additional material collected close to the type locality.

\section{Material examined}

ETHIOPIA: 54 specimens ( $\hat{\jmath} \hat{\jmath}$,, + + ), Oromia, Bale Mts, brook valley above Goba, alt. $3750-3800 \mathrm{~m}$,

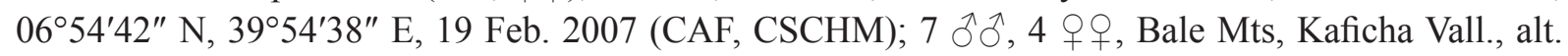

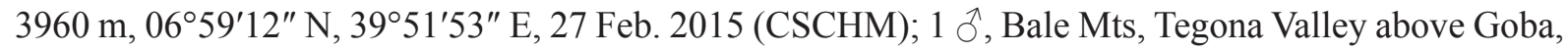
alt. $3550 \mathrm{~m}, 06^{\circ} 54^{\prime} 42^{\prime \prime} \mathrm{N}, 39^{\circ} 53^{\prime} 35^{\prime \prime} \mathrm{E}, 20$ Feb. 2007 (CAF).

\section{Distribution}

Locally endemic of the northeastern slope of the Bale Mts above Goba and the adjacent parts of the Sanetti Plateau (see Magrini et al. 2012). The vertical distribution of the species ranges from approximately $3700 \mathrm{~m}$ to $4100 \mathrm{~m}$. 

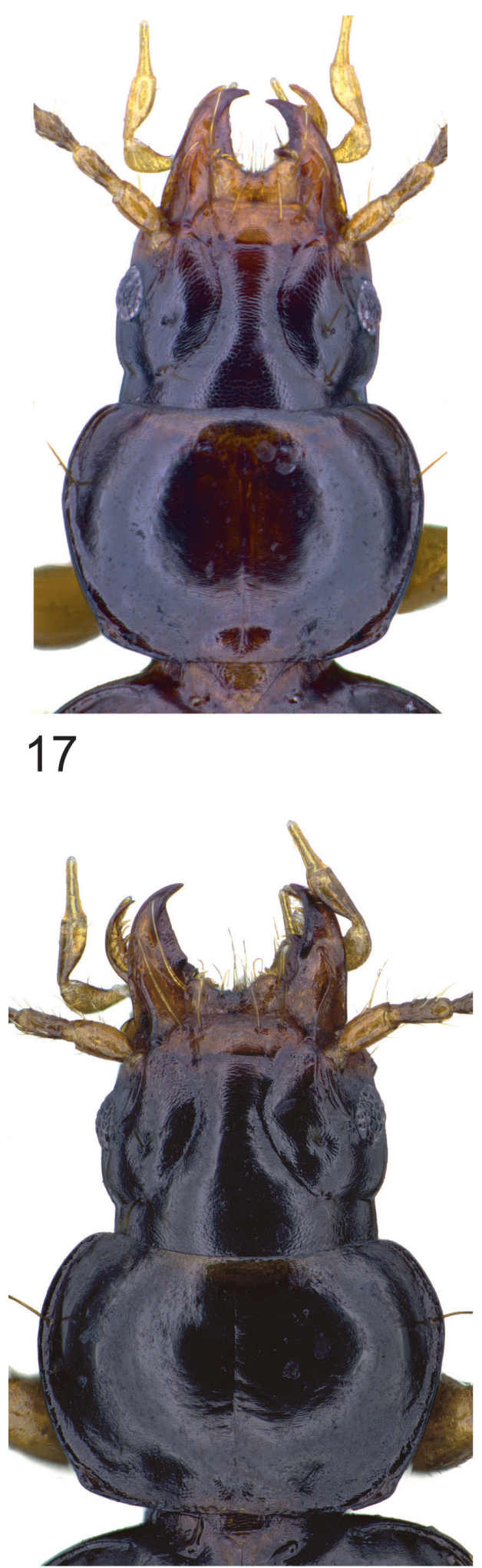

19

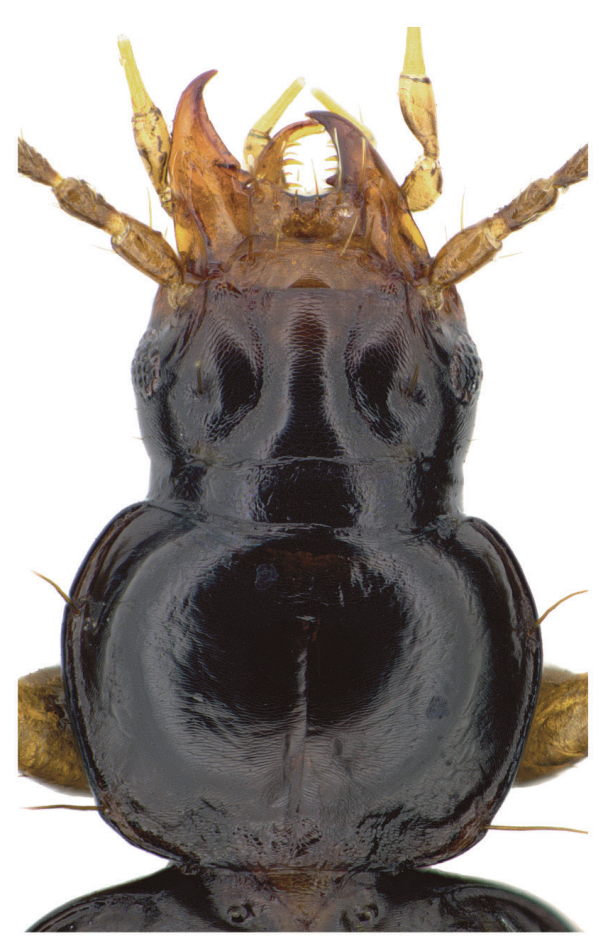

18

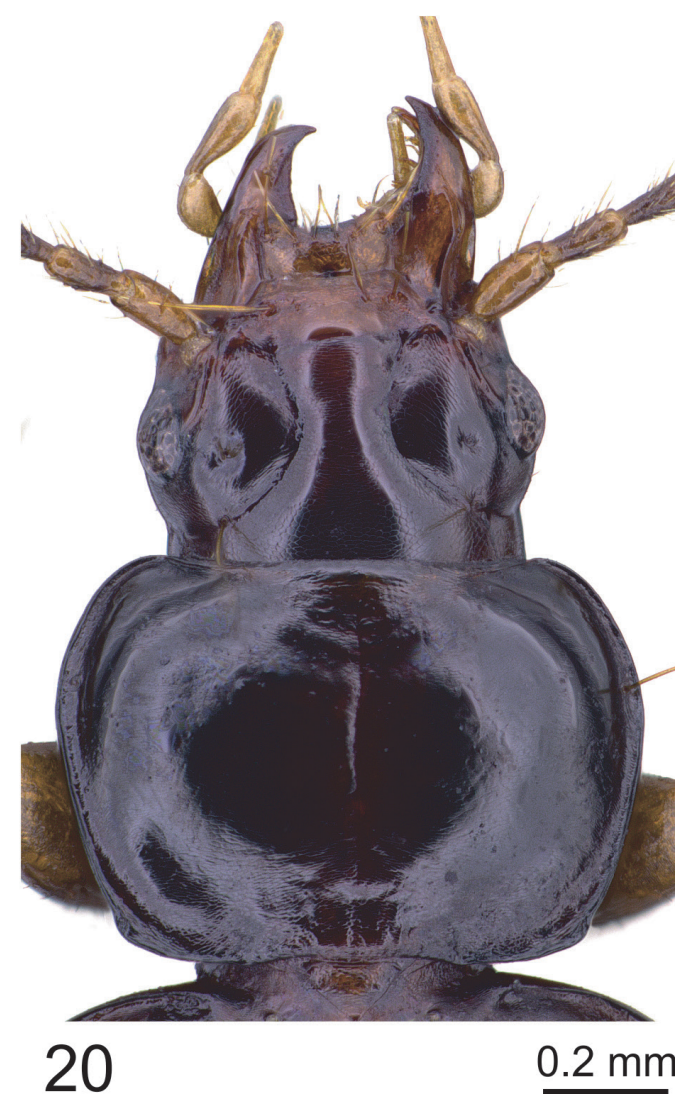

Figs 17-20. Trechus spp., head, pronotum. 17. T. rira sp. nov., holotype. 18. T. iridescens sp. nov., holotype. 19. T. oppositus sp. nov., paratype, §. 20. T. bombi sp. nov., holotype. 
Trechus iridescens sp. nov. urn:Isid:zoobank.org:act:3C59476B-17BA-4DAF-A3C8-FDC8B111D196

Figs $14,18,22,45-46$

\section{Diagnosis}

In external and male genital characters very similar to T. relictus from northeastern slope of Bale Mts, but colour of body darker, with elytra distinctly iridescent, pronotum more discoidal with lateral margin more markedly bent anteriorly, elytra broader with lateral margin more markedly convex, and aedeagal median lobe shorter with ventral margin not sinusoidal. For differentiation with the very similar $T$. oppositus sp. nov. from the western Bale Mts, see diagnosis of the latter species below.

\section{Etymology}

The specific epithet refers to the markedly iridescent elytra of the new species.

\section{Material examined}

\section{Holotype}

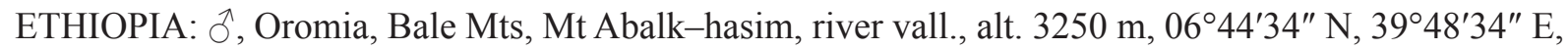
Feb. 2007 (CSCHM, registration number ZSM_COL_2018_006).

\section{Paratype}

ETHIOPIA: $2 \hat{\jmath} \widehat{\jmath}, 3$ 우, same data as for holotype (CAF, CSCHM).

\section{Description}

Body Length. 2.5-2.9 mm (Ø = 2.75 mm; $\mathrm{n}=6)$.

Proportions $(\mathrm{n}=6) . \mathrm{PW} / \mathrm{HW}=1.33-1.42(\varnothing=1.38) ; \mathrm{PW} / \mathrm{PL}=1.39-1.45(\varnothing=1.42) ; \mathrm{PW} / \mathrm{PBW}=$ $1.22-1.27(\varnothing=1.25) ; \mathrm{EW} / \mathrm{PW}=1.53-1.65(\varnothing=1.58) ; \mathrm{EL} / \mathrm{EW}=1.27-1.38(\varnothing=1.30)$.

Colour. Head, pronotum and elytra blackish brown, very shiny, elytra markedly iridescent. Clypeus, labrum, palpi, antennal base and legs yellowish; antennae distally darkened beginning from second antennomere.

Microsculpture. Same in males and females. Head with comparatively large, almost isodiametric meshes on disc and supraorbital area, and smaller meshes on clypeus. Pronotum and elytra with slightly engraved narrow transverse meshes, which are much narrower and hardly visible on elytra.

HeAD. Comparatively robust. Mandibles short. Labrum with apical margin widely emarginated. Eyes small, distinctly convexly protruded. Tempora convex, markedly wrinkled to the neck, 1.1 times as long as eyes, very finely and sparsely pubescent. Frons and supraorbital area strongly convex, with supraorbital furrows almost uniformly bent on disc, deep throughout. Antennae short, proportions of the first four antennomeres as follows: $1 / 1 / 0.85 / 0.75$; antennomeres $7-9$ only slightly longer than broad.

Prothorax. Pronotum large, transverse, with lateral margin more markedly bent towards apex than to base and with broadest portion in or slightly before middle; base slightly broader than apical margin. Disc markedly convex. Anterior margin slightly concave with anterior angles rounded, slightly protruded. Sides rounded throughout but less markedly towards base. Laterobasal angles very obtuse, blunt at apex. Marginal gutter very narrow, slightly widened near laterobasal angles. Base slightly concave in middle, distinctly bent anteriorly at outer quarter. Median longitudinal impression fine but distinct, not deepened near base, disappearing at apex; anterior transverse impression indistinct, smooth; posterior transverse 

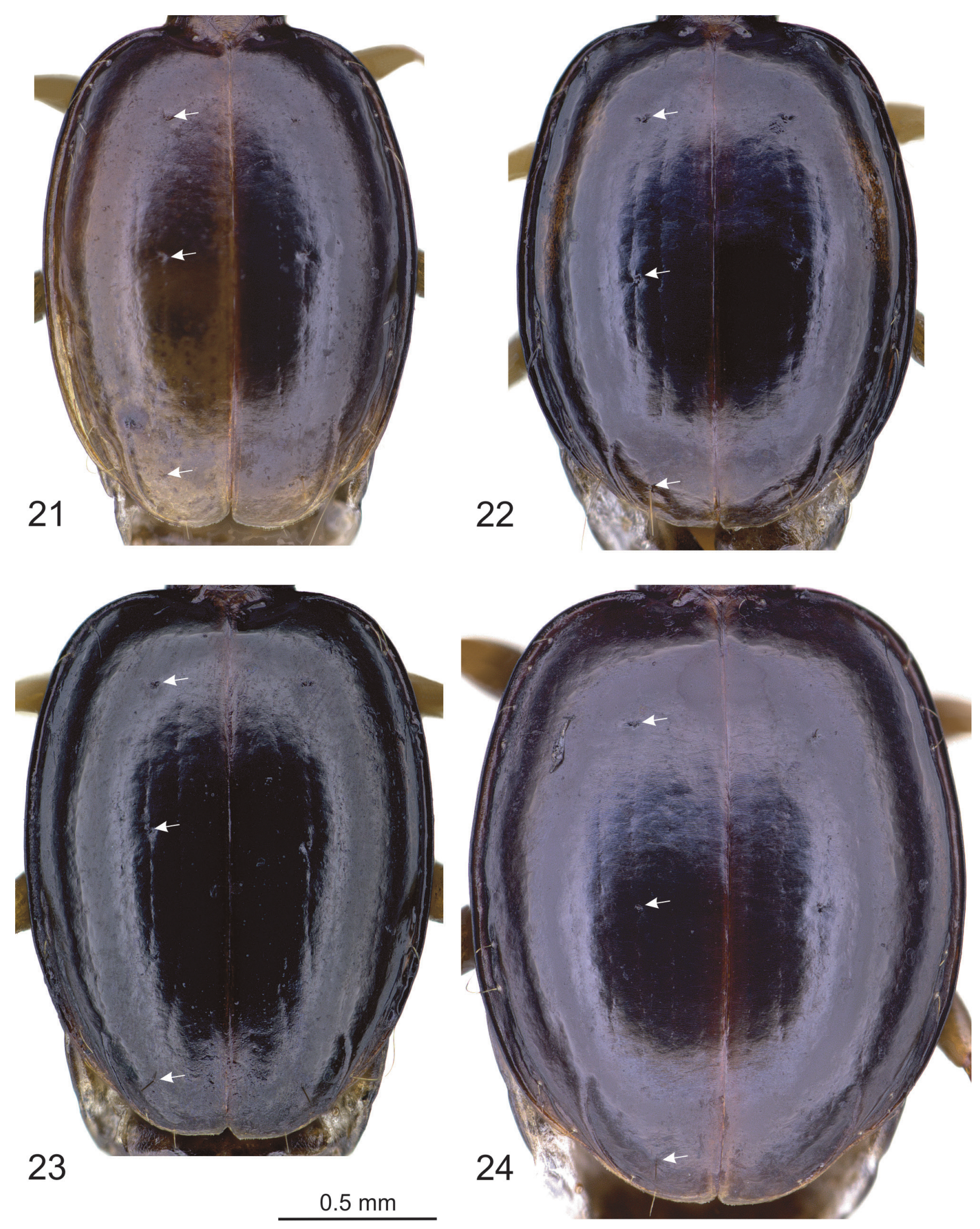

Figs 21-24. Trechus spp., elytra. 21. T. rira sp. nov., holotype. 22. T. iridescens sp. nov., holotype. 23. T. oppositus sp. nov., paratype, $\sigma^{\top}$. 24. T. bombi sp. nov., holotype. The arrows point to the insertions of the discal setae and the preapical seta. 
impression very shallow, laterobasal foveae diffuse limited towards disc and sides, moderately small, smooth. Pronotum with laterobasal setae present.

Pterothorax. Elytra convex on disc, in dorsal view moderately short and broad, broadest in mid-length or slightly before, with shoulders fully rounded; broadly rounded at apex. Striae impunctate, parascutellar stria absent; all other striae hardly visible or absent apart from stria 8 which is slightly impressed from level of the middle or subapical groups of the marginal umbilicate pores towards apex. All intervals flat. Recurrent preapical stria deep, curved in front, directed to the fifth stria. Third stria with two setiferous dorsal pores, the anterior one between anterior elytral fifth and quarter, the posterior one in middle, and with preapical seta situated at the apical anastomosis of second and third striae, slightly closer to the elytral apex than to the suture. Number and positions of the setae of the marginal umbilicate series as in Trechus s. str.

LEGS. Short and comparatively thin; protibia slightly dilated towards apex, hardly bowed, finely but distinctly grooved on external surface. Only one basal protarsomere of male dilated.

Male genitalia. EL/AL $=3.01-3.13(\varnothing=3.06, \mathrm{n}=3)$. Aedeagal median lobe moderately small, moderately slender, in lateral view almost evenly bent throughout; apical lamella moderately long with distinct button-like apical capitulum; basal bulb and sagittal aileron average. Endophallus with copulatory piece narrowly triangular, arcuate towards apex, in lateral view more strongly sclerotized on dorsal side.

\section{Distribution}

Known only from the type locality, along a brook valley near Mt Abalk-hasim, on southeastern slope of Bale Mts, at an altitude of $3250 \mathrm{~m}$.

Trechus oppositus $\mathrm{sp}$. nov. urn:1sid:zoobank.org:act:71A0EAC2-C525-4C4D-A685-0BEC8A8911E7

Figs 15, 19, 23, 48-49

\section{Diagnosis}

In external characters very similar to T. relictus and T. iridescens sp. nov., both from the eastern part of Bale Mts. Trechus oppositus sp. nov. differs from these species by distinctly more robust aedeagal median lobe with broader copulatory piece of endophallus. It differs additionally from $T$. relictus by iridescent and broader elytra, and from $T$. iridescens sp. nov. by less dark colour of body, smaller pronotum with lateral margin less markedly bent anteriorly and with base approximately as broad as apical margin.

\section{Etymology}

The specific epithet is derived from the Latin adjective "oppositus" and refers to the particular distributional patterns of this species with respect to its probable close relatives, T. relictus and T. iridescens sp. nov., which both occur on the eastern and thus opposite site of the Bale Mts.

\section{Material examined}

Holotype

ETHIOPIA: ${ }^{\top}$, Oromia, western Bale Mts, above Dodola, alt. 3400-3700 m, 06 ${ }^{\circ} 51^{\prime} \mathrm{N}, 39^{\circ} 14^{\prime} \mathrm{E}$, Dec. 2006 (CSCHM, registration number ZSM_COL_2018_007). 
Paratypes

ETHIOPIA: $9 \hat{\jmath} \hat{\jmath}, 5$ 우, same data as for holotype (CAF, CSCHM).

\section{Description}

Body LENGTH. 2.6-3.1 mm (Ø = $2.9 \mathrm{~mm} ; \mathrm{n}=15)$.

Proportions $(\mathrm{n}=10) . \mathrm{PW} / \mathrm{HW}=1.30-1.40(\varnothing=1.34) ; \mathrm{PW} / \mathrm{PL}=1.41-1.51(\varnothing=1.45) ; \mathrm{PW} / \mathrm{PBW}=$ $1.21-1.29(\varnothing=1.25) ; \mathrm{EW} / \mathrm{PW}=1.51-1.63(\varnothing=1.56) ; \mathrm{EL} / \mathrm{EW}=1.27-1.36(\varnothing=1.32)$.

Colour. Head, pronotum, and elytra blackish brown. In all other characters as described in T. iridescens sp. nov.

Microsculpture. As described in T. iridescens sp. nov.

HEAD. Tempora 1.15 times longer than eyes. In all other characters as described in T. iridescens sp. nov.

Prothorax. Pronotum moderately large, with broadest portion distinctly before middle and with base as wide as apical margin. In all other characters as described in T. rira sp. nov.

Pterothorax. As described for T. iridescens sp. nov.

Legs. As described for T. iridescens sp. nov.

Male genitalia. EL/AL $=2.83-3.03(\varnothing=2.94, \mathrm{n}=6)$. Aedeagal median lobe moderately small, moderately robust, in lateral view more markedly bent in basal half, with ventral margin almost straight in middle; apical lamella moderately long with distinct button-like apical capitulum; basal bulb and sagittal aileron average. Endophallus with copulatory piece bag-like, triangular in lateral and dorsal view, arcuate towards apex, slightly sclerotized throughout.

\section{Distribution}

Known only from the type locality, the western part of Bale Mts, on the northern slope of the mountain range south of the city Dodola, at altitudes of 3400-3700 m.

Trechus bombi sp. nov.

urn:1sid:zoobank.org:act:972996F7-8192-4045-A2F6-E8DF0B30C38F

Figs 16, 20, 24, 56

\section{Diagnosis}

Externally very similar to the above-described T. iridescens sp. nov. but larger, with elytra broader, and with aedeagal median lobe much slenderer. In addition, $T$. bombi sp. nov. differs from latter and similar species mentioned above by the male protarsi with two basal protarsomeres dilated.

\section{Etymology}

The name is derived from "bombi", the Oromic term for beetle.

\section{Material examined}

\section{Holotype}

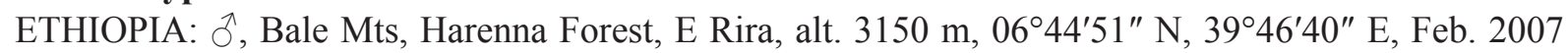
(CSCHM, registration number ZSM_COL_2018_008). 


\section{Paratypes}

ETHIOPIA: 1 , same data as for holotype (CSCHM).

\section{Description}

BoDy LENGTH. 3.2-3.3 mm.

Proportions $(\mathrm{n}=2) . \mathrm{PW} / \mathrm{HW}=1.42-1.43 ; \mathrm{PW} / \mathrm{PL}=1.45-1.47 ; \mathrm{PW} / \mathrm{PBW}=1.24-1.25 ; \mathrm{EW} / \mathrm{PW}=$ $1.60-1.61 ; \mathrm{EL} / \mathrm{EW}=1.24$.

Colour AND microsculpture. As described in T. iridescens sp. nov.

HEAD. Eyes moderately small, tempora $0.7-0.8$ times as long as eyes. Antennae moderately short, proportions of the first four antennomeres as follows: 1/0.93/0.93/0.8; antennomeres 7-9 approx. 1.8 times as long as broad. In all other characters as described in T. iridescens sp. nov.

Prothorax. As described in T. iridescens sp. nov.

Pterothorax. Elytra markedly broad. In all other characters as described in T. iridescens sp. nov.

LEGS. Short and comparatively thin; protibia slightly dilated towards apex, almost straight, finely but distinctly grooved on external surface. Two basal protarsomeres of male dilated, dentoid at the inner apical border.

Male genitalia. EL/AL $=2.76(n=1)$. Aedeagal median lobe slender, in lateral view more markedly bent in basal half, almost straight near apical lamella, and shortly bent upward at apex; basal bulb and sagittal aileron moderately large. Endophallus with copulatory piece elongated, indistinctly limited ventrally, more strongly sclerotized dorsally.

\section{Distribution}

Known only from the type location, on the southern slope of the Bale Mts, in the Harenna Forest east of the village Rira, at an altitude of $3150 \mathrm{~m}$.

Trechus dodola sp. nov. urn:lsid:zoobank.org:act:08D6193D-BAEF-4341-9982-52F40BC7C51E

Figs 25, 29, 33, 52

\section{Diagnosis}

Very similar to T. nanulus sp. nov. but slightly larger, colour of body lighter brown, aedeagal median lobe more markedly and more evenly curved, and - the most distinctive character - with two basal protarsomeres of male dilated. For comparison with the likewise similar species T. adaba sp. nov., T. harenna sp. nov. and T. harryi sp. nov. see descriptions below.

\section{Etymology}

The specific epithet refers to the city Dodola, situated on the northern slope of the western Bale Mts, close to the type locality of the new species. 


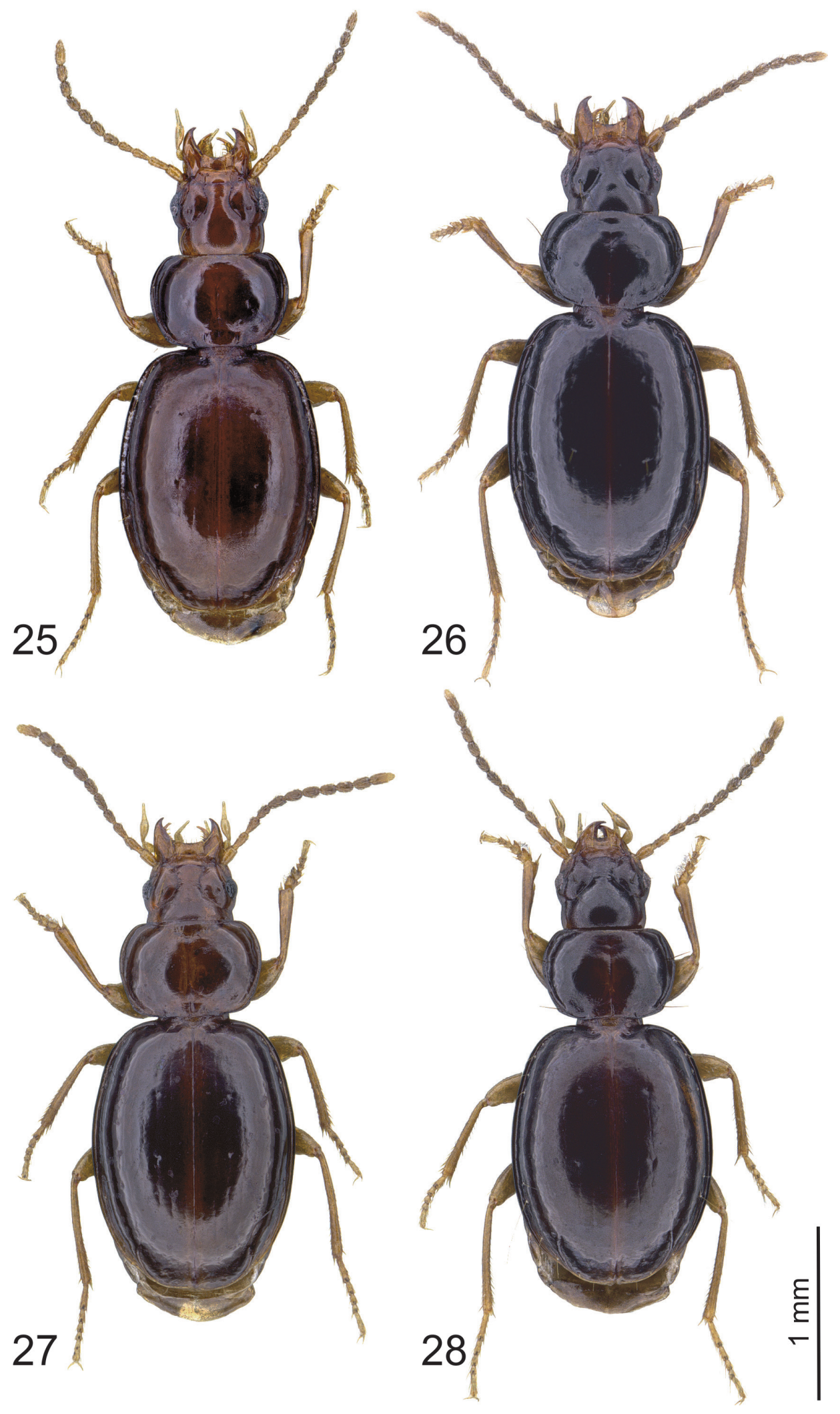

Figs 25-28. Trechus spp., habitus. 25. T. dodola sp. nov., holotype. 26. T. adaba sp. nov., paratype, ઊ. 27. T. harryi sp. nov., paratype, §. 28. T. harenna sp. nov., paratype, $\overbrace{}^{\lambda}$. 


\section{Material examined}

\section{Holotype}

ETHIOPIA: ô, Oromia, western Bale Mts, above Dodola, alt. 2700-2850 m, 06 $53^{\prime} 49^{\prime \prime}$ N, 39¹1'32" E, Dec. 2006 (CSCHM, registration number ZSM_COL_2018_009).

\section{Paratypes}

ETHIOPIA: 1 ô, 3 qq+, same data as for holotype (CAF, CSCHM).

\section{Description}

Body Length. 2.3-2.7 mm (

Proportions $(\mathrm{n}=5) . \mathrm{PW} / \mathrm{HW}=1.34-1.44(\varnothing=1.40) ; \mathrm{PW} / \mathrm{PL}=1.50-1.57(\varnothing=1.53) ; \mathrm{PW} / \mathrm{PBW}=$ $1.24-1.29(\varnothing=1.26) ; \mathrm{EW} / \mathrm{PW}=1.43-1.48(\varnothing=1.46) ; \mathrm{EL} / \mathrm{EW}=1.29-1.33(\varnothing=1.30)$.

Colour. Head, pronotum and elytra brown, shiny, elytra slightly iridescent. Clypeus, labrum, palpi, antennal base and legs yellowish; antennae distally indistinctly darkened beginning from apical third of third antennomere.

Microsculpture. Same in males and females. Head with almost isodiametric meshes on disc and supraorbital area, smaller and slightly transverse meshes on clypeus. Pronotum with very finely engraved transverse meshes. Elytra with hardly visible, very finely engraved and very narrow transverse meshes.

HEAD. Comparatively robust. Mandibles short. Labrum with apical margin widely emarginated. Eyes moderately small, distinctly convexly protruded. Tempora convex, markedly wrinkled to the neck, 0.7-0.8 times as long as eyes, smooth. Frons and supraorbital area strongly convex, with supraorbital furrows almost uniformly bent on disc, deep throughout. Antennae short, proportions of the first four antennomeres as follows: 1/1/0.9/0.7-0.8; antennomeres 7-9 approx. 1.3 times as long as broad.

Prothorax. Pronotum large, markedly transverse, broadest portion in or slightly before middle, base slightly wider than apical margin. Disc markedly convex. Anterior margin slightly concave with anterior angles slightly protruded. Sides almost evenly rounded throughout. Laterobasal angles very obtuse, blunt at apex. Marginal gutter very narrow, not widened near laterobasal angles. Base straight in middle, distinctly bent anteriorly at outer quarter. Median longitudinal impression fine, not deepened near base, disappearing at apex; anterior transverse indistinct, smooth; posterior transverse impression very shallow; laterobasal foveae very small, shallow, smooth. Pronotum with laterobasal setae present.

Pterothorax. Elytra convex on disc, in dorsal view short and broad, broadest in mid-length, with shoulders fully rounded; broadly rounded at apex. Striae impunctate, parascutellar stria absent, first stria absent or indistinct on disc, very finely impressed near apex, striae 2-4 (5) indistinct, external striae absent but stria 8 moderately impressed from level of the middle group of the marginal umbilicate pores towards apex. All intervals flat. Recurrent preapical stria deep, curved in front, directed to the fifth stria. Parascutellar setiferous pore present; third stria with two setiferous dorsal pores, the anterior one at the end of the anterior elytral quarter, the posterior one in middle, and with preapical seta which is situated at the apical anastomosis of second and third striae, slightly closer to elytral apex than to suture. Number and positions of the setae of the marginal umbilicate series as in Trechus s. str.

LEGS. Short and comparatively thin; protibia slightly dilated towards apex, almost straight, finely grooved on external surface. Two basal protarsomeres of male dilated.

Male genitalia. EL/AL $=3.96-4.16(n=2)$. Aedeagal median lobe small and stout, in lateral view almost evenly bent throughout but with apex very slightly bent upward; apical lamella short with apex 


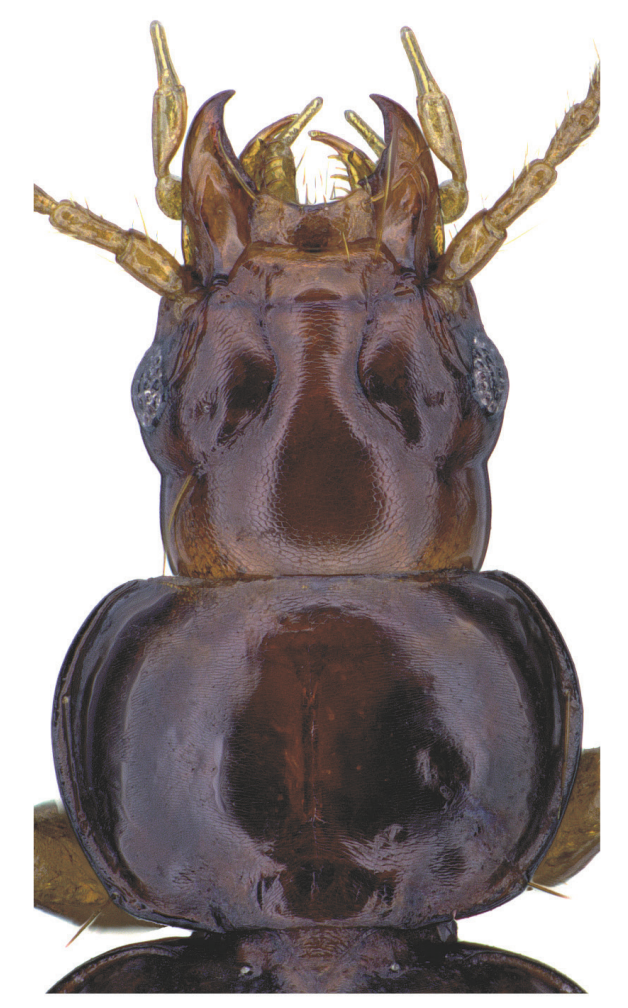

29

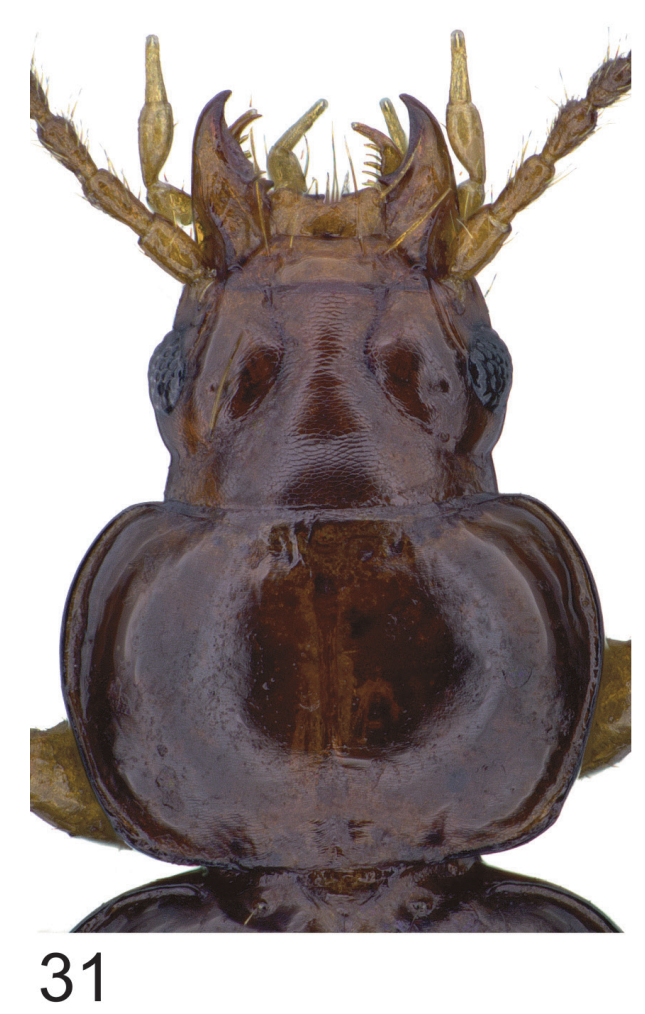

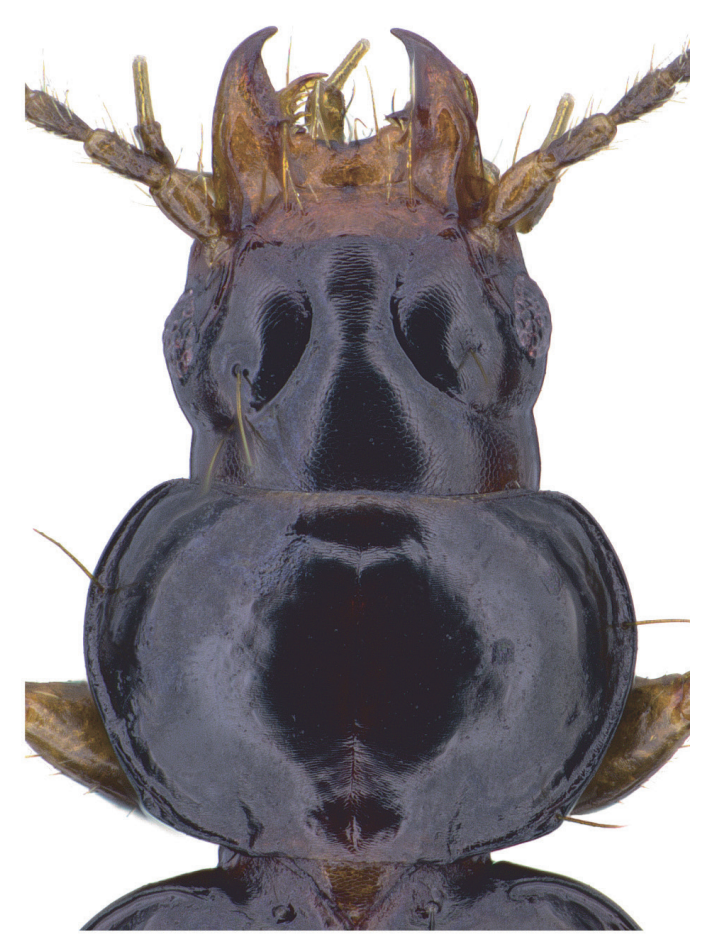

30

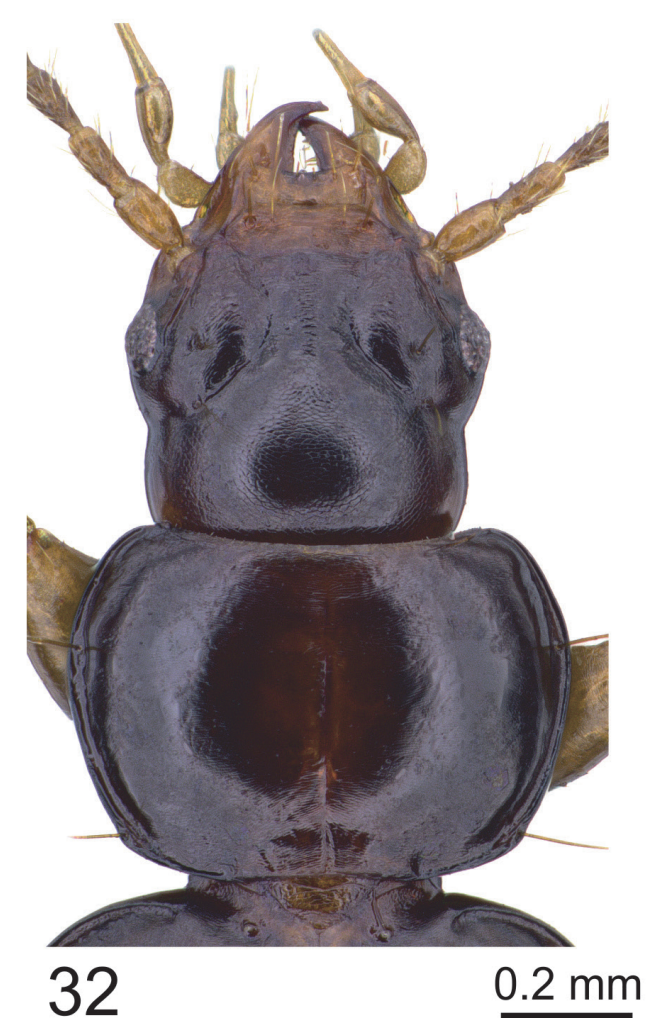

Figs 29-32. Trechus spp., head, pronotum. 29. T. dodola sp. nov., holotype. 30. T. adaba sp. nov.,

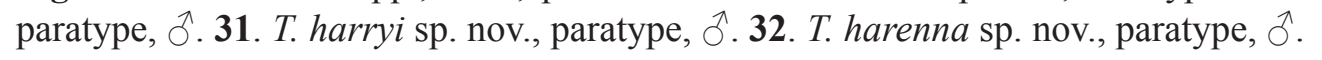


simply tapered; basal bulb moderately large, sagittal aileron average. Endophallus with copulatory piece bag-like, arcuate towards apex, very slightly sclerotized in most parts, somewhat more distinctly sclerotized on dorsal side if viewed from lateral.

\section{Distribution}

Known only from the western part of the Bale Mts, on the northern slope of the mountain above the city of Dodola, at altitudes of $2700-2850 \mathrm{~m}$.

Trechus adaba sp. nov.

urn:1sid:zoobank.org:act:2C3B7054-4931-4B09-8245-A0DB622EC104

Figs 26, 30, 34, 53-54

\section{Diagnosis}

In habitus very similar to the above-described T. dodola sp. nov., but colour of body darker, more markedly iridescent; aedeagal median lobe unevenly curved, less markedly in middle and apical half, with apex suggestively hooked, and without endophallic copulatory piece. For comparison with the likewise similar species $T$. harenna sp. nov. and $T$. harryi sp. nov., see descriptions of the latter below.

\section{Etymology}

The specifi epithet refers to the city of Adaba on the northern slope of the western Bale Mts, close to the type locality of the new species.

\section{Material examined}

\section{Holotype}

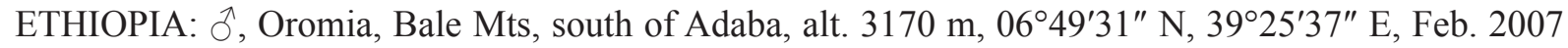
(CSCHM, registration number ZSM_COL_2018_010).

\section{Paratypes}

ETHIOPIA: $23 \hat{\partial} \hat{\partial}, 16 \hat{q} q$, same data as for holotype (CAF, CSCHM); $6 \hat{\jmath} \hat{\partial}, 4$ $q$, , Bale Mts, near pass south of Adaba, 3250 m, 0646'33" N, 39²4'58" E, 22 Feb. 2017 (CAF, CSCHM).

\section{Description}

Body LENGTH. 2.5-2.8 mm (Ø $=2.62 \mathrm{~mm}, \mathrm{n}=15)$.

Proportions $(\mathrm{n}=10) . \mathrm{PW} / \mathrm{HW}=1.35-1.43(\varnothing=1.40) ; \mathrm{PW} / \mathrm{PL}=1.45-1.54(\varnothing=1.50) ; \mathrm{PW} / \mathrm{PBW}=$ $1.23-1.33(\varnothing=1.27) ; \mathrm{EW} / \mathrm{PW}=1.41-1.51(\varnothing=1.46) ; \mathrm{EL} / \mathrm{EW}=1.27-1.33(\varnothing=1.31)$.

Colour. Head, pronotum and elytra blackish brown, markedly shiny, elytra markedly iridescent. Clypeus, labrum, palpi, antennal base and legs yellowish; antennae distally darkened beginning from second antennomere.

MicrosculPture. As described in T. dodola sp. nov.

Head, Prothorax, pterothorax and legs. As described in T. dodola sp. nov.

Male GENitAlia. EL/AL $=3.88-4.29(\varnothing=4.03, \mathrm{n}=6)$. Aedeagal median lobe small and stout, in lateral view more markedly bent behind basal bulb, almost straight towards apex; apical lamella short with apex very shortly bent upward, forms a very small hook; basal bulb moderately large, sagittal aileron average. Endophallus very slightly sclerotized throughout, without suggestion of a copulatory piece. 

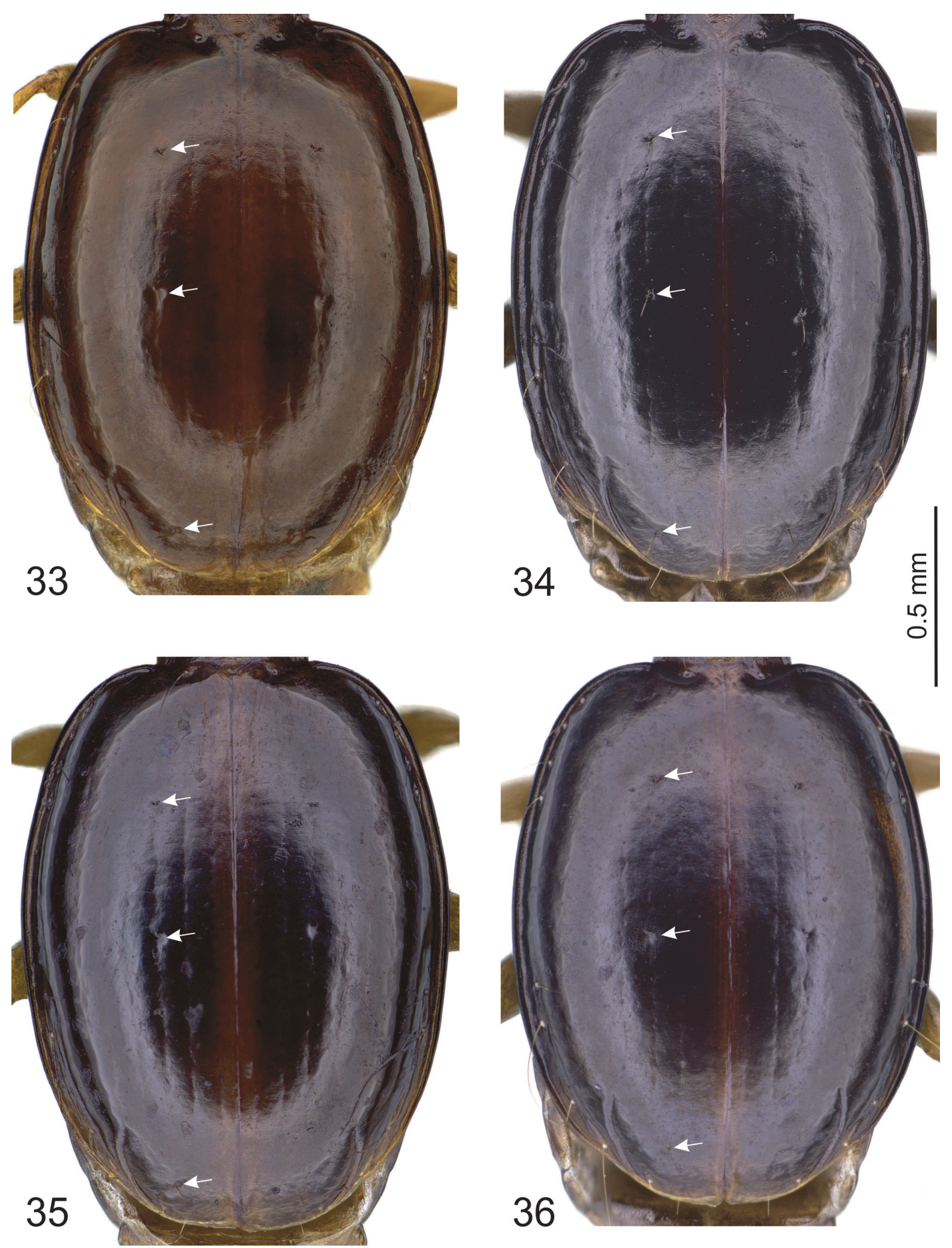

Figs 33-36. Trechus spp., elytra. 33. T. dodola sp. nov., holotype. 34. T. adaba sp. nov., paratype, ${ }^{\lambda}$. 35. T. harryi sp. nov., paratype, ${ }^{\lambda}$. 36. T. bayedika sp. nov., paratype, $\sigma^{\lambda}$. The arrows point to the insertions of the discal setae and the preapical seta. 


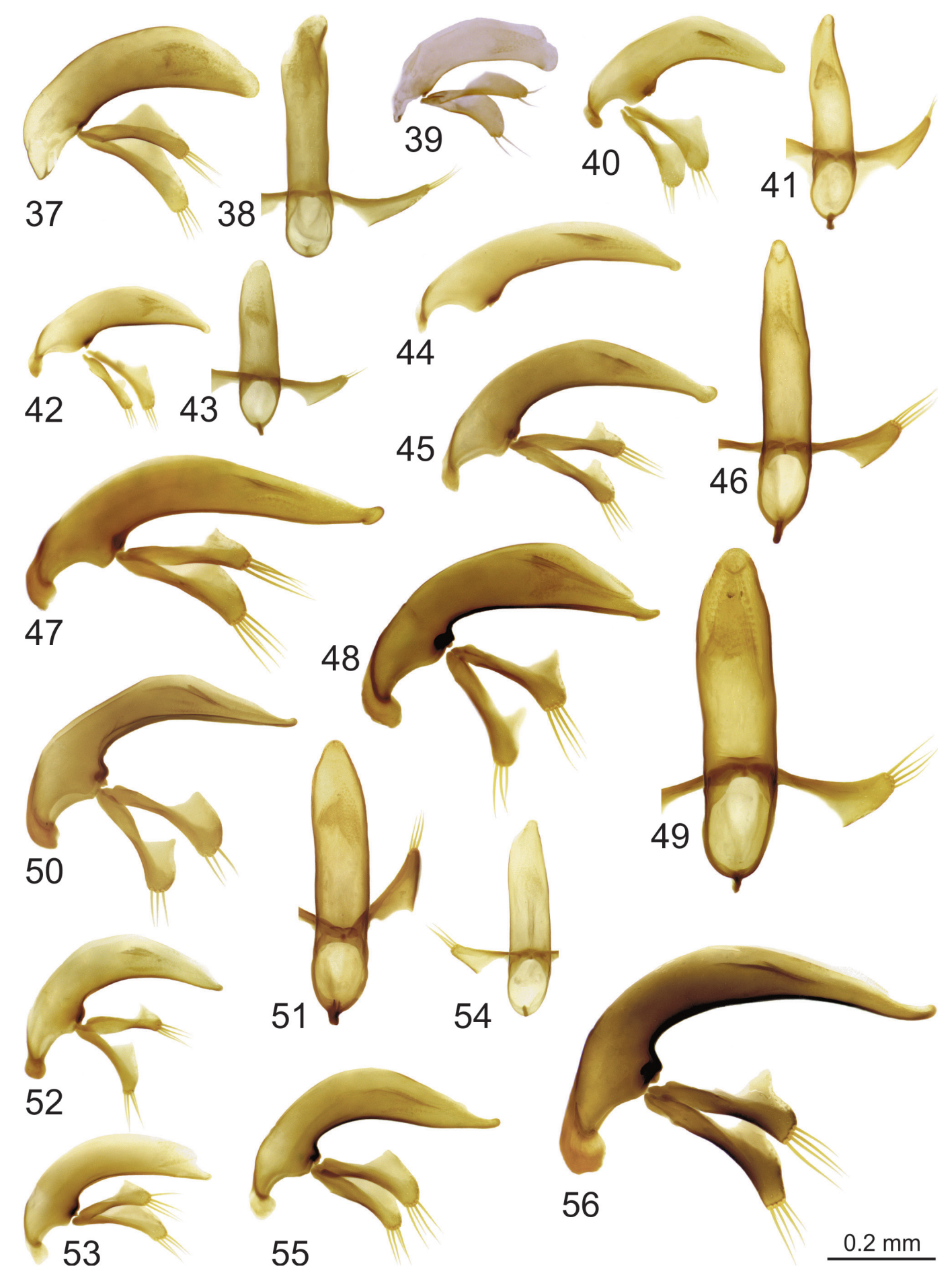

Figs 37-56. Trechus spp., aedeagal median lobe, left lateral view $(37,39,40,42,44-45,47-48$, 50, 52-53, 55-56) and dorsal view (38, 41, 43, 46, 49, 51, 54). 37-38. T. mattisi sp. nov., paratype. 39. T. transversicollis sp. nov., holotype. 40-41. T. minitrechus sp. nov., paratype. 42-43. T. nanulus sp. nov., paratype. 44. T. rira sp. nov., holotype. 45-46. T. iridescens sp. nov., holotype. 47. T. relictus Magrini, Quéinnec \& Vigna Taglianti, 2012, specimen from brook valley above Goba. 48-49. T. oppositus sp. nov., paratype. 50-51. T. harryi sp. nov., paratype. 52. T. dodola sp. nov., holotype. 53-54. T. adaba sp. nov., paratype. 55. T. harenna sp. nov., paratype. 56. T. bombi sp. nov., holotype. 


\section{Distribution}

Known only from the western part of the Bale Mts, on the northern slope above the city of Adaba, at altitudes of $3170-3250 \mathrm{~m}$.

Trechus harryi sp. nov.

urn:lsid:zoobank.org:act:F8A18087-F403-41A6-9F81-FD7FC8D38944

Figs 27, 31, 35, 50-51

\section{Diagnosis}

Very similar to the above-described $T$. dodola sp. nov. and T. adaba sp. nov., but base of pronotum distinctly broader than apical margin, and aedeagal median lobe larger and distinctly slenderer. The new species differs additionally from $T$. adaba sp. nov. by the lighter body colour and less iridescent elytra, and by the more markedly sclerotized endophallus. For comparison with the likewise similar species T. harenna sp. nov., see description of the latter below.

\section{Etymology}

Dedicated to Mr. Ingmar Harry, Freiburg, who kindly provided us with Trechus specimens for study, and who indicated to us the occurrence of this new species in the Harenna Forest near Rira.

\section{Material examined}

\section{Holotype}

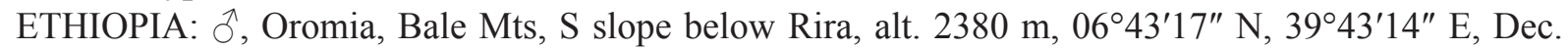
2006 (CSCHM, registration number ZSM_COL_2018_011).

\section{Paratypes}

ETHIOPIA: $10 \hat{\partial} \hat{\partial}, 17$ 우, same data as for holotype (CAF, CSCHM). $1 \hat{\partial}$, same data as for preceding

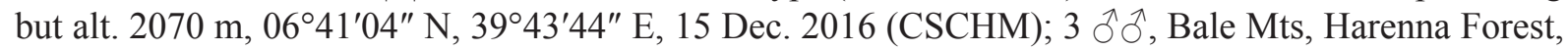
E Rira, alt. $2690 \mathrm{~m}, 06^{\circ} 43^{\prime} 25^{\prime \prime} \mathrm{N}, 39^{\circ} 45^{\prime} 25^{\prime \prime} \mathrm{E}, \mathrm{Feb} .2007$ (CSCHM); 2 우, same data as for preceding but 13 Dec. 2017 (CSCHM); 1 ô, 1 ㅇ, Bale Berge, Kacha Camp, alt. 2370 m, 6.717 N, 39.726 E,

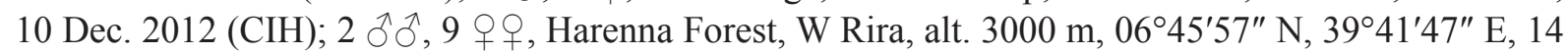
Dec. 2017 (CAF, CSCHM, ZMAA).

\section{Additional material}

ETHIOPIA: 1 +, Bale Berge, Harenna Forest, "Gora Hawo" Wald [forest], 1950 m, 6.71 N, 39.61 E, 8-9 Dec. 2012 (CIH).

\section{Description}

Body LENGTH. 2.5-2.8 mm (Ø =2.65 mm, $\mathrm{n}=15)$.

Proportions $(\mathrm{n}=10)$. PW/HW $=1.43-1.50(\varnothing=1.46) ; \mathrm{PW} / \mathrm{PL}=1.42-1.51(\varnothing=1.48) ; \mathrm{PW} / \mathrm{PBW}=$ $1.20-1.26(\varnothing=1.24) ; \mathrm{EW} / \mathrm{PW}=1.37-1.49(\varnothing=1.44) ; \mathrm{EL} / \mathrm{EW}=1.30-1.37(\varnothing=1.33)$.

Colour. As described in T. dodola sp. nov.

HEAD. Tempora 0.5-0.6 times as long as eyes. In all other characters as described in T. dodola sp. nov.

Prothorax. Pronotal base distinctly wider than apical margin, sides evenly rounded throughout, laterobasal foveae formed as tiny pits near basal margin. In all other characters as described in T. dodola sp. nov. 
Pterothorax. First elytral stria indistinct but present on disc. In all other characters as described in T. dodola sp. nov.

Legs. As described in T. dodola sp. nov.

MALE GENITALIA. EL/AL $=3.03-3.22(\varnothing=3.13 ; n=6)$. Aedeagal median lobe moderately small, rather slender, in lateral view more markedly bent in basal half, ventral margin almost straight towards apex; apical lamella moderately long, very faintly bent upward at tip. Basal bulb and sagittal aileron moderately large. Endophallus with copulatory piece indistinctly delimited, in lateral view more markedly sclerotized on dorsal side near ostium.

\section{Distribution}

Known only from the southern slope of the Bale Mts, south, east and west of the village Rira, at altitudes of 2070-2690 m.

Trechus harenna sp. nov. urn:1sid:zoobank.org:act:81566043-215A-4AA5-B0ED-E60549012793

Figs 28, 32, 36, 55

\section{Diagnosis}

Very similar to the above described species $T$. adaba sp. nov., T. dodola sp. nov., and T. harryi sp. nov., but easily distinguished by the aedeagal median lobe which is slightly sinusoidal in view from laterad with ventral margin slightly but distinctly convex. The median lobe is distinctly shorter than in the allopatric species $T$. harryi sp. nov., more elongated than in $T$. dodola sp. nov., and its endophallus is more markedly sclerotized than in T. adaba sp. nov.

\section{Etymology}

The specific epithet refers to the habitat of the new species, the Harenna Forest, which is the largest unspoiled forest in Ethiopia.

\section{Material examined}

\section{Holotype}

ETHIOPIA: गै, Bale Mts, Harenna Forest, E Rira, alt. 3150 m, 06 $44^{\prime} 51^{\prime \prime}$ N, 39 $46^{\prime} 40^{\prime \prime}$ E, Feb. 2007 (CSCHM, registration number ZSM_COL_2018_012).

\section{Paratypes}

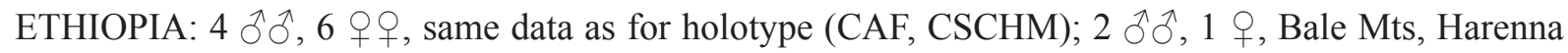

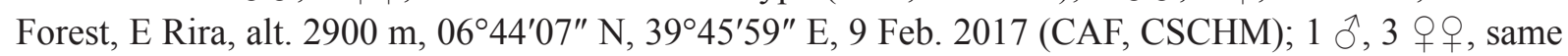
data as for preceding but alt. 3050-3150 m, 06 ${ }^{\circ} 44^{\prime} 59^{\prime \prime}$ N, 39 47'36" E, 12 Feb. 2017 (CAF, CSCHM);

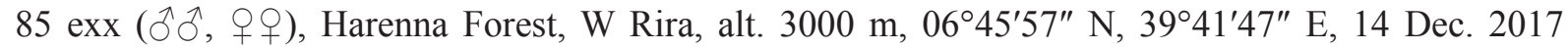
(NHMUK, CAF, CDH, CSCHM, MNHN, ZMAA).

\section{Description}

Body Length. 2.5-2.8 mm (Ø $=2.7 \mathrm{~mm}, \mathrm{n}=15)$.

Proportions $(\mathrm{n}=10) . \mathrm{PW} / \mathrm{HW}=1.37-1.44(\varnothing=1.41) ; \mathrm{PW} / \mathrm{PL}=1.47-1.56(\varnothing=1.52) ; \mathrm{PW} / \mathrm{PBW}=$ $1.22-1.29(\varnothing=1.26) ; \mathrm{EW} / \mathrm{PW}=1.45-1.53(\varnothing=1.49) ; \mathrm{EL} / \mathrm{EW}=1.24-1.36(\varnothing=1.30)$. 
CoLour. Head, pronotum and elytra dark brown, shiny, elytra more markedly iridescent. Clypeus, labrum, palpi, antennal base and legs yellowish; antennae distally darkened beginning from third antennomere, in some specimens from apical half of second antennomere.

Microsculpture. As described in T. dodola sp. nov.

HEAD. Tempora 0.8 times as long as eyes, smooth or, in some specimens, with very few very fine hairs. In all other characters as described in T. dodola sp. nov.

Prothorax. Marginal gutter faintly widened at laterobasal angles. Laterobasal foveae moderately small, very shallow, more distinctly limited interiorly, indistinctly limited towards disc and sides. In all other characters as described in T. dodola sp. nov.

Pterothorax. In most specimens recurrent preapical stria of elytra anteriorly prolonged towards the end of the fifth stria with tip ending distinctly anteriad of level of the penultimate setiferous pore of the marginal umbilicate series. In all other characters as described in T. dodola sp. nov.

LEGS. As described in T. dodola sp. nov.

Male genitalia. EL/AL $=3.16-3.42(\varnothing=3.33, \mathrm{n}=6)$. Aedeagal median lobe moderately small and moderately stout, in lateral view slightly sinusoidal, more strongly bent in basal half, with ventral margin convex and apical lamella slightly bent upward; latter moderately short with apex simply tapered or suggestively hooked; basal bulb and sagittal aileron average. Endophallus with copulatory piece indistinctly delimited, in lateral view more markedly sclerotized on dorsal side near ostium.

\section{Distribution}

Known only from the southeastern slope of the Bale Mts, east of the village Rira, at altitudes of 2900 $3150 \mathrm{~m}$

\section{Trechus depressipennis sp. nov. urn:lsid:zoobank.org:act:6FEF0E44-C6B1-4C6A-93CA-4C3F0F8757C4}

Figs $67,71,75,115$

\section{Diagnosis}

Within the Trechus fauna of the study area this species is easily recognizable by the combination of the following characters: elytral microsculpture consists of rather large, very slightly transverse meshes; eyes moderately large; pronotal laterobasal angles large and acute; sides of pronotal base not protruded posteriorly; two basal protarsomeres of male dilated.

\section{Etymology}

The specific epithet refers to the depressed elytra which is a distinctive character of the new species.

\section{Material examined}

Holotype

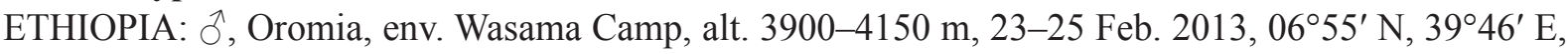
(CSCHM, registration number ZSM_COL_2018_013).

Paratype

ETHIOPIA: 1 , same data as for holotype (CSCHM). 


\section{Description}

BoDy LeNGTH. 4.2-4.6 mm $(\mathrm{n}=2)$.

Proportions $(\mathrm{n}=2) . \mathrm{PW} / \mathrm{HW}=1.33-1.34 ; \mathrm{PW} / \mathrm{PL}=1.33-1.38 ; \mathrm{PW} / \mathrm{PBW}=1.25-1.30 ; \mathrm{EW} / \mathrm{PW}=$ $1.51-1.54 ; \mathrm{EL} / \mathrm{EW}=1.44$.

Colour. Head, pronotum and elytra blackish brown, moderately shiny; lateral margin of labrum, palpi, antennal base and legs middle brown; antennae distally darkened beginning from the second or third antennomere.

Microsculpture. Same in male and female. Head with rather large and deeply engraved almost isodiametric meshes on neck and in supraorbital furrows, more slightly engraved meshes on disc, and smaller meshes on clypeus. Pronotum with rather small, very finely engraved slightly transverse meshes on disc, and deeply engraved meshes near base. Elytra with rather large and deeply engraved, slightly transverse or somewhat irregularly formed meshes.

HeAD. Size normal for Trechus. Mandibles moderately short. Labrum with apical margin widely emarginated. Eyes moderately large, moderately convex. Tempora convex, markedly wrinkled to the neck, almost half as long as eyes, very finely and very sparsely pubescent. Frons and supraorbital area strongly convex, with supraorbital furrows somewhat unevenly bent on disc, deep in middle, shallower near posterior supraorbital seta. Antennae moderately slender, proportions of the first four antennomeres as follows: $1 / 0.8 / 0.9 / 0.8$.

Prothorax. Pronotum average for Trechus, moderately transverse, broadest portion slightly before middle, base slightly wider than apical margin. Disc slightly convex. Anterior margin slightly concave with anterior angles slightly protruded, rounded. Sides convexly rounded in anterior $4 / 5$, concave before base. Laterobasal angles moderately large, slightly acute, slightly protruded laterally. Marginal gutter moderately narrow, distinctly widened near laterobasal angles. Base straight in middle, slightly bent anteriorly at outer quarter. Median longitudinal fine, not deepened near base, disappearing at apex; anterior transverse very shallow, smooth; posterior transverse impression moderately shallow; laterobasal foveae moderately large, roundish, moderately deep, smooth. Pronotum with laterobasal setae present.

Pterothorax. Elytra distinctly flattened on disc, in dorsal view oval, broadest in mid-length, with shoulders and apex broadly rounded. Striae very finely punctate, parascutellar stria moderately long, deep, striae 1-4 deeply impressed, 5 and 6 finer, 7 and anterior part of 8 indistinct, 8 deeply impressed from level of the middle group of the marginal umbilicate pores towards apex. Internal 3 intervals moderately convex. Recurrent preapical stria deep, long, curved in front, directed to the end of the seventh stria. Third stria with two setiferous dorsal pores, the anterior one near the end of the anterior elytral quarter, the posterior one slightly behind middle, and with preapical seta which is situated at the apical anastomosis of second and third striae, somewhat closer to elytral apex than to suture. Number and positions of the setae of the marginal umbilicate series as in Trechus s. str.

Legs. Moderately short and comparatively thin; protibia slightly dilated towards apex, almost straight, distinctly grooved on external surface. Two basal protarsomeres of male dilated.

Male genitalia. EL/AL $=2.73(\mathrm{n}=1)$. Aedeagal median lobe moderately large, in lateral view with ventral margin more markedly bent behind basal bulb, almost straight towards apex; apical lamella moderately short, very oblique, button-like, pointed with tip shortly bent upward; basal bulb average with sagittal aileron small. Endophallic copulatory piece moderately large, somewhat cone-shaped, but with upward bent tip. 


\section{Distribution}

Endemic to the northern slope of the Bale Mts; only known from the Wasama Valley. The species was found at altitudes of $3900-4150 \mathrm{~m}$.

\section{Trechus clarkeianus (Basilewsky, 1974)}

Cothresia clarkeiana Basilewsky, 1974: 154; locus typicus: Bale Province, Ridge of Mt Batu, Deekasura Pass, ca $36 \mathrm{~km} \mathrm{~S}$ of Dinshu, Bale Mts, alt. $4150 \mathrm{~m}, 6^{\circ} 55^{\prime} \mathrm{N}, 39^{\circ} 46^{\prime} \mathrm{E}$.

Trechus clarkeianus - Geginat 2008: 124.

\section{Type material}

Not studied. This species was revised by Geginat (2008: 125) with presentation of a photo of the male genitalia.

\section{Material examined}

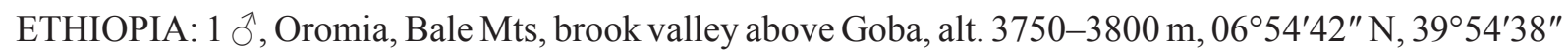
E, 19 Feb. 2017 (CSCHM).

\section{Identification}

Within the Trechus fauna of the Oromia region, this species is easily recognizable based on the combination of the following characters: body length above $5 \mathrm{~mm}$, eyes markedly flat and small, tempora slightly longer than eyes, pronotal base almost straight with laterobasal angles large, rectangular, two protarsomeres of male dilated, aedeagal median lobe simply narrowed towards apex.

\section{Distribution}

Probably endemic to the northern slope of the Bale Mts. The vertical distribution of the species ranges from approximately $3750 \mathrm{~m}$ to $4150 \mathrm{~m}$.

Trechus scotti Jeannel, 1936

Trechus (s. str.) scotti Jeannel, 1936: 208; locus typicus: Mt Chillalo, alt. approx. 4000 m.

Trechus scotti - Ortuño \& Novoa 2011: 137.

\section{Type material}

Not studied. Identification of this unique species is based on its original description including figures of habitus and genital characters.

\section{Additional material}

Not available.

\section{Identification}

Easily recognizable due to the remarkable shape of the aedeagal median lobe which is markedly funnelshaped, widening near apex (Jeannel 1936: 209). Within the Trechus fauna of Mt Chillalo this species is also easily distinguished externally due to the head with small flat eyes and long tempora. 


\section{Distribution}

Probably endemic to Mt Chillalo; the holotype specimen was found at an altitude of approximately $4000 \mathrm{~m}$ (Jeannel 1936).

Trechus mekbibi sp. nov. urn:1sid:zoobank.org:act:E5D250CA-25F7-406D-90B0-E40FF9299CF1

Figs $68,72,76,116-117$

\section{Diagnosis}

Within the fauna of the study area this species is easy to distinguish from all other Trechus species by the combination of the following characters: eyes large; pronotal laterobasal angles very large, acute, distinctly protruded lateriad and posteriad; two basal protarsomeres of male dilated. A very marked similarity of the male genital characters of T. mekbibi sp. nov. is observed with T. hagenia sp. nov.; for differentiation see Identification chapter of the latter species below.

\section{Etymology}

This very characteristic new species is dedicated to Mr. Mekbib Fekadu, Addis Ababa and Marburg, expert of mountain and plant ecology of Ethiopia, for his long-standing help and support given to the research teams on the Bale Mts biogeography.

\section{Material examined}

\section{Holotype}

ETHIOPIA: ô, Oromia, Bale Mts, road N Rira, Ericaceous forest, alt. 3000-3200 m, 06 $46^{\circ} \mathrm{N}^{\prime} 39^{\circ} 44^{\prime} \mathrm{E}$, 28 Feb. 2013 (CSCHM, registration number ZSM_COL_2018_014).

\section{Paratypes}

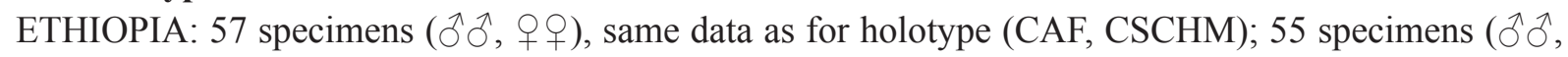
우우), S slope Bale Mts, Rira Vall., alt. 3130 m, 06 466'36" N, 3944'18" E, 1 Mar. 2015 (CSCHM); 106

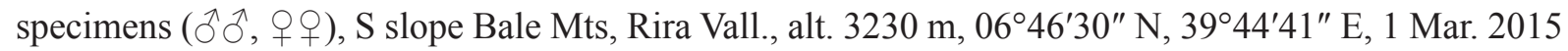

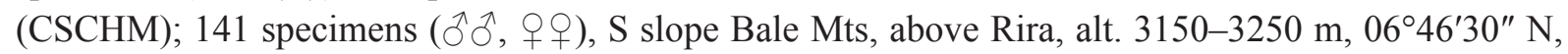
3944'31" E, Dec. 2006 (CAF, CSCHM); 1 †, Bale Berge, Harenna Forest, near Gora, alt. 2800 m,

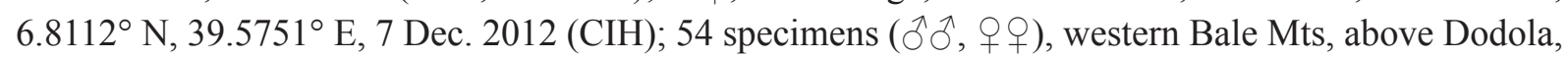
alt. 2700-2850 m, 06 $53^{\prime} 49^{\prime \prime} \mathrm{N}, 39^{\circ} 11^{\prime} 32^{\prime \prime} \mathrm{E}, \mathrm{Dec} .2006$ (CAF, CSCHM); 1 ¡ , 2 q 우, same data as for

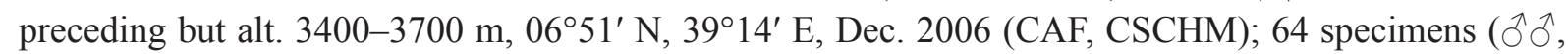
웅), Bale Mts, south of Adaba, alt. 3170 m, 06 49'31" N, 39²5'37" E, Feb. 2007 (CAF, CSCHM);

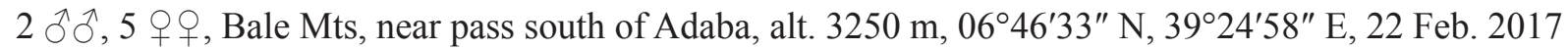

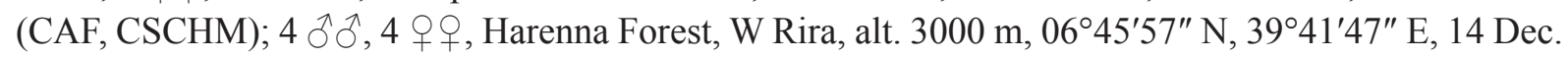
2017 (CAF, CSCHM); same data as for preceding but alt. $2750 \mathrm{~m}, 06^{\circ} 45^{\prime} 40^{\prime \prime} \mathrm{N}, 39^{\circ} 42^{\prime} 23^{\prime \prime} \mathrm{E}$, (CAF);

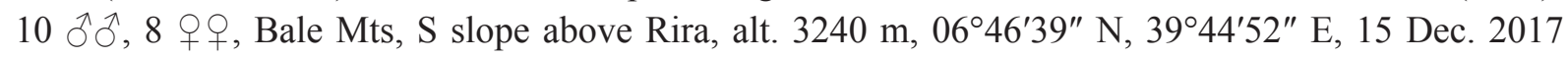
(NHMUK, CDH, MNHN, ZMAA).

\section{Description}

Body LENGTH. 4.2-4.8 mm (Ø = $4.45 \mathrm{~mm}, \mathrm{n}=20)$.

Proportions $(\mathrm{n}=10)$. PW/HW $=1.48-1.53(\varnothing=1.51) ; \mathrm{PW} / \mathrm{PL}=1.46-1.53(\varnothing=1.49) ; \mathrm{PW} / \mathrm{PBW}=$ $1.20-1.29(\varnothing=1.25) ; \mathrm{EW} / \mathrm{PW}=1.39-1.45(\varnothing=1.43) ; \mathrm{EL} / \mathrm{EW}=1.31-1.36(\varnothing=1.34)$. 
Colour. Head, pronotum, and elytra blackish brown, markedly shiny, elytra iridescent. Labrum, palpi, antennal base, elytral margin and apex, and legs light brown; antennae distally darkened beginning from the second third of the third antennomere.

Microsculpture. Same in males and females. Head with rather large, almost isodiametric meshes on disc and supraorbital area, and smaller meshes on clypeus. Pronotum with moderately large, somewhat irregularly formed or slightly transverse meshes. Elytra with hardly visible, very slightly engraved, very narrow transverse meshes.

HeAD. Size normal for Trechus. Mandibles moderately short. Labrum with apical margin widely emarginated. Eyes large, convexly protruded. Tempora moderately short, convex, markedly wrinkled to the neck, $0.35-0.37$ times as long as eyes, smooth. Frons and supraorbital area strongly convex, with supraorbital furrows almost uniformly bent on disc, deep throughout. Antennae moderately slender, proportions of the first four antennomeres as follows: 1/0.7/0.9/0.8.

Prothorax. Pronotum large, transverse, broadest portion slightly before middle, base distinctly wider than apical margin. Disc moderately convex. Anterior margin concave with anterior angles slightly protruded, rounded. Sides convexly rounded in anterior $2 / 3$, concave before base. Laterobasal angles large, acute, distinctly laterally protruded. Marginal gutter moderately narrow, distinctly widened near laterobasal angles. Base straight in middle, distinctly bent posteriorly at outer quarter. Median longitudinal impression distinct, slightly deepened near base, disappearing at apex; anterior transverse impression indistinct, smooth; posterior transverse impression very shallow; laterobasal foveae moderately large, rather shallow, smooth, bordered from the lateral gutter by a slightly elevated area. Pronotum with laterobasal setae present.

Pterothorax. Elytra markedly convex on disc, in dorsal view broad oval, broadest in mid-length, with shoulders markedly broad, shortly rounded towards base; apex suggestively pointed. Striae impunctate or suggestively punctate, parascutellar stria moderately short, deep, striae 1-2 (3) moderately impressed, external striae finer, 6-7 usually absent, 8 deeply impressed from level of the middle group of the marginal umbilicate pores towards apex. Intervals flat or internal 1-3 intervals very slightly convex. Recurrent preapical stria deep, short, slightly curved in front, directed to the seventh stria. Third stria with two setiferous dorsal pores, the anterior one near the end of the anterior elytral quarter, the posterior one in middle, and with preapical seta which is situated at the apical anastomosis of second and third striae almost as close to the elytral apex as to the suture. Number and positions of the setae of the marginal umbilicate series as in Trechus s. str.

LEGs. Moderately short and comparatively thin; protibia slightly dilated towards apex, almost straight, distinctly grooved on external surface. Two basal protarsomeres of male dilated.

Male genitalia. EL/AL $=2.50-2.68(\varnothing=2.56, \mathrm{n}=8)$. Aedeagal median lobe elongated, in lateral view with ventral margin slightly bent behind basal bulb, slightly convex in middle, slightly sinuate towards apex, longitudinally keel-like reinforced (keel bar visible in both ventral and dorsal views as a straight dark longitudinal strip); apical lamella rather short with hook-like apex bent upward; basal bulb rather small with sagittal aileron rather large. Dorsal surface of median lobe more strongly sclerotized in anterior quarter (just below apical ostium), forming an elongate bowl for the endophallic copulatory piece; latter in lateral view spine-like, slightly curved, in dorsal view dagger-like with broad base. 


\section{Distribution}

From the Rira Valley, on the southern escarpment of the Bale Mts to the western part of the Bale Mts near the city of Dodola; not on the eastern and northeastern slopes of the massif. The species was found at altitudes of $2700-3400 \mathrm{~m}$.

Trechus patrizii Jeannel, 1960

Trechus (s. str.) patrizii Jeannel, 1960: 265; locus typicus: "mont Chillálo".

Trechus patrizii - Ortuño \& Novoa 2011: 135.

\section{Type material}

Not studied. Identification of this distinctive species is based on its detailed description including figures of habitus and genital characters.

\section{Type locality}

The description is based on two specimens collected on Mt Chillalo by S. Patrizii on April, 27 $7^{\text {th }}$, 1936, one from "Torre Asciaba, alt. $2500 \mathrm{~m}$ env.", the other from "pays Aselle, alt. $2600 \mathrm{~m}$ env." (Jeannel 1960: 266). However, Jeannel (1960) gave no information about the details of the label data of the holotype specimen.

\section{Identification}

Within the Trechus fauna of the Oromia region this species is unique due to the absence of the laterobasal setae of pronotum. Additional diagnostic features are: medium body length (approx. $3.6 \mathrm{~mm}$ ), two protarsomeres of male dilated, each elytron with a single seta on disc (posterior discal seta lacking).

\section{Distribution}

Known only from two localities at the western slope of Mt Chillalo at altitudes of $2500 \mathrm{~m}$ and $2600 \mathrm{~m}$ (Jeannel 1960).

Trechus oromiensis Magrini, Quéinnec \& Vigna Taglianti, 2012

Figs 57-66

Trechus (s. str.) oromiensis Magrini, Quéinnec \& Vigna Taglianti, 2012: 26; locus typicus: Oromia Province, Bale massif, South of Goba, alt. approx. 3200 m.

\section{Type material}

Not studied. Identification of this distinctive species is based on its detailed description including figures of habitus and genital characters, and on additional material collected at the type locality.

\section{Material examined}

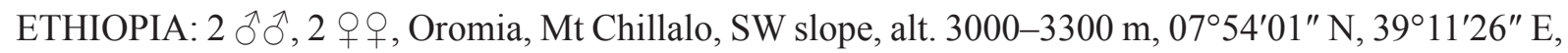

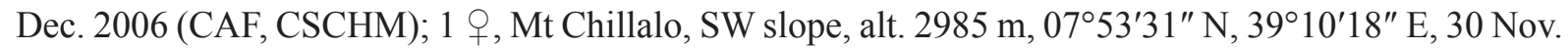

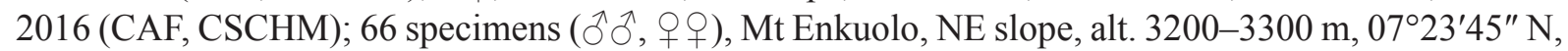

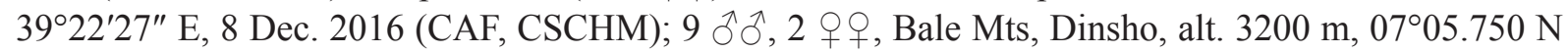

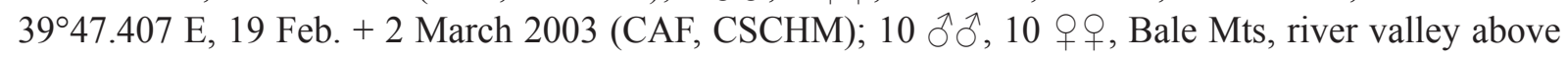
Goba, alt. 2990 m, 06 56'08" N, 3957'20" E, Feb. 2007 (CAF, CSCHM). 

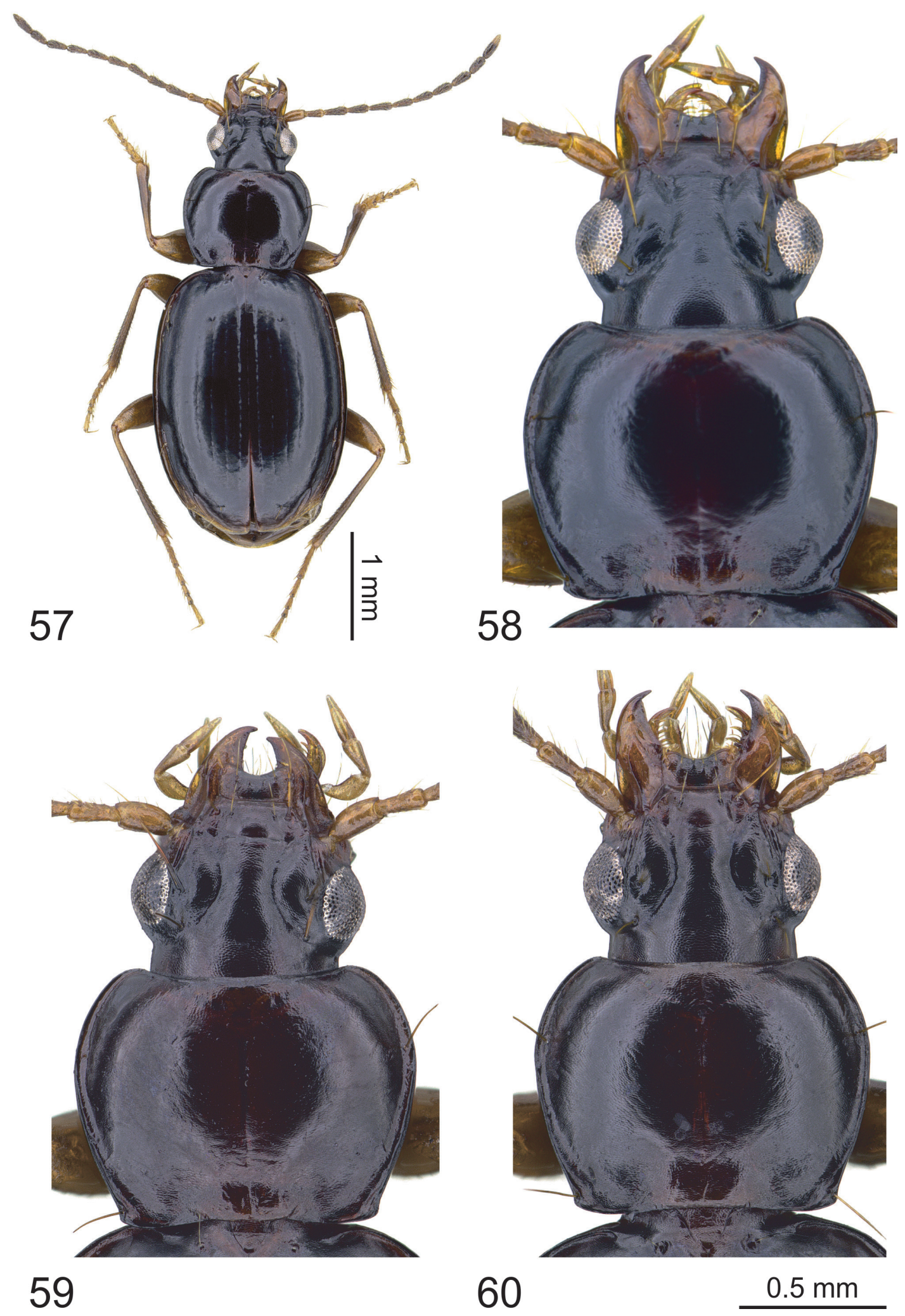

59

60

Figs 57-60. Trechus oromiensis Magrini, Quéinnec \& Vigna Taglianti, 2012, habitus (57) and head, pronotum (58-60). 57-58. $\curvearrowright$ from Mt Chillalo. 59. $\curvearrowright$ from Mt Enkuolo. 60. $\curvearrowright$ from Goba, Bale Mts, locus typicus of T. oromiensis. 

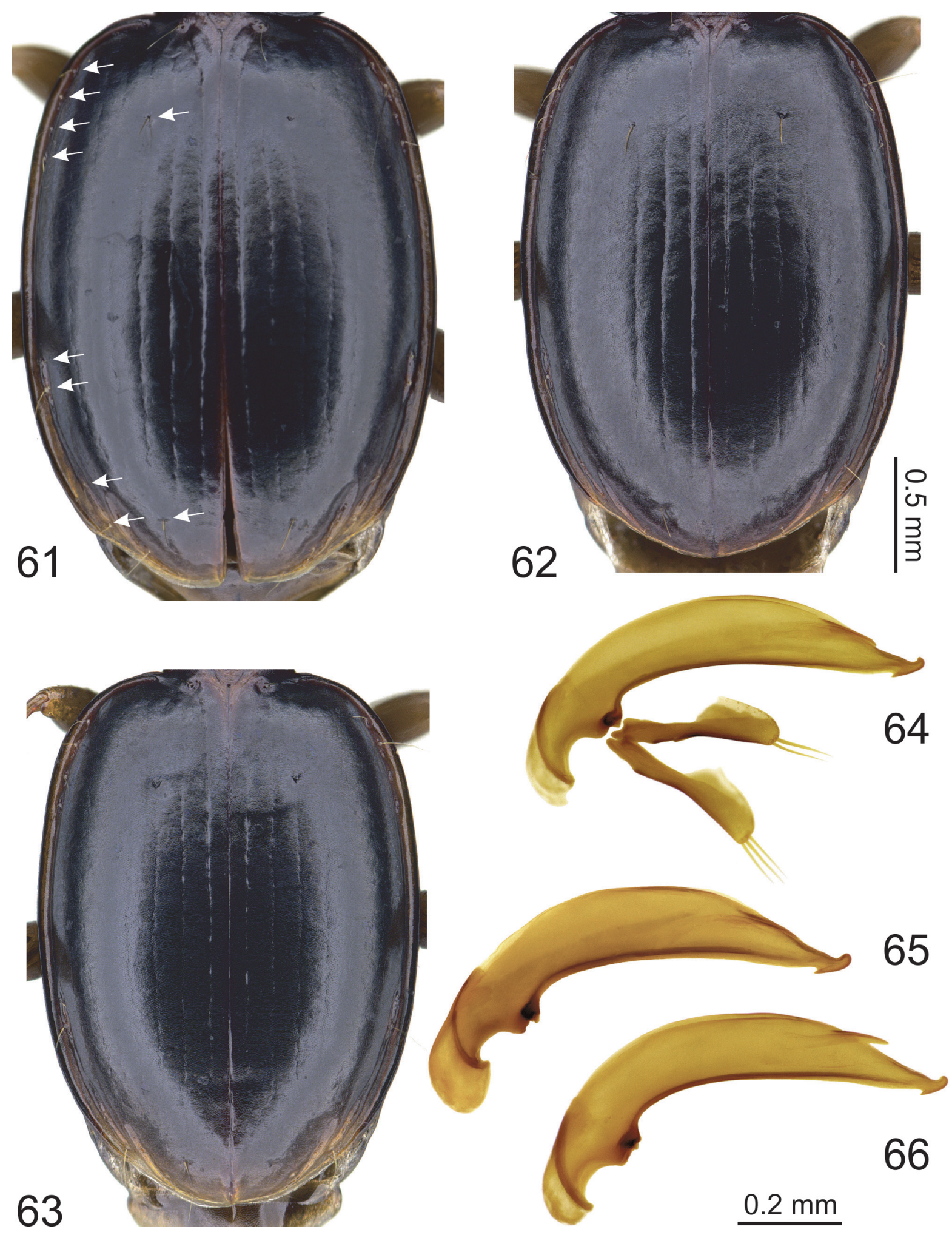

Figs 61-66. Trechus oromiensis Magrini, Quéinnec \& Vigna Taglianti, 2012, elytra (61-63) and aedeagal median lobe (64-66). 61, 64. Specimen from Mt Chillalo (the arrows point to the insertions of the discal seta, preapical seta, and setae of the umbilical series). 62, 65. Specimen from Mt Enkuolo. 63, 66. Specimen from Goba, Bale Mts, locus typicus of T. oromiensis. 


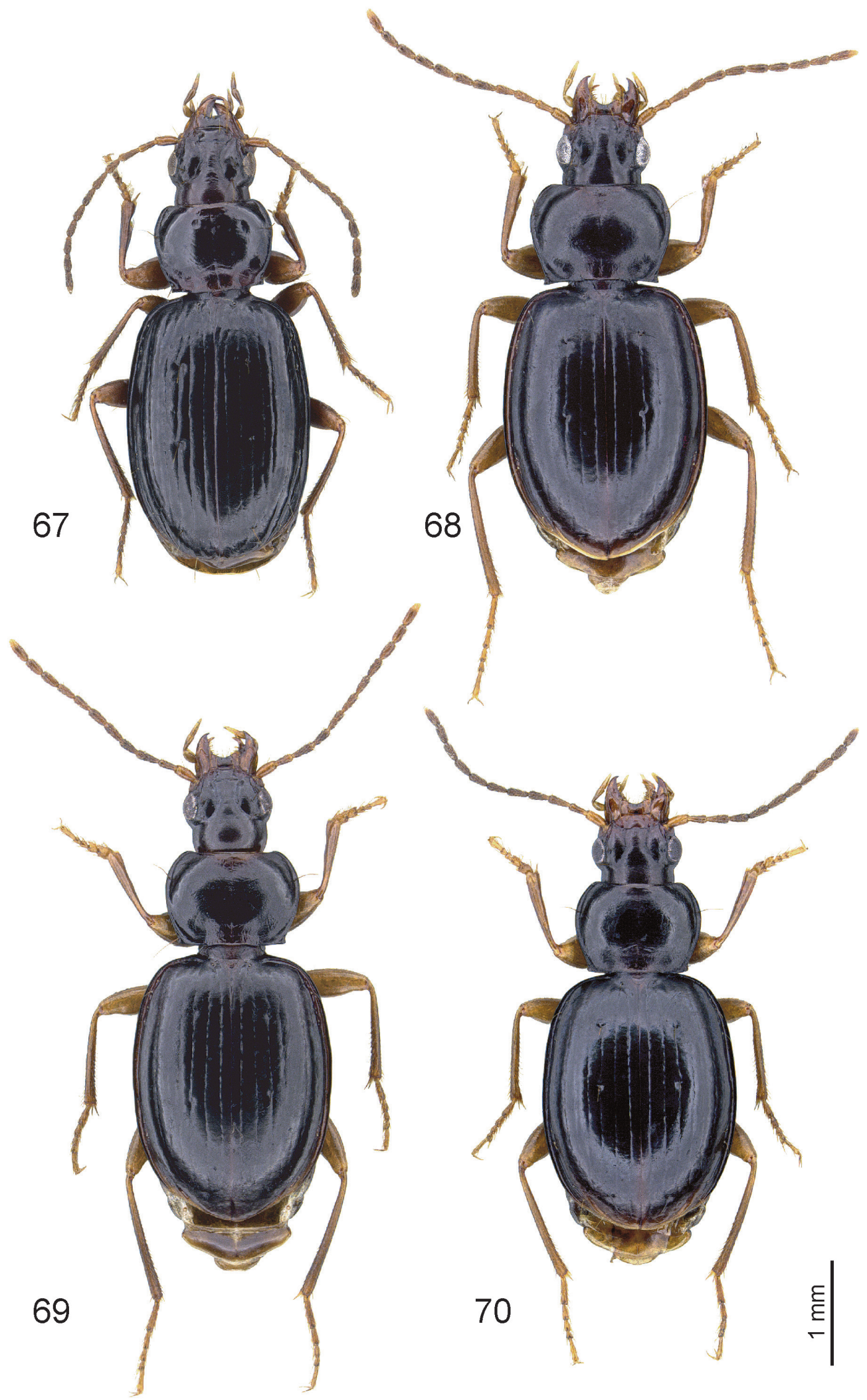

Figs 67-70. Trechus spp., habitus. 67. T. depressipennis sp. nov., holotype. 68. T. mekbibi sp. nov.,

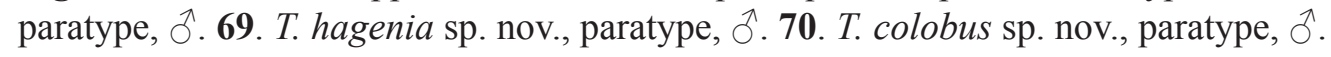




\section{Identification}

Within the Trechus fauna of the Oromia region this species is easily recognizable by the combination of the following characters: body length above $3.5 \mathrm{~mm}$, two protarsomeres of male dilated, each elytron with a single seta on disc (posterior discal seta lacking), pronotum with laterobasal setae present. Latter character distinguishes $T$. oromiensis from the sympatric species $T$. patrizii (see Identification chapter of the latter above).

\section{Distribution}

The most widely distributed Trechus of the study area and, up to today, the only species known from different volcanic mountains. It was found on south western slope of Mt Chillalo, northeastern slopes of Mt Enkuolo, and northern slopes of Bale Mts between Dinsho and Goba (for additional localities in northern Bale Mts see Magrini et al. 2012). The vertical distribution of the species ranges from approximately $2985 \mathrm{~m}$ to $3300 \mathrm{~m}$.

Trechus bastianinii Magrini \& Sciaky, 2006

Trechus bastianinii Magrini \& Sciaky, 2006: 183; locus typicus: Prov. Bale, Monte Batu, alt. 3100$3600 \mathrm{~m}$.

Trechus bastianinii - Ortuño \& Novoa 2011: 136.

\section{Type material}

Not studied. Identification is based on the detailed description including figures of habitus and genital characters, and on additional material collected at the type locality.

\section{Material examined}

ETHIOPIA: $4 \widehat{\partial}^{\lambda}$, Oromia, Bale Mts, river valley above Goba, alt. $2990 \mathrm{~m}, 06^{\circ} 56^{\prime} 08^{\prime \prime} \mathrm{N}, 39^{\circ} 57^{\prime} 20^{\prime \prime} \mathrm{E}$, Feb. 2007 (CAF, CSCHM).

\section{Identification}

Similar to the sympatric and syntopic species $T$. oromiensis, however, easy to distinguish due to presence of two discal setae on each elytron. Other species of that region differ by having smaller eyes (T. clarkeianus), smaller body size and only one protarsomere of male dilated (T. relictus), or outer quarter of pronotal base more markedly bent anteriorly (T. baleensis, T. batuensis, T. ericalis, T. fisehai sp. nov., T. wiersbowskyi sp. nov.). For comparison with the very similar allopatric species $T$. colobus sp. nov. and T. hagenia sp. nov., see descriptions of the latter species below.

\section{Distribution}

Known only from the northern slope of the Bale Mts, south of Goba city. The species was found at altitudes of approximately $2990 \mathrm{~m}$ to $3200 \mathrm{~m}$ (see also Magrini \& Sciaky 2006).

Trechus colobus sp. nov. urn:1sid:zoobank.org:act:2A138A6D-177D-46B5-8AE0-1F7CD050B9E6

Figs $70,74,78,120-121$

\section{Diagnosis}

Externally, this new species is very similar to T. bastianinii, but its body length is average smaller (3.8-4.5 $\mathrm{mm}$ instead of 4.5-5.0 $\mathrm{mm}$ in T. bastianinii). However, it differs markedly by the shape of 
the aedeagal median lobe and the structures of endophallus: In lateral view, the median lobe is more markedly bent behind basal bulb and much more convex in middle; in dorsal view, the median lobe is awl-like, narrowed towards apex and not widened as in $T$. bastianinii; the markedly sclerotized sheetlike folding structure of endophallus below the copulatory piece is unique amongst Trechus of the study area.

\section{Etymology}

Named after the famous monkey Guereza Colobus (Colobus guereza Rüppell, 1835) which occurs in the forests along slopes of the western Bale Mts together with this new species of Trechus.

\section{Material examined}

\section{Holotype}

ETHIOPIA: ${ }^{`}$, Oromia, western Bale Mts, above Dodola, alt. 3400-3700 m, 06 ${ }^{\circ} 51^{\prime} \mathrm{N}, 39^{\circ} 14^{\prime} \mathrm{E}$, Dec. 2006 (CSCHM, registration number ZSM_COL_2018_015).

\section{Paratypes}

ETHIOPIA: 39 specimens ( $\hat{\partial} \hat{\partial}, q+q)$, same data as for holotype (CAF, CSCHM); $7 \hat{\jmath}, 2$ 우, same

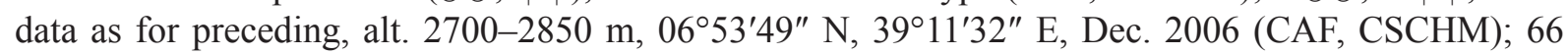

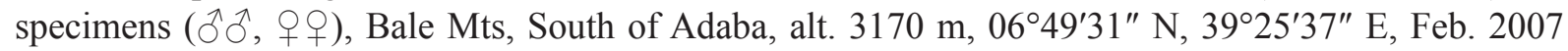
(NHMUK, CAF, MNHN, CSCHM); 7 đิð, 7 우, near pass south of Adaba, alt. $3250 \mathrm{~m}, 06^{\circ} 46^{\prime} 33^{\prime \prime} \mathrm{N}$, $39^{\circ} 24^{\prime} 58^{\prime \prime}$ E, 22 Feb. 2017 (CAF, CSCHM).

\section{Description}

Body LENGTH. $3.8-4.5 \mathrm{~mm}(\varnothing=4.26 \mathrm{~mm}, \mathrm{n}=20)$.

Proportions $(\mathrm{n}=10) . \mathrm{PW} / \mathrm{HW}=1.38-1.45(\varnothing=1.42) ; \mathrm{PW} / \mathrm{PL}=1.38-1.45(\varnothing=1.41) ; \mathrm{PW} / \mathrm{PBW}=$ $1.24-1.30(\varnothing=1.27) ; \mathrm{EW} / \mathrm{PW}=1.42-1.51(\varnothing=1.47) ; \mathrm{EL} / \mathrm{EW}=1.32-1.42(\varnothing=1.37)$.

Colour. Head, pronotum and elytra blackish brown, elytra markedly shiny, iridescent. Clypeus and elytral side margin reddish brown lightened. Lateral margin of labrum, palpi, antennal base, elytral apex, and legs light brown; antennae distally darkened beginning from third antennomere.

Microsculpture. Same in males and females. Head with rather large, deeply engraved, almost isodiametric meshes on disc and supraorbital area, and smaller, slightly engraved meshes on clypeus. Pronotum with moderately large, slightly transverse meshes. Elytra with very slightly engraved very narrow transverse meshes.

HEAD. Moderately robust. Mandibles moderately short. Labrum with apical margin widely emarginated. Eyes large, convexly protruded. Tempora moderately short, convex, markedly wrinkled to the neck, $0.35-0.45$ times as long as eyes, smooth. Frons and supraorbital area strongly convex, with supraorbital furrows almost uniformly bent on disc, deep throughout. Length of antennae average for Trechus, proportions of the first four antennomeres as follows: 1/0.8/0.9/0.8.

Prothorax. Pronotum moderately large and transverse, broadest portion slightly before middle, base slightly wider than apical margin. Disc moderately convex. Anterior margin slightly concave with anterior angles slightly protruded, rounded. Sides almost evenly rounded throughout, sometimes straight before laterobasal angles; latter small, rectangular or slightly obtuse, not or very slightly protruded laterally. Marginal gutter narrow in anterior $8 / 10$, distinctly widened near laterobasal angles. Base straight in middle, very slightly bent anteriorly near laterobasal angles. Median longitudinal impression very fine, not deepened near base, disappearing at apex; anterior transverse impression indistinct, smooth; 
posterior transverse impression and laterobasal foveae very shallow, smooth. Pronotum with laterobasal setae present.

Pterothorax. Elytra convex on disc, not or very slightly flattened if viewed from behind, in dorsal view broad oval, broadest in mid-length, with shoulders broadly rounded; apex suggestively pointed. Striae impunctate or suggestively punctate, parascutellar stria moderately short, deep, striae 1-2 (3) deeply impressed, 4 and 5 very fine, 6-7 usually absent, 8 deeply impressed from level of the middle group of the marginal umbilicate pores towards apex. Internal 3-4 intervals slightly convex. Recurrent preapical stria deep, short, slightly curved in front, directed to the seventh stria. Third stria with two setiferous dorsal pores, the anterior one near the end of the anterior elytral quarter, the posterior one in middle, and with preapical seta, which is situated at the apical anastomosis of second and third striae, almost as close to the elytral apex as to the suture. Number and positions of the setae of the marginal umbilicate series as in Trechus s. str.

LEGS. Moderately short and comparatively thin; protibia slightly dilated towards apex, almost straight, distinctly grooved on external surface. Two basal protarsomeres of male dilated.

Male Genitalia. EL/AL $=2.31-2.65(\varnothing=2.42, \mathrm{n}=8)$. Aedeagal median lobe rather slender, its ventral margin in lateral view sinusoidal, markedly bent behind basal bulb and convex in middle; apical lamella rather long, in dorsal view awl-shaped, in lateral view with apex formed as a small hook bent upward; basal bulb and sagittal aileron average. Endophallic copulatory piece rather small, spine-like, its distal portion surrounded from a small, markedly sclerotized, sheet-like folding structure.

\section{Distribution}

Endemic to the western portion of the Bale Mts, here found along slopes south of the cities Dodola and Adaba. The species was collected at altitudes of 2700-3500 m.

Trechus hagenia sp. nov.

urn:1sid:zoobank.org:act:33A3D9A9-4941-4BC1-9389-65472E4BF482

Figs $69,73,77,118-119$

\section{Diagnosis}

Very similar to the allopatric $T$. bastianinii, but aedeagal median lobe in dorsal view with terminal lamella longer, not widened but almost parallel-sided before apex, with ventral margin longitudinally reinforced keel-like, with a dagger-shaped endophallic copulatory piece, and with a more extensive sclerotization of the anterior portion of the dorsal surface of median lobe, which forms a bowl for the copulatory piece. Also very similar to the allopatric T. colobus sp. nov., but larger and broader on average, with pronotum more transverse, and with aedeagal median lobe more elongated, not sinusoidal, with terminal lamella in dorsal view distinctly broader, and with different folding structures of endophallus. In male genital characters, T. hagenia sp. nov. is very similar to the parapatric T. mekbibi sp. nov., but it differs markedly by the shape of pronotum with smaller base and much smaller laterobasal angles, which are not protruded posteriorly.

\section{Etymology}

Named after the African Redwood (Hagenia abyssinica Willd.) which is a nice and very characteristic tree of the montane forests where the new species of Trechus occurs. 

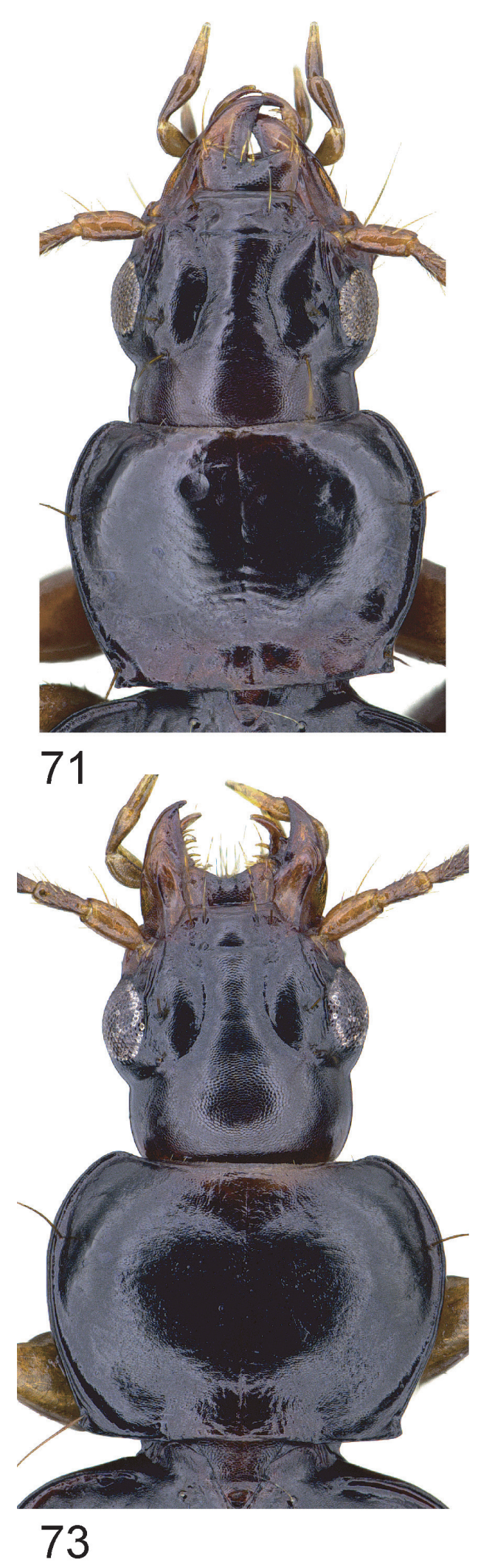

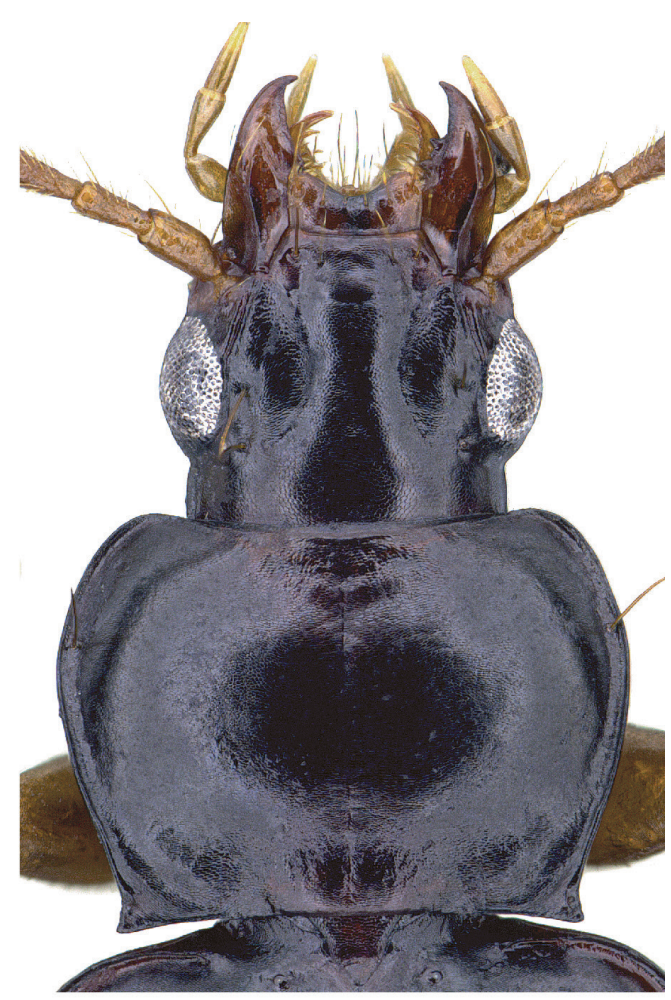

72

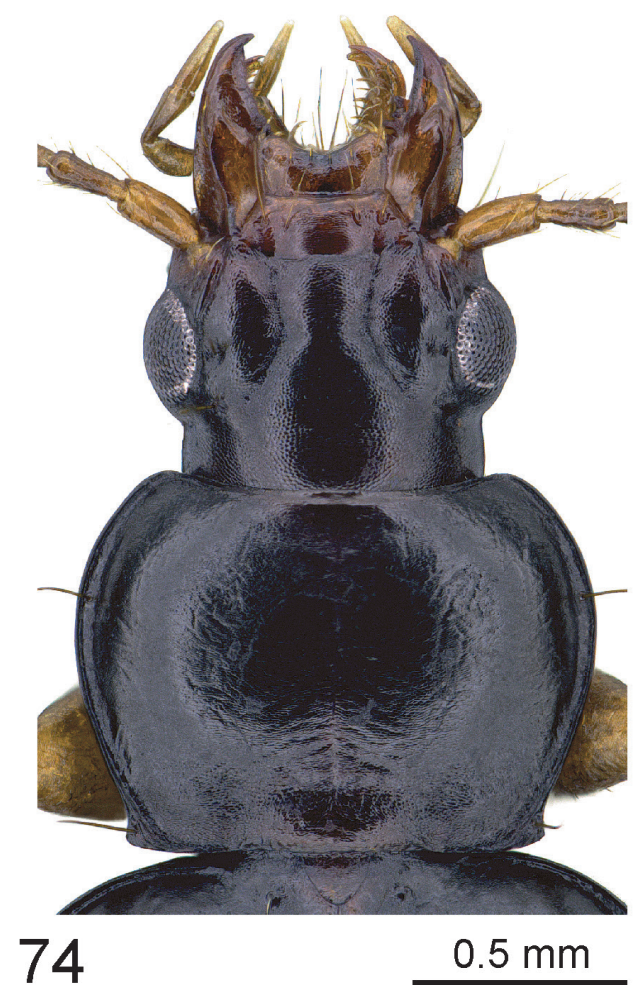

Figs 71-74. Trechus spp., head, pronotum. 71. T. depressipennis sp. nov., holotype. 72. T. mekbibi

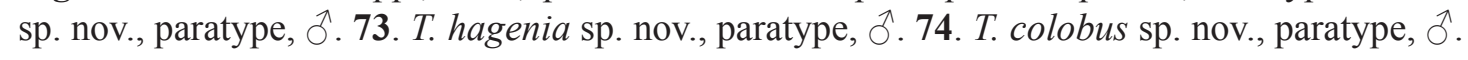



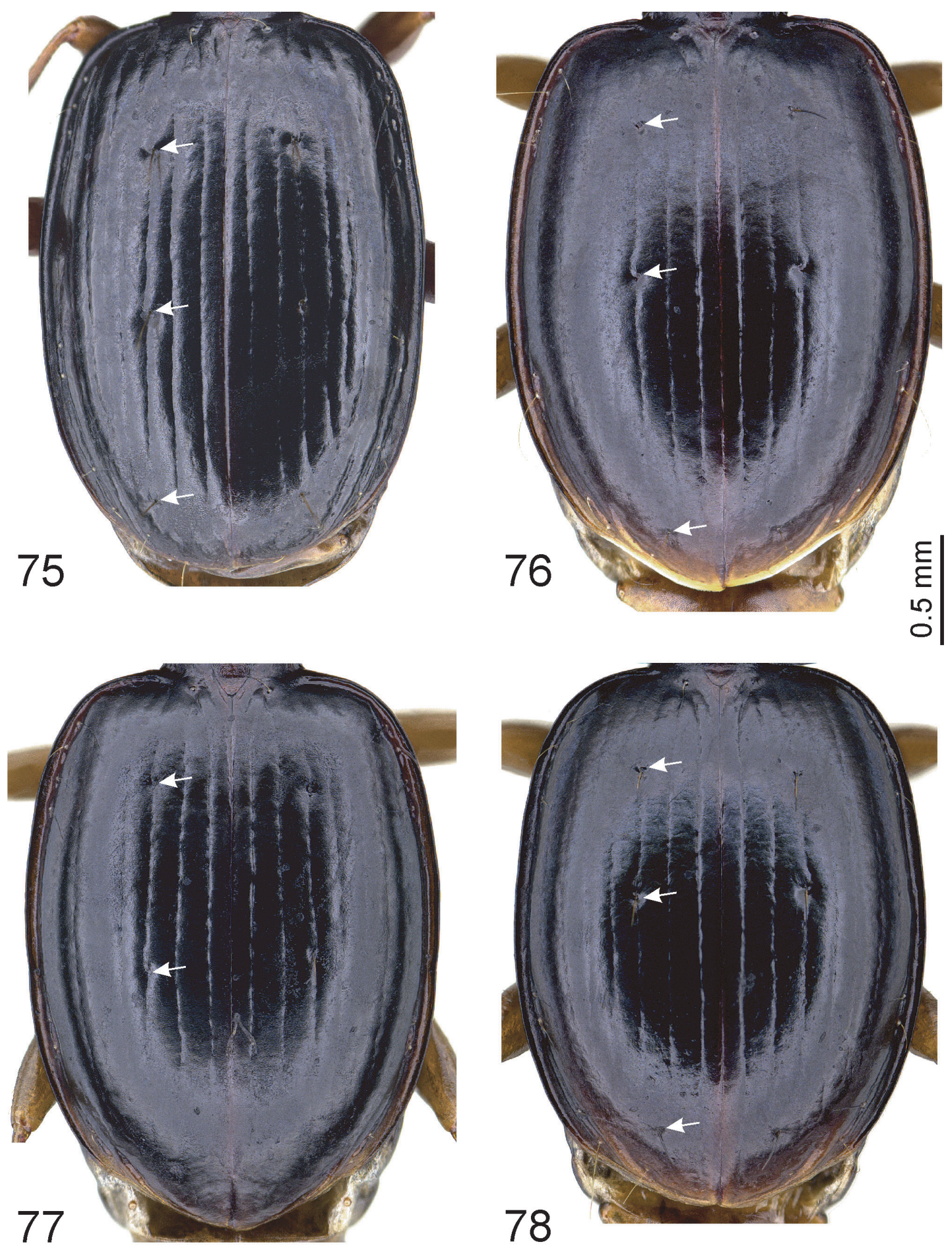

Figs 75-78. Trechus spp., elytra. 75. T. depressipennis sp. nov., holotype. 76. T. mekbibi sp. nov.,

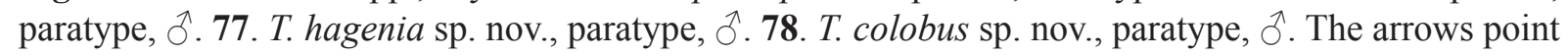
to the insertions of the discal setae and the preapical seta (if present). 


\section{Material examined}

\section{Holotype}

ETHIOPIA: ô, Oromia, Bale Mts, Harenna Forest, E Rira, alt. 3150 m, 06 $44^{\prime} 51^{\prime \prime}$ N, 3946'40" E, Feb. 2007 (CSCHM, registration number ZSM_COL_2018_016).

\section{Paratypes}

ETHIOPIA: $19 \hat{\jmath} \widehat{\partial}, 14$ 우, same data as for holotype (CAF, CSCHM); $10 \hat{\jmath} \hat{\partial}, 9$ $\phi$ , , Harenna Forest,

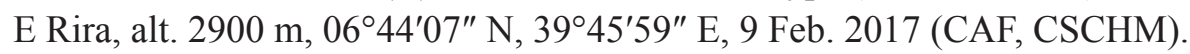

\section{Additional material}

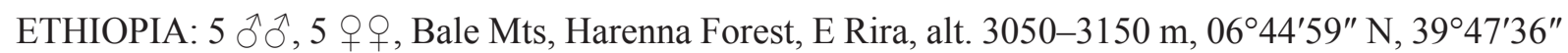
E, 12 Feb. 2017 (CAF, CSCHM); $13 \widehat{\partial}^{\lambda}, 7$ 9 우, same data as for preceding but Mt Abalk-hasim, river vall., alt. 3250-3450 m, 0644'34" N, 3948'34" E, Feb. 2007 (CAF, CSCHM).

\section{Description}

Body LENGTH. $4.3-4.7 \mathrm{~mm}(\varnothing=4.52 \mathrm{~mm}, \mathrm{n}=20)$.

Proportions $(\mathrm{n}=10) . \mathrm{PW} / \mathrm{HW}=1.48-1.58(\varnothing=1.51) ; \mathrm{PW} / \mathrm{PL}=1.41-1.53(\varnothing=1.48) ; \mathrm{PW} / \mathrm{PBW}=$ $1.22-1.29(\varnothing=1.26) ; \mathrm{EW} / \mathrm{PW}=1.42-1.53(\varnothing=1.48) ; \mathrm{EL} / \mathrm{EW}=1.29-1.36(\varnothing=1.33)$.

CoLour. Head, pronotum and elytra blackish brown, elytra markedly shiny, iridescent, elytral side margin reddish brown lightened. Lateral margin of labrum, palpi, antennal base, legs and sometimes elytral apex, light brown; antennae distally darkened beginning from second or third antennomere (sometimes indistinctly darkened).

Microsculpture. As described in T. colobus sp. nov.

HEAD. Tempora $0.35-0.45$ times as long as eyes; proportions of the first four antennomeres as follows: $1 / 0.85 / 1 / 0.9-1$. In all other characters as described in T. colobus sp. nov.

Prothorax. Pronotum more transverse, base distinctly wider than apical margin. In all other characters as described in T. colobus sp. nov.

Pterothorax. Elytra slightly flattened on disc; internal 2-3 intervals slightly convex; preapical seta absent (specimen from populations of the type series) or present (specimens from populations occurring east of the type locality, see Additional material above, and Geographical variation below). In all other characters as described in T. colobus sp. nov.

Legs. As described in T. colobus sp. nov.

MALE Genitalia. EL/AL $=2.27-2.44(\varnothing=2.35, \mathrm{n}=8)$. Aedeagal median lobe elongated, in lateral view slightly bent behind basal bulb, with ventral margin slightly convex in middle; ventral margin reinforced keel-like longitudinally (keel bar visible in both ventral and dorsal views as a straight dark longitudinal strip); apical lamella rather long, shortly bent upward at tip, forming a small hook, in dorsal view almost parallel-sided; basal bulb rather small, sagittal aileron rather large. Dorsal surface of median lobe more strongly sclerotized in anterior quarter (just below apical ostium), forming an elongate bowl for the endophallic copulatory piece; the latter in lateral view spine-like, slightly curved, in dorsal view daggerlike with broad base. 


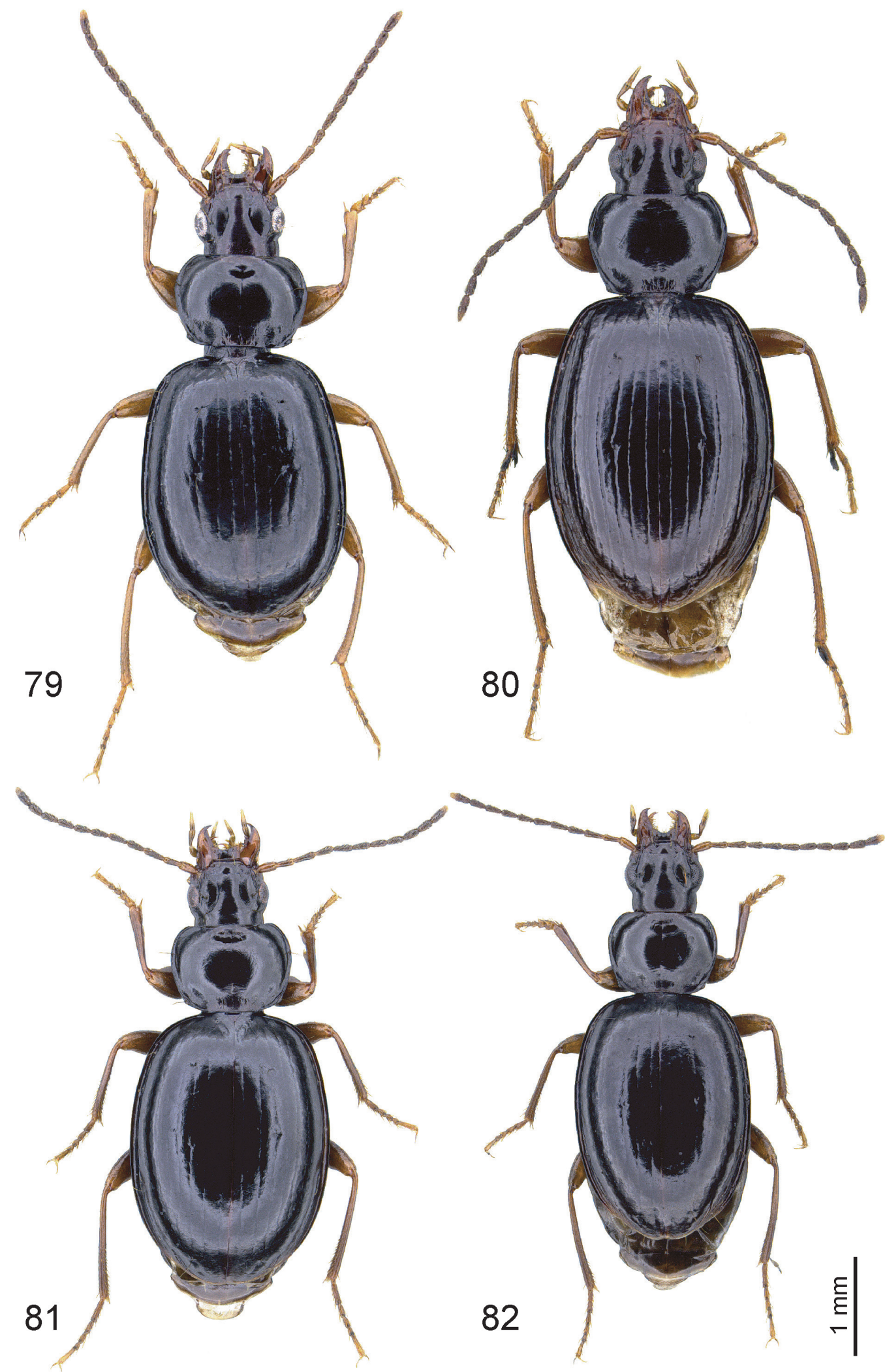

Figs 79-82. Trechus spp., habitus. 79. T. wiersbowskyi sp. nov., paratype, $\lesssim$; 80. T. grandipennis sp. nov.,

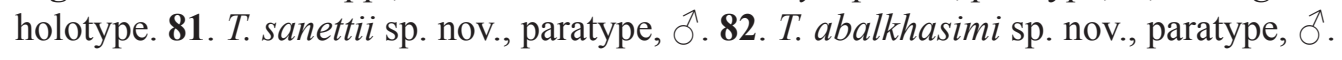




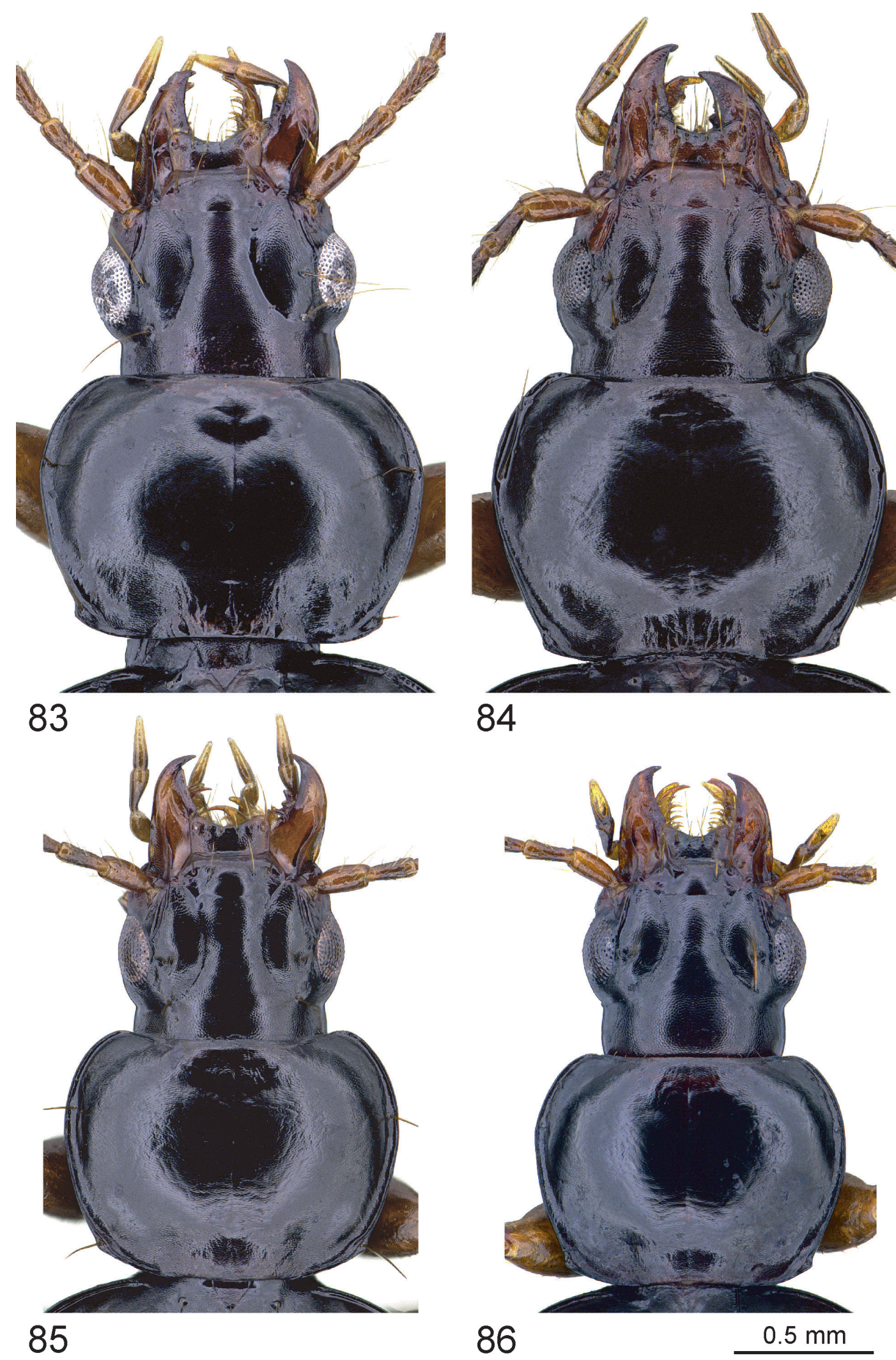

Figs 83-86. Trechus spp., head, pronotum. 83. T. wiersbowskyi sp. nov., paratype, §. 84. T. grandipennis sp. nov., holotype. 85. T. sanettii sp. nov., paratype, đ̂. 86. T. abalkhasimi sp. nov., paratype, $\hat{\partial}$. 


\section{Distribution}

Endemic to the southeastern slope of the Bale Mts east of Rira village. The species was collected at altitudes of $2900-3300 \mathrm{~m}$.

\section{Geographical variation}

The variation of proportions of different body parts is important compared to other species (see Proportions, above). In addition, in populations from the type locality, a river valley on southeastern slope of Bale Mts at a latitude of approx. $39^{\circ} 46^{\prime} \mathrm{E}$, the elytral preapical seta is constantly absent, while farther east, below Mt Abalk-hasim ( $\left.39^{\circ} 48^{\prime} 34^{\prime \prime} \mathrm{E}\right)$, this seta is present, and in the geographical intermediate population at a latitude of $39^{\circ} 47^{\prime} 36^{\prime \prime} \mathrm{E}$, this seta is absent, present or present on only one elytra.

Trechus wiersbowskyi sp. nov. urn:Isid:zoobank.org:act:4C6B2D23-ED5D-4A29-840E-4D9F927E3A88

Figs $79,83,87,122-123$

\section{Diagnosis}

Due to the broad oval elytra with markedly convex disc, and the laterally rounded pronotal base, this new species is very similar to T. ericalis, however, it is easily distinguishable due to the very different shape of aedeagal median lobe which is markedly tube-like in middle portion. Based on male genital morphology, T. wiersbowskyi sp. nov. seems closely related to T. bastianinii, however, it differs by the more markedly bent base of median lobe (lateral view), the truncate apical lamella (dorsal view), the dorsal surface of median lobe which is not markedly sclerotized near apical ostium, and the shape of the endophallic folding structures. In external characters, the new species differs additionally from T. bastianinii and the above-described T. colobus sp. nov. and T. hagenia sp. nov. by the shape of the pronotum with pronotal base markedly bent anteriorly at outer quarters.

\section{Etymology}

Dedicated to Mr. Daniel Wiersbowsky, Addis Ababa, for his interest in the biodiversity of Ethiopia, and for his longstanding support to entomological researches in this wonderful country.

\section{Material examined}

\section{Holotype}

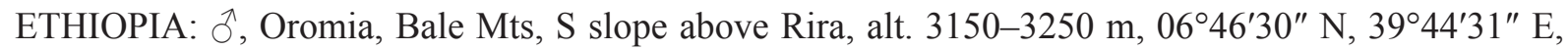
Dec. 2006 (CSCHM, registration number ZSM_COL_2018_017).

\section{Paratypes}

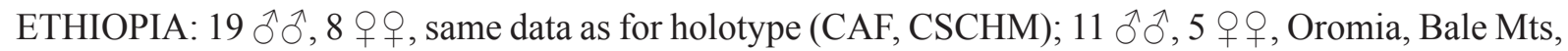
S slope above Rira, alt. 3240 m, 06²4'39" N, 3944'52" E, 15 Dec. 2017 (NHMUK, CDH, CSCHM, ZMAA).

\section{Description}

Body LENGTH. 3.8-4.5 mm (Ø=4.26 mm, $\mathrm{n}=20)$.

Proportions $(\mathrm{n}=10)$. PW/HW $=1.38-1.42(\varnothing=1.40) ; \mathrm{PW} / \mathrm{PL}=1.41-1.48(\varnothing=1.45) ; \mathrm{PW} / \mathrm{PBW}=$ $1.23-1.27(\varnothing=1.25) ; \mathrm{EW} / \mathrm{PW}=1.54-1.60(\varnothing=1.57) ; \mathrm{EL} / \mathrm{EW}=1.30-1.38(\varnothing=1.36)$. 
CoLour. Head, pronotum and elytra blackish brown, elytra markedly shiny, iridescent. Lateral margin of labrum, palpi, antennal base and legs light brown; antennae distally darkened beginning from second antennomere.

Microsculpture. As described in T. colobus sp. nov.

HEAD. Tempora 0.4 times as long as eyes, proportions of the first four antennomeres as follows: 1/0.9/1/0.8. In all other characters as described in T. colobus sp. nov.

Prothorax. Pronotum markedly transverse, broadest portion distinctly before middle, base distinctly wider than apical margin. Anterior margin concave with anterior angles slightly protruded, broadly rounded. Sides almost rounded throughout, laterobasal angles very obtuse but pointed as a small laterally protruded tooth. Marginal gutter slightly widened near laterobasal angles. Laterobasal foveae moderately large and deep. In all other characters as described in T. colobus sp. nov.

Pterothorax. As described in T. colobus sp. nov.

LEGS. As described in T. colobus sp. nov.

Male Genitalia. EL/AL $=2.38-2.50(\varnothing=2.45, \mathrm{n}=8)$. Aedeagal median lobe elongated, in lateral view moderately bent behind basal bulb, tube-like in middle, with dorsal and ventral margins parallel, similar so in dorsal view, but slightly widened before apex; apical lamella short, broad and truncated in dorsal view, with tip distinctly bent upward in lateral view; basal bulb average, sagittal aileron large. Endophallus with two short, more markedly sclerotized folding structures, which lie on top of each other just below apical ostium, the dorsal one in dorsal view much broader, trapezoidal, in lateral view markedly bent backwards.

\section{Distribution}

The new species seems endemic to the upper Rira valley on the southern slope of the Bale Mts. It was found at altitudes of $3150-3250 \mathrm{~m}$.

Trechus ericalis Magrini, Quéinnec \& Vigna Taglianti, 2013

Trechus (s. str.) ericalis Magrini, Quéinnec \& Vigna Taglianti, 2013: 18; locus typicus: Oromia Province, Bale massif, Goba, Mt Sgona (Mt Batu), alt. approx. 3800 m.

\section{Type material}

Not studied. Identification is based on the detailed description including figures of habitus and genital characters, and on additional material collected near to the type locality.

\section{Material examined}

ETHIOPIA: 45 specimens ( $\hat{\jmath}$, 우), Bale Mts, brook valley above Goba, alt. 3750-3800 m,

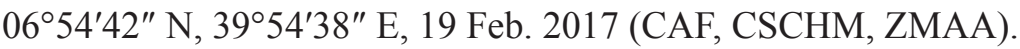

\section{Identification}

Conspicuous due to the broad oval elytra which are markedly convex on disc and thus easy to distinguish from the syntopic $T$. oromiensis, but very similar to the above-described T. wiersbowskyi sp. nov., and the below-described T. abalkhasimi sp. nov., T. fisehai sp. nov., and T. sanettii sp. nov. For differentiation see chapter Identification of the latter species. 

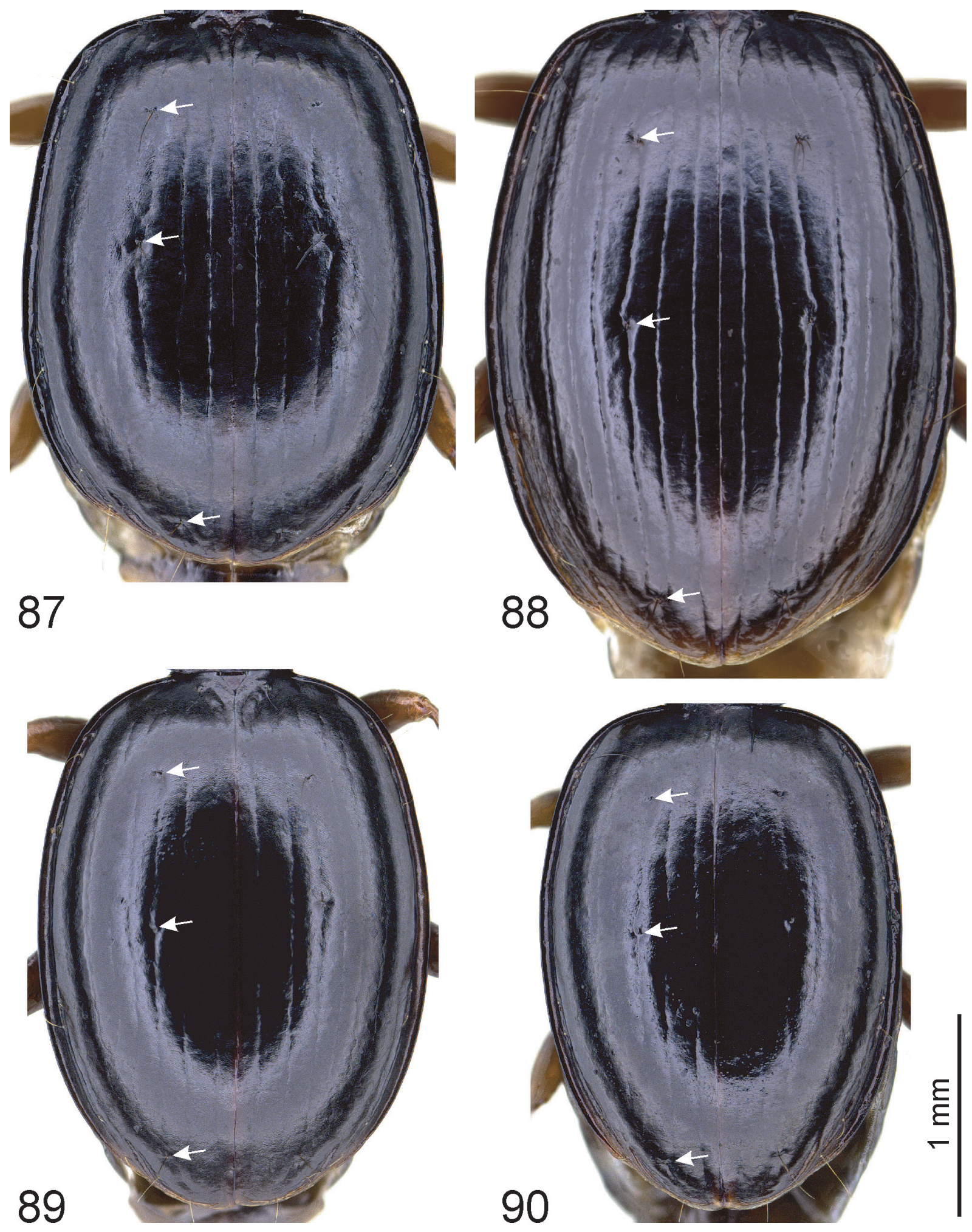

Figs 87-90. Trechus spp., elytra. 87. T. wiersbowskyi sp. nov., paratype, ふ. 88. T. grandipennis sp. nov., holotype. 89. T. sanettii sp. nov., paratype, $\precsim$. 90. T. abalkhasimi sp. nov., paratype, $ð$. The arrows point to the insertions of the discal setae and the preapical seta. 


\section{Distribution}

Northern slope of the Bale Mts, south of Goba city and adjacent part of the Sanetti Plateau. The species was found at altitudes of 3150-4138 m (see also Magrini et al. 2013).

Trechus sanettii sp. nov.

urn:1sid:zoobank.org:act:ED365F36-D797-498A-AE53-46C389582C7C

Figs $81,85,89,126-127$

\section{Diagnosis}

Externally, this new species is very similar to T. ericalis, and the below newly described T. abalkhasimi sp. nov., T. angovaensis sp. nov., T. grandipennis sp. nov. and T. fisehai sp. nov., but it differs by the elytra which are not iridescent, and by the elytral microsculpture which consists of larger, less transverse meshes with more deeply engraved lines. It differs additionally by the median lobe with endophallic copulatory piece located in the centre of the median lobe while in the aforementioned species this piece is shifted more apicad and differently shaped. For additional differential characters see Identification chapters of the respective species below.

\section{Etymology}

The specific epithet is derived from the Sanetti Plateau of the Bale Mts, of which the southeastern margin is the type locality of the new species.

\section{Material examined}

\section{Holotype}

ETHIOPIA: ${ }^{\wedge}$, Bale Mts, Sanetti Plateau, near Mt Abalk-hasim, alt. 3600-3800 m, 06 $45^{\prime} 12^{\prime \prime} \mathrm{N}$, 3949'36" E, Feb. 2007 (CSCHM, registration number ZSM_COL_2018_018).

\section{Paratypes}

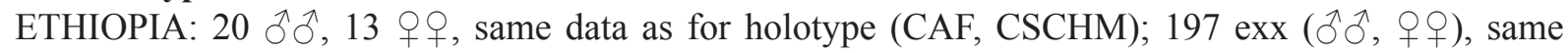
data as for preceding but alt. $3760 \mathrm{~m}, 10$ Dec. 2017, 06 $45^{\prime} 10^{\prime \prime} \mathrm{N}, 39^{\circ} 49^{\prime} 36^{\prime \prime} \mathrm{E}$ (NHMUK, CAF, CDH, CSCHM, MNHN, ZMAA).

\section{Description}

Body Length. 3.7-4.6 mm $(\varnothing=4.2 \mathrm{~mm}, \mathrm{n}=20)$.

Proportions $(\mathrm{n}=10)$. PW/HW = 1.41-1.47 $(\varnothing=1.44) ; \mathrm{PW} / \mathrm{PL}=1.31-1.44(\varnothing=1.36) ; \mathrm{PW} / \mathrm{PBW}=$ $1.23-1.29(\varnothing=1.26) ; \mathrm{EW} / \mathrm{PW}=1.54-1.69(\varnothing=1.64) ; \mathrm{EL} / \mathrm{EW}=1.30-1.40(\varnothing=1.35)$.

CoLour. Head, pronotum and elytra blackish brown, elytra silk-shiny, not iridescent, lateral margins of labrum and elytra reddish brown lightened. Basal maxillary palpomere, apex of apical palpomere, antennal base and legs light brown; middle portion of palps dark brown, antennae distally darkened beginning from second antennomere.

Microsculpture. Same in males and females. Head with rather large, deeply engraved, almost isodiametric meshes on disc and supraorbital area, and smaller, slightly engraved meshes on clypeus. Pronotum with moderately large, slightly transverse meshes. Elytra with rather large, more deeply engraved, slightly transverse meshes.

HeAD. Size average for Trechus. Mandibles moderately short. Labrum with apical margin widely emarginated. Eyes moderately large, moderately convexly protruded. Tempora moderately short, 
convex, markedly wrinkled to the neck, about 0.6 times as long as eyes, very sparsely and very finely pubescent. Frons and supraorbital area strongly convex, with supraorbital furrows almost uniformly bent on disc, deep throughout. Length of antennae average for Trechus, proportions of the first four antennomeres as follows: 1/0.8/0.95/0.95.

Prothorax. Pronotum comparatively small, transverse, suggestively discoidal, broadest portion distinctly before middle, base distinctly wider than apical margin. Disc moderately convex. Anterior margin moderately concave with anterior angles slightly protruded, rounded. Sides almost evenly rounded throughout, laterobasal angles very obtuse, marked as a very small blunt tooth. Marginal gutter narrow in anterior $4 / 5$, slightly widened near laterobasal angles. Base straight in middle, markedly bent anteriorly at outer quarters. Median longitudinal impression very fine, not deepened near base, disappearing at apex; anterior transverse impression very shallow or indistinct, smooth; posterior transverse impression moderately shallow, smooth or finely rugose; laterobasal foveae moderately deep, roundish, smooth. Pronotum with laterobasal setae present.

PTEROTHORAX. Elytra markedly convex on disc, not or very slightly flattened if viewed from behind, in dorsal view broad oval, broadest in mid-length, with shoulders shallowly rounded; apex rounded. Striae impunctate or suggestively punctate, parascutellar stria short, shallow, striae 1-3 moderately finely impressed, 4 and 5 very fine, 6-7 usually absent, 8 deeply impressed from level of the middle group of the marginal umbilicate pores towards apex. Internal three intervals very slightly convex. Recurrent preapical stria deep, moderately short, slightly curved in front, directed to the seventh stria. Third stria with two setiferous dorsal pores, the anterior one near the end of the elytral anterior fifth, the posterior one slightly before middle, and with preapical seta which is situated at the apical anastomosis of second and third striae, almost as close to the elytral apex as to the suture. Number and positions of the setae of the marginal umbilicate series as in Trechus s. str.

LEGS. Moderately short and thin; protibia slightly dilated towards apex, almost straight, distinctly grooved on external surface. Two basal protarsomeres of male dilated.

Male Genitalia. EL/AL $=2.54-2.89(\varnothing=2.73, \mathrm{n}=8)$. Aedeagal median lobe moderately short, in lateral view more markedly bent behind basal bulb, its ventral margin somewhat straight in middle, bent downward before apex, its dorsal margin convex; apical lamella moderately long, slightly bent upward at tip; basal bulb large, sagittal aileron markedly small. Endophallic copulatory piece moderately sclerotized, moderately small, located in centre of median lobe, in lateral view sloping, in dorsal view sickle-shaped.

\section{Distribution}

Endemic to the southeastern margin of the Sanetti Plateau of the Bale Mts near Mt Abalk-hasim. The species was collected at altitudes between $3600 \mathrm{~m}$ and $3800 \mathrm{~m}$.

Trechus grandipennis sp. nov. urn:1sid:zoobank.org:act:8E2050AD-FFC8-4B4C-B3D3-B2E97470B0B9

Figs $80,84,88,125$

\section{Diagnosis}

Similar to T. ericalis and the newly described T. abalkhasimi sp. nov., T. angovaensis sp. nov., T. fisehai sp. nov., and T. sanettii sp. nov., but easily distinguishable due to the larger size of body and longer aedeagal median lobe; the latter has a much larger button-like apical capitulum and a differently sclerotized endophallus. 

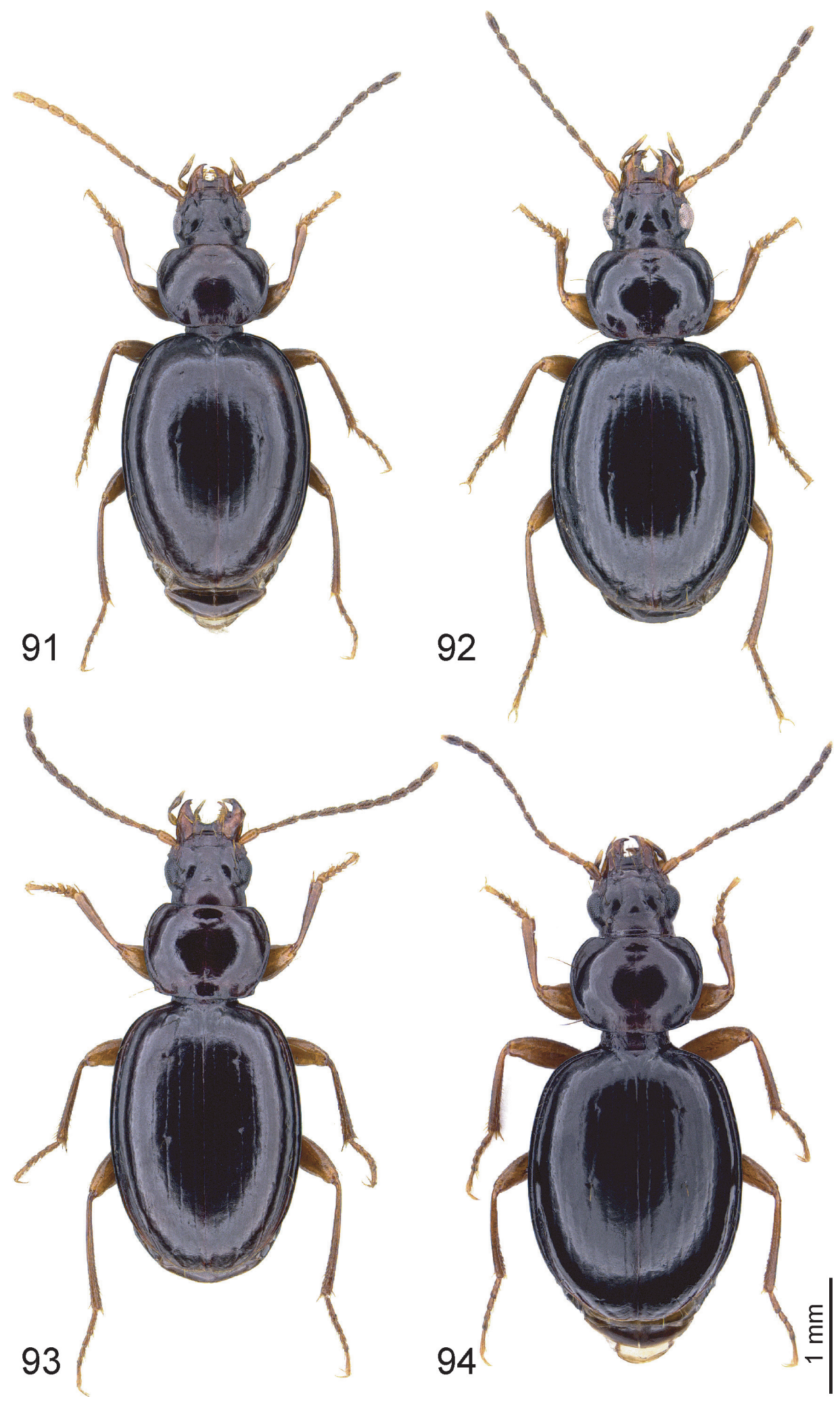

Figs 91-94. Trechus spp., habitus. 91. T. fisehai sp. nov., paratype, ð̊.92. T. angavoensis sp. nov., holotype. 93. T. batuensis Magrini \& Sciaky, 2006, ठึ from Sanetti Plateau near Tulo Dimptu. 94. T. batuensis, $\overbrace{}^{\Uparrow}$ from Tegona Valley. 


\section{Etymology}

The specific epithet refers to the markedly large and broad elytra.

\section{Material examined}

\section{Holotype}

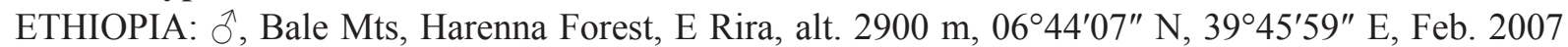
(CSCHM, registration number ZSM_COL_2018_019).

\section{Description}

BODY LENGTH. $5.4 \mathrm{~mm}$.

Proportions $(\mathrm{n}=1) . \mathrm{PW} / \mathrm{HW}=1.41 ; \mathrm{PW} / \mathrm{PL}=1.41 ; \mathrm{PW} / \mathrm{PBW}=1.34 ; \mathrm{EW} / \mathrm{PW}=1.65 ; \mathrm{EL} / \mathrm{EW}=1.40$.

Colour. Head, pronotum and elytra dark brown, elytra markedly shiny, iridescent, clypeus reddish brown lightened. Lateral margin of labrum, palpi, antennal base, elytral apical margin and legs light brown; antennae distally darkened beginning from second antennomere.

Microsculpture (MALE). Head with rather large, deeply engraved, almost isodiametric meshes on disc and supraorbital area, and smaller, slightly engraved meshes on clypeus. Pronotum with moderately large, slightly transverse meshes. Elytra with very slightly engraved, very narrow transverse meshes.

HEAD. Tempora about half as long as eyes; proportions of the first four antennomeres as follows: 1/0.75/0.9/0.85. In all other characters as described in $T$. sanettii sp. nov.

Prothorax. As described in T. sanettii sp. nov.

Pterothorax. Elytra markedly convex on disc, slightly flattened if viewed from behind, in dorsal view broad oval, broadest in mid-length, with shoulders broadly rounded; apex suggestively pointed. Striae suggestively punctate, parascutellar stria moderately long and deep, striae 1-3 moderately deeply impressed, 4-6 finer, 7 indistinct, 8 deeply impressed from level of the middle group of the marginal umbilicate pores towards apex. First interval slightly convex, external intervals flat. Recurrent preapical stria deep, moderately short, slightly curved in front, directed to the seventh stria. Third stria with two setiferous dorsal pores, the anterior one near the end of the anterior elytral quarter, the posterior one in middle, and with preapical seta which is situated at the apical anastomosis of second and third striae, as close to the elytral apex as to the suture.

Legs. As described in T. sanettii sp. nov.

MALE GENItALIA. EL/AL $=2.33(n=1)$. Aedeagal median lobe rather large, in lateral view more markedly bent in basal half, straight from the middle towards apex; apical lamella long with apex formed as a large button with dorsal tip slightly bent upward; basal bulb and sagittal aileron average. Endophallus with a rather large, moderately sclerotized longitudinal triangular copulatory piece in apical half of median lobe.

\section{Distribution}

Endemic to the Harenna forest on the southern slope of the Bale Mts; known only from along a single brook valley east of Rira village at an altitude of $2900 \mathrm{~m}$. 


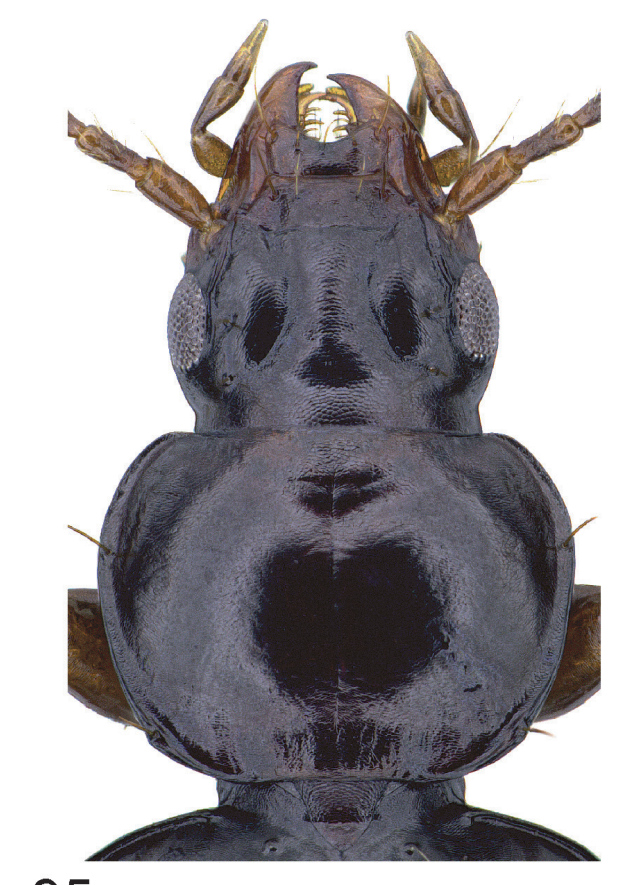

95

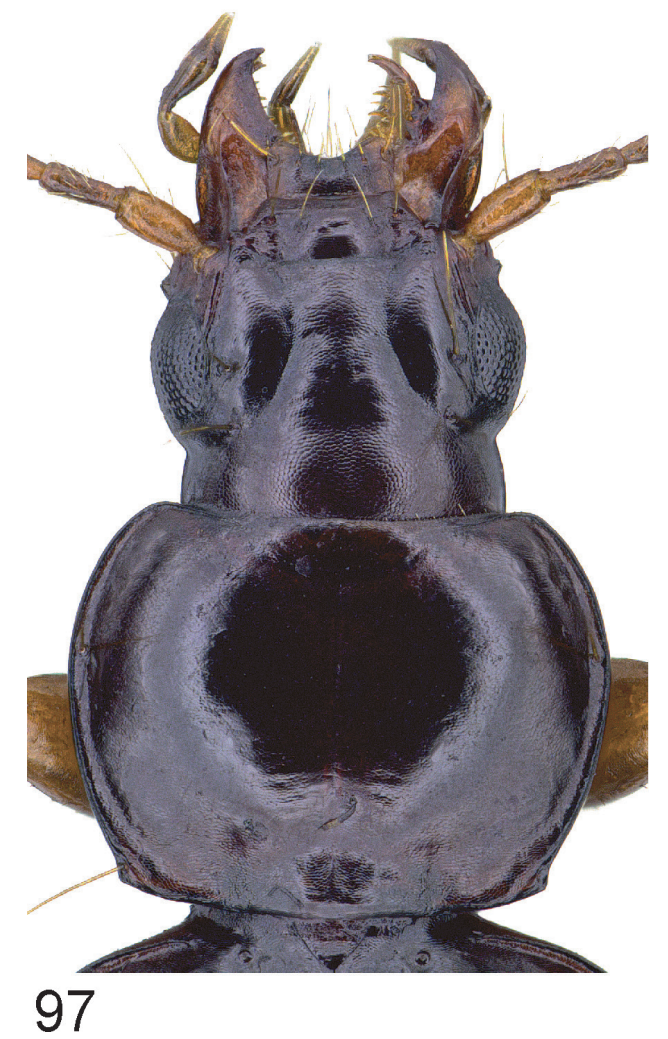

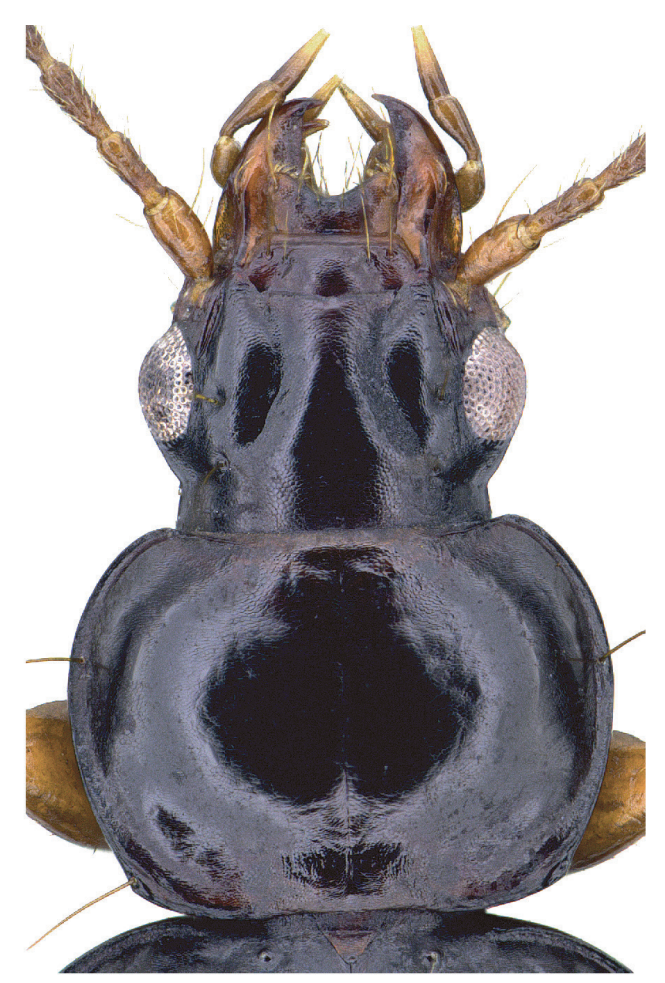

96

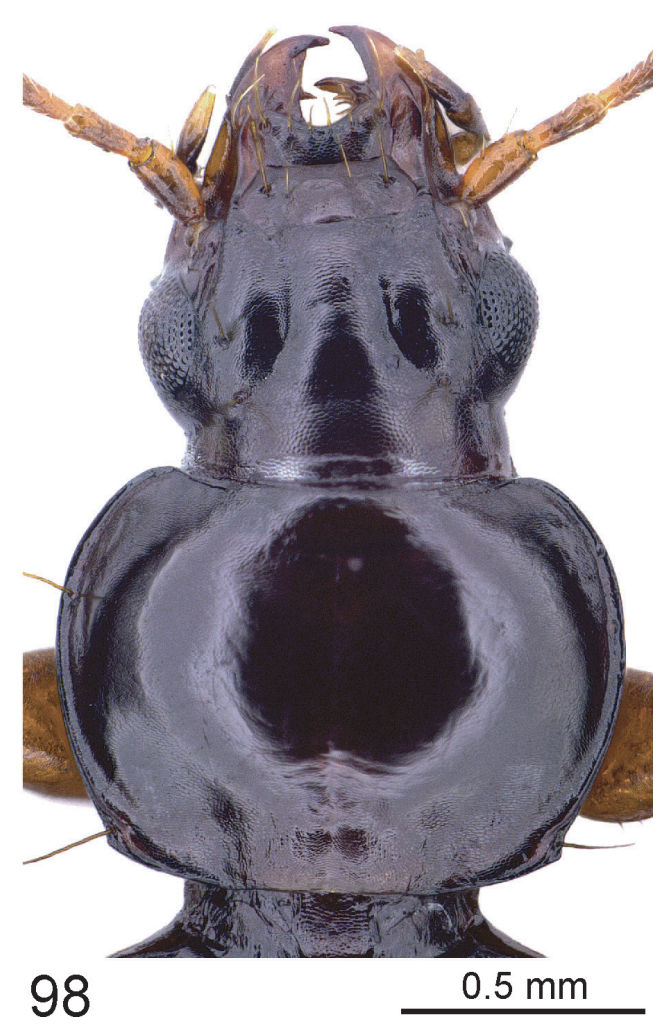

Figs 95-98. Trechus spp., head, pronotum. 95. T. fisehai sp. nov., paratype, O. 96. T. angavoensis sp. nov., holotype. 97. T. batuensis Magrini \& Sciaky, 2006, §ิ from Sanetti Plateau near Tulo Dimptu. 98. T. batuensis, ठ̊ from Tegona Valley. 


\section{Trechus fisehai sp. nov. urn:1sid:zoobank.org:act:42EA54E8-5D0C-4139-800E-EC7A8CF6E6A4}

Figs 91, 95, 99, 133-134

\section{Diagnosis}

Very similar to the syntopic T. ericalis, but smaller on average pronotum with basolateral angles more rounded, with lateral gutter not widened towards base, and aedeagal median lobe less robust with endophallic copulatory piece much smaller. Trechus fisehai sp. nov. differs from $T$. grandipennis sp. nov. by the distinctly smaller length of body and aedeagal median lobe, from $T$. sanettii sp. nov. by the transverse patterns of elytral microsculpture, and by the copulatory piece which is located in the apical half of median lobe, from T. angovaensis sp. nov. by the more markedly bent aedeagal median lobe with smaller copulatory piece, and from T. abalkhasimi sp. nov. by the smaller aedeagal median lobe with button-like apex very slightly bent upward at tip (see key to species).

\section{Etymology}

This new species is dedicated to Mr. Fiseha Getachew, Addis Ababa, great friend of the beautiful nature of Ethiopia, for his invaluable help and support during the field campaigns of JS.

\section{Material examined}

\section{Holotype}

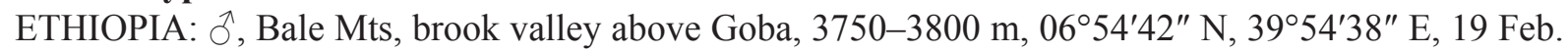
2017 (CSCHM, registration number ZSM_COL_2018_020).

\section{Paratypes}

ETHIOPIA: $16 \hat{\jmath}, 14$ 우, same data as for holotype (CAF, CSCHM); $5 \hat{\jmath}, 4$ $q$, , same data as for preceding but Dec. 2006 (CAF, CSCHM); 1 đ, 1 क , Bale Mts, Tegona Valley above Goba, alt. 3550 m, 06 $54^{\prime} 42^{\prime \prime}$ N, 3953'35" E, 20 Feb. 2017 (CAF, CSCHM).

\section{Description}

BODY LENGTH. 3.5-4.1 mm $(\varnothing=3.82 \mathrm{~mm}, \mathrm{n}=20)$.

Proportions $(\mathrm{n}=10) . \mathrm{PW} / \mathrm{HW}=1.37-1.46(\varnothing=1.40) ; \mathrm{PW} / \mathrm{PL}=1.29-1.35(\varnothing=1.32) ; \mathrm{PW} / \mathrm{PBW}=$ $1.21-1.27(\varnothing=1.25) ; \mathrm{EW} / \mathrm{PW}=1.55-1.72(\varnothing=1.66) ; \mathrm{EL} / \mathrm{EW}=1.32-1.39(\varnothing=1.34)$.

Colour. Head, pronotum and elytra blackish brown, elytra shiny, slightly iridescent, lateral margins of labrum reddish brown, lightened. Basal maxillary palpomere, apex of apical palpomere, antennal base and legs light brown; middle portion of palps dark brown, antennae distally darkened beginning from second or third antennomere.

Microsculpture. Same in males and females. Head with rather large, deeply engraved, almost isodiametric meshes on disc and supraorbital area, and smaller, slightly engraved meshes on clypeus. Pronotum and elytra with smaller and more slightly engraved distinctly transverse meshes.

HEAD. Tempora about half as long as eyes; proportions of the first four antennomeres as follows: $1 / 0.7 / 0.9 / 0.8$. In all other characters as described in $T$. sanettii sp. nov.

Prothorax. Anterior margin very slightly concave. Marginal gutter not widened near laterobasal angles. In all other characters as described in T. sanettii sp. nov.

Pterothorax. As described in T. sanettii sp. nov. 

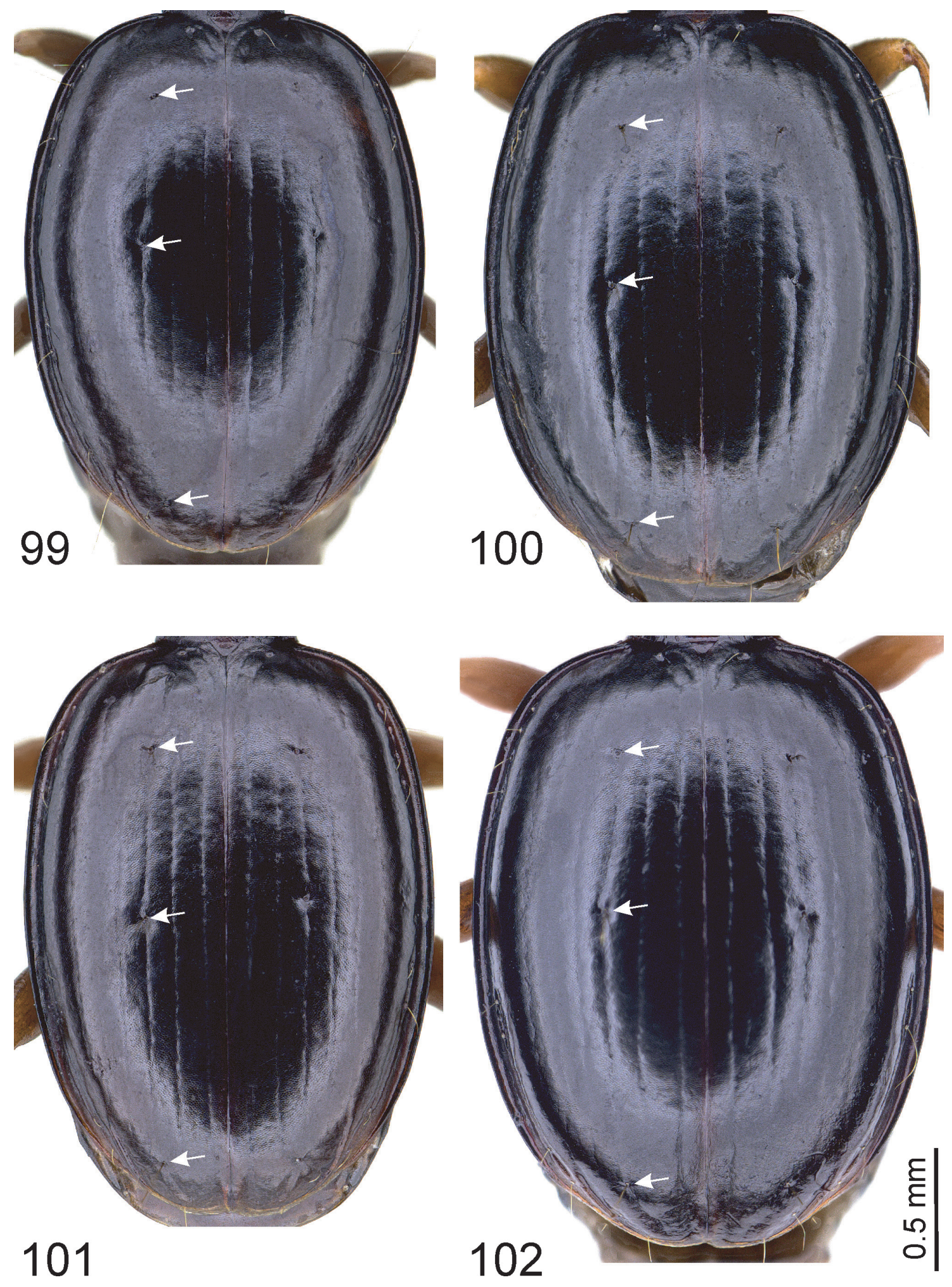

Figs 99-102. Trechus spp., elytra. 99. T. fisehai sp. nov., paratype, ठ̂. 100. T. angavoensis sp. nov., holotype. 101. T. batuensis Magrini \& Sciaky, 2006, ô from Sanetti Plateau near Tulo Dimptu. 102. T. batuensis, $\widehat{o}$ from Tegona Valley. The arrows point to the insertions of the discal setae and the preapical seta. 
Legs. As described in T. sanettii sp. nov.

Male genitalia. EL/AL $=2.86-3.07(\varnothing=2.98, \mathrm{n}=8)$. Aedeagal median lobe moderately short, in lateral view more markedly bent behind basal bulb, its ventral margin straight in middle, indistinctly bent downward before apex, its dorsal margin convex; apical lamella moderately long, very slightly bent upward at tip; basal bulb average, sagittal aileron small. Endophallic copulatory piece moderately sclerotized, moderately small, located in apical half of median lobe, shaped like a fish trap.

\section{Distribution}

Endemic to the northeastern slope of the Bale Mts above Goba city. The species was collected at altitudes between $3550 \mathrm{~m}$ and $3800 \mathrm{~m}$.

Trechus abalkhasimi sp. nov.

urn:1sid:zoobank.org:act:6DC1FFBF-60A7-40A4-A476-51905E98D392

Figs $82,86,90,131-132$

\section{Diagnosis}

Differs from T. ericalis by the much smaller copulatory piece of the endophallus, from T. grandipennis sp. nov. by the distinctly smaller length of body and aedeagal median lobe, from $T$. sanettii sp. nov. by the transverse patterns of elytral microsculpture, and by the copulatory piece which is located in the apical half of median lobe, from T. angovaensis sp. nov. by the more markedly bent aedeagal median lobe with smaller copulatory piece, and from $T$. fisehai sp. nov. by the larger aedeagal median lobe with button-like apex more markedly bent upward at tip (see key to species).

\section{Etymology}

The specific epithet refers to the beautiful Mt Abalk-hasim on which the new species occurs.

\section{Material examined}

Holotype

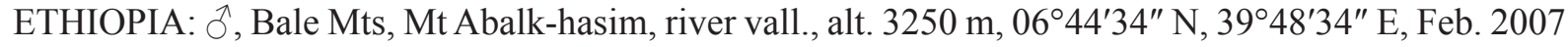
(CSCHM, registration number ZSM_COL_2018_021).

\section{Paratypes}

ETHIOPIA: $13 \hat{\jmath} \widehat{\delta}, 11 q q$, same data as for holotype (CAF, CSCHM).

\section{Description}

Body LenGth. 3.5-4.4 mm (Ø=4.06 mm, $\mathrm{n}=20)$.

Proportions $(\mathrm{n}=10)$. PW/HW $=1.37-1.44(\varnothing=1.39) ; \mathrm{PW} / \mathrm{PL}=1.32-1.42(\varnothing=1.35) ; \mathrm{PW} / \mathrm{PBW}=$ $1.21-1.28(\varnothing=1.26) ; \mathrm{EW} / \mathrm{PW}=1.60-1.69(\varnothing=1.64) ; \mathrm{EL} / \mathrm{EW}=1.33-1.43(\varnothing=1.37)$.

Colour and microsculpture. As described in T. fisehai sp. nov.

HEAD. Tempora about half as long as eyes; proportions of the first four antennomeres as follows: 1/0.8/1/0.9. In all other characters as described in T. sanettii sp. nov.

Prothorax, Pterothorax and legs. As described in T. sanettii sp. nov. 
Male genitalia. EL $/ \mathrm{AL}=2.74-2.83(\varnothing=2.79, \mathrm{n}=6)$. Aedeagal median lobe moderately short, in lateral view more markedly bent behind basal bulb, its dorsal margin slightly convex, its ventral margin straight in middle, slightly bent downward before apex; apical lamella moderately long, distinctly bent upward at tip; basal bulb moderately large, sagittal aileron moderately small. Endophallic copulatory piece moderately sclerotized, moderately large, located in apical half of median lobe, shaped like a fish trap.

\section{Distribution}

Endemic to the southeastern slope of the Bale Mts. Known only from along a brook valley below Mt Abalk-hasim at an altitude of $3250 \mathrm{~m}$.

Trechus angavoensis sp. nov.

urn:1sid:zoobank.org:act:F0880D26-2631-49C1-9848-E868F25E6AAA

Figs 92, 96, 100, 128

\section{Diagnosis}

Differs from T. ericalis by the slenderer aedeagal median lobe with bag-shaped copulatory piece smaller and less markedly sclerotized, from T. fisehai sp. nov. and T. abalkhasimi sp. nov. by the less markedly bent median lobe with larger copulatory piece, from $T$. grandipennis sp. nov. by the distinctly smaller length of body and aedeagal median lobe, and from T. sanettii sp. nov. by the transverse patterns of elytral microsculpture. The bag-like shape of the copulatory piece is very similar to that of T. batuensis, however, the latter species differs by the median lobe more markedly bent behind basal bulb, and by almost isodiametric patterns of elytral microsculpture.

\section{Etymology}

The specific epithet refers to Angova, which is the local name of the valley and surrounding mountains were the new species occurs.

\section{Material examined}

\section{Holotype}

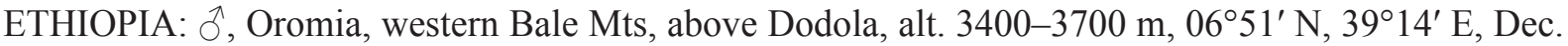
2006 (CSCHM, registration number ZSM_COL_2018_022).

\section{Paratype}

ETHIOPIA: 1 ${ }^{\lambda}$, same data as for holotype (CSCHM).

\section{Description}

Body LENGTH. 4.1-4.3 mm ( $\mathrm{n}=2)$.

Proportions $(\mathrm{n}=2) . \mathrm{PW} / \mathrm{HW}=1.40-1.41 ; \mathrm{PW} / \mathrm{PL}=1.36-1.40 ; \mathrm{PW} / \mathrm{PBW}=1.23-1.24 ; \mathrm{EW} / \mathrm{PW}=1.58 ;$ $\mathrm{EL} / \mathrm{EW}=1.37$.

Colour And microsculpture. As described in T. abalkhasimi sp. nov.

HEAD. Tempora 0.4-0.5 times as long as eyes; proportions of the first four antennomeres as follows: 1/0.85/0.9/0.8. In all other characters as described in $T$. sanettii sp. nov.

Prothorax. Parascutellar stria moderately short and deep; anterior discal seta in third stria located near the end of the anterior elytral quarter, posterior one in elytral middle. In all other characters as described in T. sanettii sp. nov. 
Legs. As described in T. sanettii sp. nov.

MALE GENITALIA. EL/AL $=2.75-2.77$. Aedeagal median lobe moderately short, in lateral view moderately bent behind basal bulb, its ventral margin almost straight from the end of the basal third towards apex, its dorsal margin slightly convex; apical lamella moderately short, button-like shaped with tip slightly bent upward; basal bulb and sagittal aileron average. Endophallic copulatory piece moderately sclerotized, bag-like shaped, located in apical half of median lobe, in lateral view distally narrowed, with apex rounded.

\section{Distribution}

Known only from the type location, on the northern slope of the western Bale Mts above Dodola city (Angavo Valley), at altitudes between 3400 and $3700 \mathrm{~m}$.

Trechus batuensis Magrini \& Sciaky, 2006

Figs 93-94, 97-98, 101-102, 129-130

Trechus batuensis Magrini \& Sciaky, 2006: 186; locus typicus: Prov. Bale, SW Goba, Monte Batu, Nordic Lake.

Trechus batuensis - Ortuño \& Novoa 2011: 137.

\section{Type material}

Not studied. Identification of this species is based on its detailed original description including photos of habitus and genital characters, and on additional material from the type locality.

\section{Material examined}

ETHIOPIA: $19 \widehat{\partial} \partial^{\lambda}, 8$ q $q$, Oromia, Bale Mts, env. Wasama Camp, alt. 3900-4150 m, 23-25 Feb. 2013,

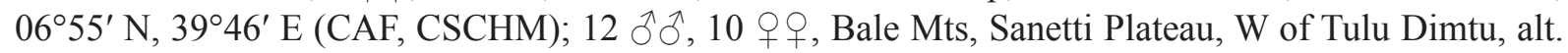

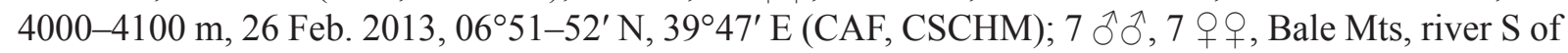

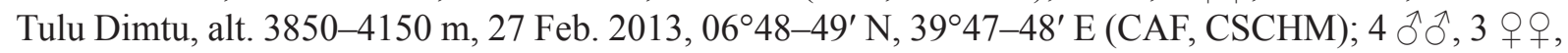
N-slope Bale Mts, Kaficha Valley, alt. 3960 m, 0659'12" N, 3951'53" E, 27 Feb. 2015 (CSCHM);

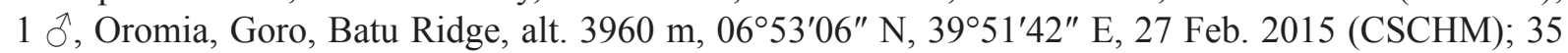

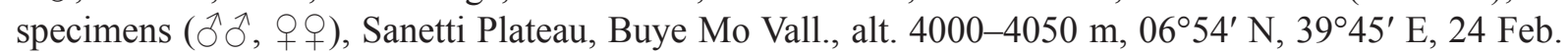
2015 (CSCHM); 1 §, Sanetti Camp, near road, alt. 3865 m, 06²4'42" N, 3947'03" E, 28 Feb. 2015 (CSCHM); 1 ō, 2 우, Bale Mts, Tegona Valley above Goba, alt. 3550 m, 20 Feb. 2017, 06 54'42" N,

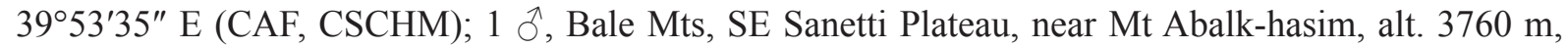

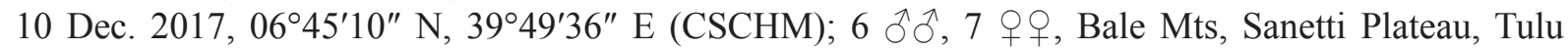

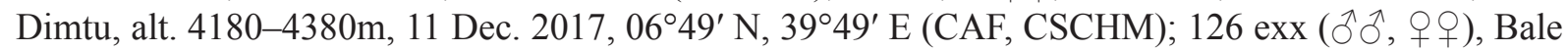
Mts, SE Sanetti Plateau, SW of Tulu Dimtu, alt. 3820 m, 15 Dec. 2017, 06 $46^{\prime} 43^{\prime \prime}$ N, 3946'47" E (CAF, CSCHM, NHMUK, MNHN, ZMAA).

\section{Identification}

Within the Trechus fauna of the Bale Mts, this species is recognized based on the combination of the following characters: body length moderately small $(3.5-4.3 \mathrm{~mm})$; elytral microsculpture consisting of deeply engraved isodiametric meshes; pronotum suggestively discoidal with base markedly bent anteriorly towards laterobasal angle, latter obtuse, marked as small blunt tooth; two basal protarsomeres of male dilated; aedeagal median lobe moderately short with dorsal margin distinctly convex; endophallus situated in apical half of median lobe, shaped like a fish trap, in dorsal view evenly narrowed towards aedeagal median lobe apex. 


\section{Distribution}

Endemic to the Bale Mts. The species seems widely distributed on the Sanetti Plateau and on its northern margin. It has been found at altitudes of $3550-4150 \mathrm{~m}$.

\section{Geographical variation}

Specimens from a population found in the Tegona Valley on the northern slope of the Bale Mts differ markedly by broader oval elytra which are not depressed on disc (Fig. 102), while specimens from the other populations studied are characterized by slenderer oval elytra, which are distinctly depressed on disc (Fig. 101). Trechus batuensis specimens from the Tegona valley are thus more similar to the sympatric and syntopic species $T$. fisehai sp. nov., however, the former can be recognized by the larger and almost isodiametric sculpticells of elytral microsculpture, and by the shape of the sclerotized portion of the endophallus (Fig. 130), which is evenly narrowed towards apex if viewed from dorsad, but abruptly narrowed in middle portion in T. fisehai sp. nov. (Fig. 134). It seems possible that the T. batuensis population from the Tegona valley represent a geographical subspecies. However, additional material needs to be studied before taxonomic conclusions can be drawn.

\section{Trechus culminicola Jeannel, 1936}

Trechus (s. str.) culminicola Jeannel, 1936: 207; locus typicus: Mt Chillalo, alt. approx. 4000 m.

Trechus culminicola - Ortuño \& Novoa 2011: 137.

\section{Type material}

Not studied. Identification of this species is based on its original description including figures of habitus and genital characters, and on additional material collected at the type locality.

\section{Material examined}

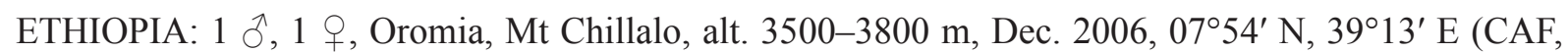
CSCHM).

\section{Identification}

The smallest Trechus species known to occur at Mt Chillalo (body length 3.0-3.5 mm). Within the Trechus fauna of this volcanic massif, T. culminicola is most similar to T. gallorites; for identification see key to species. Trechus culminicola can be easily distinguished from all species known from the Bale Mts and Mt Enkuolo with body size smaller than $3.5 \mathrm{~mm}$ based on the following combination of characters: two protarsomeres of male dilated; elytra moderately convex, slightly flattened on disc; micro-meshes on elytra rather large, more deeply engraved, almost isodiametric.

\section{Distribution}

Probably endemic to Mt Chillalo. The species has been found at altitudes of 3500-4000 m.

\section{Trechus gallorites Jeannel, 1936}

Trechus (s. str.) gallorites Jeannel, 1936: 206; locus typicus: Mt Chillalo, alt. approx. 4000 m.

Trechus gallorites - Ortuño \& Novoa 2011: 137. 


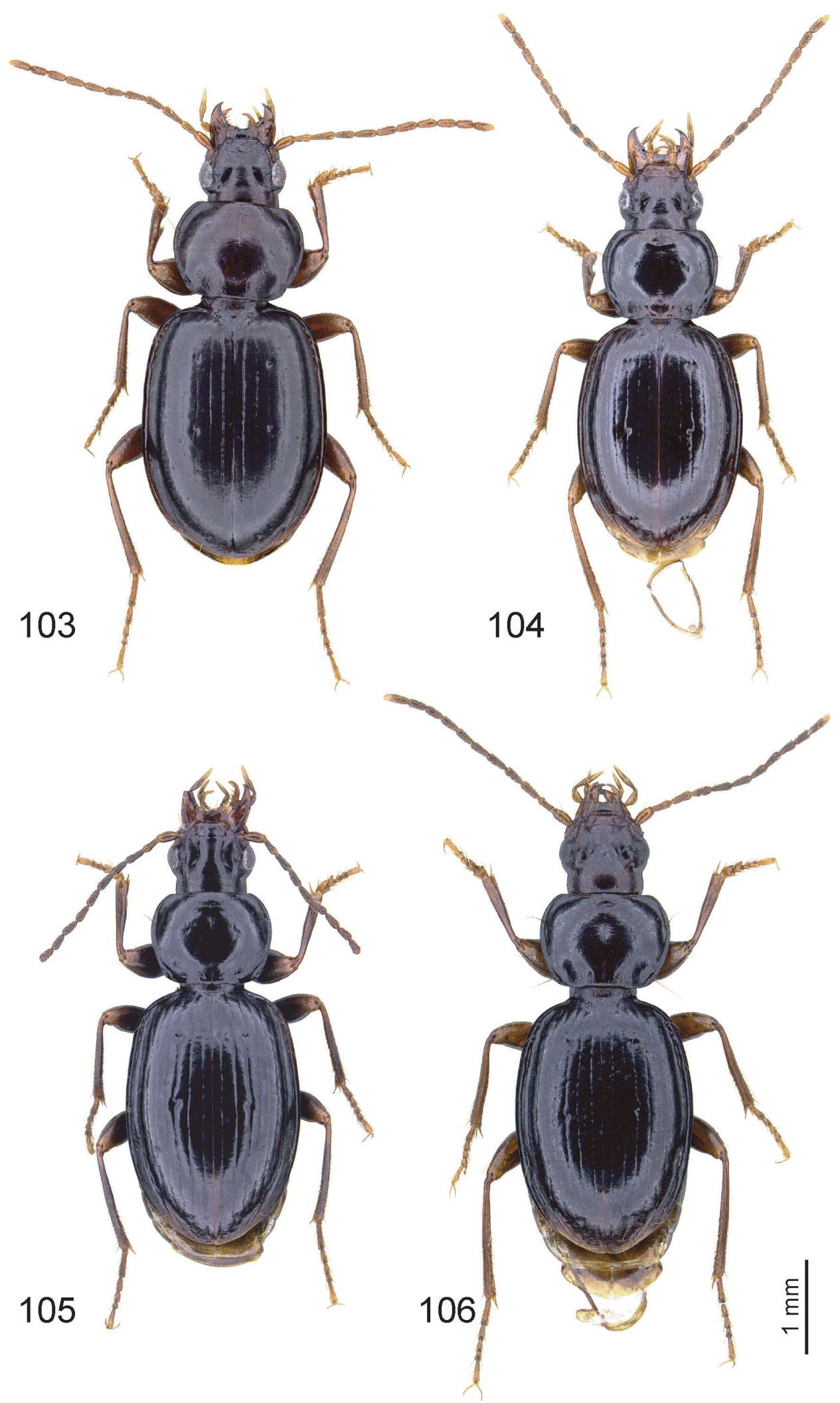

Figs 103-106. Trechus spp., habitus. 103. T. haggei sp. nov., paratype, đ. 104. T. tragelaphus sp. nov., holotype. 105. T. nigrifemoralis, sp. nov., holotype. 106. T. balesilvestris, sp. nov., holotype. 


\section{Type material}

Not studied. Identification of this species is based on its original description including figures of habitus and genital characters, and on additional material collected at the type locality.

\section{Material examined}

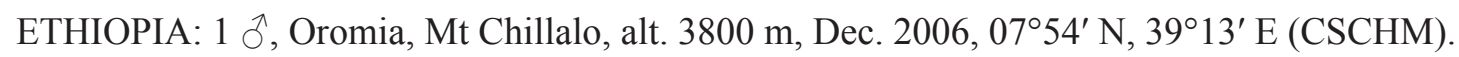

\section{Identification}

Within the Trechus fauna of Mt Chillalo, T. gallorites can be easily recognized by the moderately small body length (3.8-4 mm) and the hook-shaped apex of the aedeagal median lobe (see Jeannel 1936: 207, fig. 2). In this area, it is most similar to T. culminicola; for identification see key to species.

\section{Distribution}

Probably endemic to Mt Chillalo. The species was found at altitudes of 3800-4000 m.

Trechus tragelaphus sp. nov. urn:1sid:zoobank.org:act:9BD6D87E-FAF4-4B63-B158-E98DF905C11C

Figs 104, 108, 112, 135

\section{Diagnosis}

Due to the markedly rounded pronotal basal angles, this new species is similar to T. baleensis and T. rotundicollis, but its body length is distinctly smaller $(4.5-4.6 \mathrm{~mm}$ instead of $>5.1 \mathrm{~mm})$ and the endophallus much less extensively sclerotized. Similar species from the Bale Mts are also T. batuensis and T. haggei sp. nov., however, these species are easy to distinguish due to the large and deeply engraved meshes of elytral microsculpture. Species related to T. ericalis differ, inter alia, by the significantly broader oval elytra (EW/PW > 1.5 instead of 1.37-1.44 in T. tragelaphus sp. nov.). For differentiation with $T$. nigrifemoralis sp. nov. and T. balesylvestri sp. nov., see description of the latter species below.

\section{Etymology}

Named after the Mountain Nyala (Tragelaphus buxtoni Lydekker, 1910), an endangered and very characteristic large antelope, which occurs in the high-altitude forests of the western Bale Mts together with the new species of Trechus.

\section{Material examined}

\section{Holotype}

ETHIOPIA: ${ }^{\top}$, Oromia, western Bale Mts, above Dodola, alt. 3400-3700 m, 06 ${ }^{\circ} 51^{\prime} \mathrm{N}, 39^{\circ} 14^{\prime} \mathrm{E}$, Dec. 2006 (CSCHM, registration number ZSM_COL_2018_023).

\section{Paratypes}

ETHIOPIA: $2 \widehat{\partial}$, same data as for holotype (CAF, CSCHM).

\section{Description}

Body Length. 4.5-4.6 mm $(\varnothing=4.53 \mathrm{~mm}, \mathrm{n}=3)$.

Proportions $(\mathrm{n}=3)$. PW/HW = 1.36-1.37 ( $=1.37) ; \mathrm{PW} / \mathrm{PL}=1.29-1.31(\varnothing=1.30) ; \mathrm{PW} / \mathrm{PBW}=1.31$; $\mathrm{EW} / \mathrm{PW}=1.37-1.44(\varnothing=1.40) ; \mathrm{EL} / \mathrm{EW}=1.36-1.41(\varnothing=1.39)$. 
Colour. Head, pronotum and elytra dark brown, elytra markedly shiny, iridescent. Lateral margin of labrum, palpi, antennal base and legs light brown; antennae distally darkened beginning from second or third antennomere.

Microsculpture (MALes). Head with rather large, deeply engraved, almost isodiametric meshes on disc and supraorbital area, and smaller, slightly engraved meshes on clypeus. Pronotum with much narrower, finely engraved, transverse meshes. Elytra with hardly visible, very slightly engraved very narrow transverse meshes.

HEAD. Moderately robust. Mandibles moderately short. Labrum with apical margin widely emarginated. Eyes moderately large, convexly protruded. Tempora moderately long, about half as long as eyes, convex, markedly wrinkled to the neck, smooth. Frons and supraorbital area strongly convex, with supraorbital furrows almost uniformly bent on disc, deep throughout. Length of antennae average for Trechus, proportions of the first four antennomeres as follows: 1/0.85/1/0.95.

Prothorax. Pronotum large, moderately transverse, broadest portion distinctly before middle, base slightly wider than apical margin. Disc moderately convex. Anterior margin slightly concave with anterior angles slightly protruded, rounded. Sides rounded in anterior $6 / 7$, almost straight before laterobasal angles; latter very obtuse, rounded, not protruded laterally. Marginal gutter narrow in anterior $3 / 4$, slightly widened towards base. Base straight in middle, distinctly bent anteriorly near laterobasal angles. Median longitudinal impression very fine, not deepened near base, disappearing at apex; anterior and posterior transverse impressions very shallow, smooth; laterobasal foveae deep, moderately large, roundish, smooth, bordered from the lateral gutter by a fine carina. Pronotum with laterobasal setae present.

Pterothorax. Elytra moderately convex on disc, slightly flattened if viewed from behind, in dorsal view oval, broadest slightly before mid-length, with shoulders broadly rounded; apex suggestively pointed. Striae finely punctate, parascutellar stria moderately short and deep, striae 1-3 moderately fine impressed, 4-6 finer, 7 indistinct, 8 deeply impressed throughout. Internal 3-4 intervals very slightly convex. Recurrent preapical stria deep, short, slightly curved in front, directed to the seventh stria. Third stria with two setiferous dorsal pores (in one specimen the posterior discal pore lacking on right elytron), the anterior one near the end of the anterior elytral quarter, the posterior one in middle, and with preapical seta which is situated at the apical anastomosis of second and third striae slightly closer to suture than to elytral apex. Number and positions of the setae of the marginal umbilicate series as in Trechus s. str.

LeGs. Moderately short and thin; protibia slightly dilated towards apex, almost straight, distinctly grooved on external surface. Two basal protarsomeres of male dilated.

Male genitalia. EL/AL $=2.63-2.72(\varnothing=2.68, \mathrm{n}=3)$. Aedeagal median lobe moderately robust, in lateral view its anterior part wider than basal bulb, its ventral margin more markedly bent behind basal bulb and straight before apex, its dorsal margin convexly widened at apical ostium; apical lamella very short, button-like. Basal bulb moderately small, sagittal aileron moderately large. Endophallus with three more markedly sclerotized folding structures below apical ostium, two of which are longitudinally directed and lie on top of each other, the third one lying in diagonally upright position immediately basad of the latter.

\section{Distribution}

Known only from the type locality, a single brook valley in the western Bale Mts above Dodola city. The species was collected at an altitude of approximately $3400-3500 \mathrm{~m}$. 

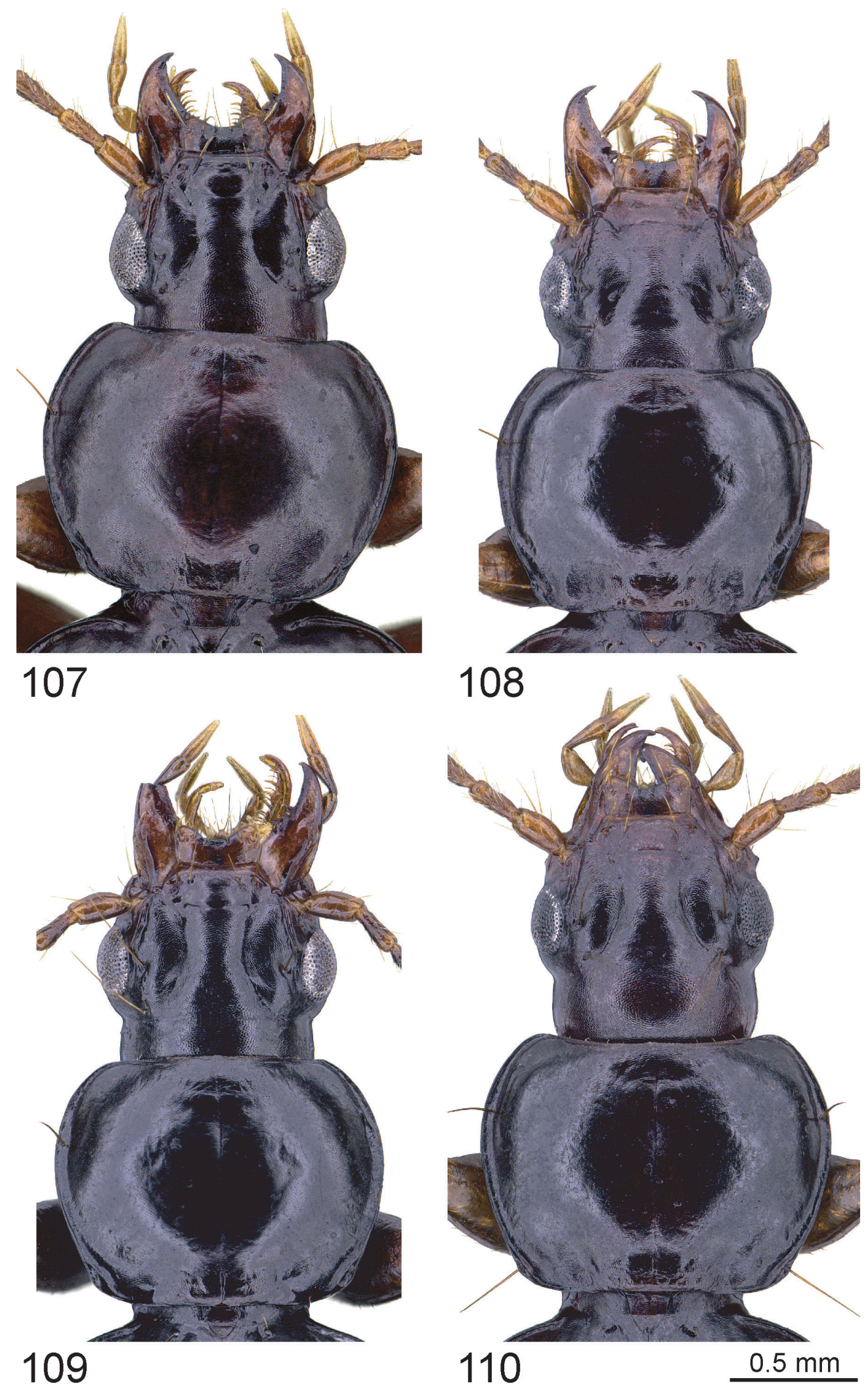

Figs 107-110. Trechus spp., head, pronotum. 107. T. haggei sp. nov., paratype, §. 108. T. tragelaphus sp. nov., holotype. 109. T. nigrifemoralis, sp. nov., holotype. 110. T. balesilvestris, sp. nov., holotype. 


\section{Trechus nigrifemoralis sp. nov. urn:1sid:zoobank.org:act:ACF4835B-96AD-453E-9872-15C277B22B6C}

Figs 105, 109, 113, 136

\section{Diagnosis}

In external characters this new species is very similar to the above-described sympatric species T. tragelaphus sp. nov.; for differentiation with other species of the study area see Identification chapter of the latter species above. Trechus nigrifemoralis sp. nov. differs from T. tragelaphus sp. nov. and the below-described T. balesilvestris sp. nov. externally by the darker colour of body with more blackish brown head, pronotum and elytra, and with basal three quarters of femora distinctly darker than apex. The aedeagal median lobe is much shorter than in T. balesilvestris sp. nov., with dorsal margin not widened at apical ostium as in T. tragelaphus sp. nov.

\section{Etymology}

The specific epithet refers to the distinctly darkened femoral base, which is a unique character within the Trechus fauna of the study area.

\section{Material examined}

\section{Holotype}

ETHIOPIA: ôn, Oromia, western Bale Mts, above Dodola, alt. 3400-3700 m, 06 $6^{\circ} 51^{\prime} \mathrm{N}, 39^{\circ} 14^{\prime} \mathrm{E}$, Dec. 2006 (CSCHM, registration number ZSM_COL_2018_024).

\section{Paratype}

ETHIOPIA: 1 , same data as for holotype (CSCHM).

\section{Description}

Body Length. 4.7-4.9 mm $(\mathrm{n}=2)$.

Proportions $(\mathrm{n}=2) . \mathrm{PW} / \mathrm{HW}=1.35-1.39 ; \mathrm{PW} / \mathrm{PL}=1.32-1.35 ; \mathrm{PW} / \mathrm{PBW}=1.28 ; \mathrm{EW} / \mathrm{PW}=1.43-1.44$; $\mathrm{EL} / \mathrm{EW}=1.41-1.46$.

CoLour. Head, pronotum and elytra blackish brown, elytra markedly shiny, iridescent. Lateral margin of labrum, palpi, antennal base, femoral apex and tibial base light brown; antennae distally darkened beginning from second (holotype) or third (paratype) antennomere; basal three quarters of femora darkened; distal four fifth of tibia darkened in the holotype.

Microsculpture. As described in T. tragelaphus sp. nov.

HEAD. Antennae moderately short, proportions of the first four antennomeres as follows: 1/0.85/0.9/0.85. In all other characters as described in T. tragelaphus sp. nov.

Prothorax. Pronotum with broadest portion slightly before middle, base with external quarters distinctly bent anteriorly; large and roundish laterobasal foveae more steeply sloped interiorly, connected with the basal portion of lateral gutter externally. In all other characters as described in T. tragelaphus sp. nov.

PTEROTHORAX. Elytra convex on disc, very slightly flattened if viewed from behind, in dorsal view broadest in mid-length. Parascutellar stria moderately long, striae 1-3 moderately deep impressed, internal 3-4 intervals moderately convex, recurrent preapical stria moderately short. In all other characters as described in T. tragelaphus sp. nov. 

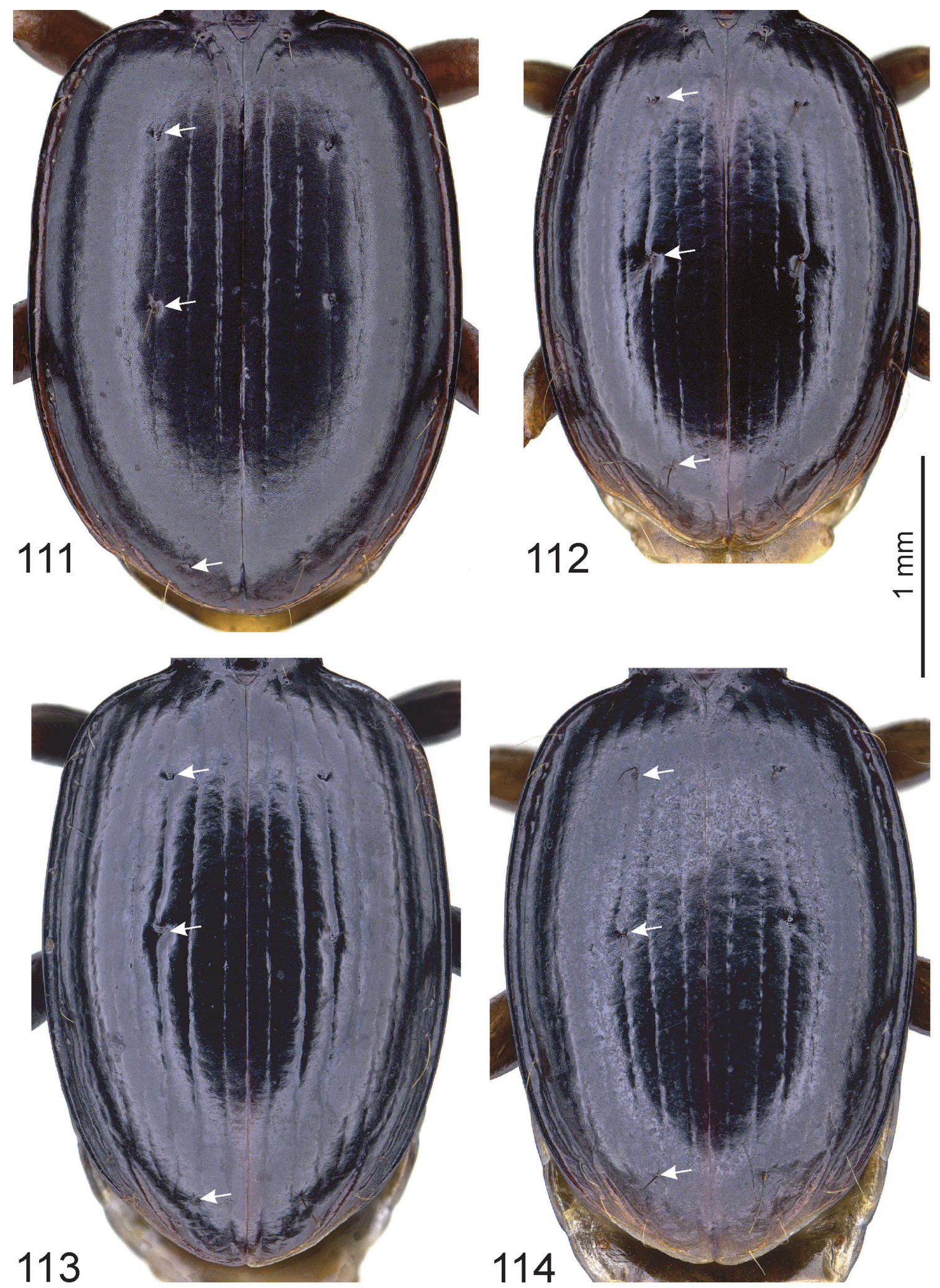

Figs 111-114. Trechus spp., elytra. 111. T. haggei sp. nov., paratype, $\widehat{\jmath}$. 112. T. tragelaphus sp. nov., holotype. 113. T. nigrifemoralis, sp. nov., holotype. 114. T. balesilvestris, sp. nov., holotype. The arrows point to the insertions of the discal setae and the preapical seta. 
Legs. As described in T. tragelaphus sp. nov.

Male genitalia. EL/AL $=2.83(\mathrm{n}=1)$. Aedeagal median lobe moderately robust, in lateral view with ventral margin more markedly bent behind basal bulb, almost straight towards apex; apical lamella very short, button-like, shortly bent upward. Basal bulb and sagittal aileron average. Endophallus with a moderately sclerotized fish trap-like structure below apical ostium.

\section{Distribution}

Known only from the type locality, a single brook valley in the western Bale Mts, above Dodola city. The species was collected at an altitude of approximately $3400-3500 \mathrm{~m}$.

Trechus balesilvestris sp. nov. urn:Isid:zoobank.org:act:7E305BAC-1ECF-4CE7-89D7-3A6257928AEC

Figs 106, 110, 114, 137

\section{Diagnosis}

Very similar to the above-described T. tragelaphus sp. nov., which is probably the allopatric sister species, but pronotum more transverse and aedeagal median lobe longer, with apex slenderer, and with dorsal margin not markedly widened near apical ostium. For differentiation with the other species of the study area, see Identification chapters of T. nigrifemoralis sp. nov. and T. tragelaphus sp. nov.

\section{Etymology}

A compound word derived from the Bale Mountain and the Latin noun "sylvestre" (forest), refering to the local habitat of the new species, which is highly endangered due to deforestation.

\section{Material examined}

\section{Holotype}

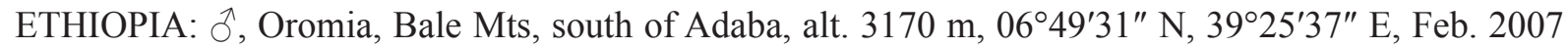
(CSCHM, registration number ZSM_COL_2018_025).

\section{Description}

Body LENGTH. $4.9 \mathrm{~mm}(\mathrm{n}=1)$.

Proportions $(\mathrm{n}=1) . \mathrm{PW} / \mathrm{HW}=1.45 ; \mathrm{PW} / \mathrm{PL}=1.43 ; \mathrm{PW} / \mathrm{PBW}=1.30 ; \mathrm{EW} / \mathrm{PW}=1.38 ; \mathrm{EL} / \mathrm{EW}=1.41$.

Colour and microsculpture. As described in T. tragelaphus sp. nov.

HEAD. Proportions of the first four antennomeres: 1/0.85/0.95/0.9. In all other characters as described in T. tragelaphus sp. nov.

Prothorax. Pronotum more transverse, broadest portion slightly before middle, base distinctly wider than apical margin, anterior margin moderately concave with anterior angles distinctly protruded, side margin rounded throughout. In all other characters as described in T. tragelaphus sp. nov.

Pterothorax. $8^{\text {th }}$ elytral stria very finely impressed in anterior portion, deeply impressed from level of middle group of marginal umbilicate pores towards apex. Metepisternum very short, glabrous and smooth, with outer margin as long as anterior margin. In all other characters as described in T. tragelaphus sp. nov. 
Legs. As described in T. tragelaphus sp. nov.

Male genitalia. EL/AL $=2.26(n=1)$. Aedeagal median lobe moderately slender, in lateral view with ventral margin suggestively sinusoidal, more markedly bent behind basal bulb, slightly convex before apex, with moderately long button-like apical lamella slightly bent upward. Basal bulb and sagittal aileron average. Endophallus with three more markedly sclerotized folding structures below apical ostium, two of which are longitudinally directed and lie on top of each other, the third one lying in upright position immediately basad of the latter.

\section{Distribution}

Known only from the type locality, a single brook valley in the western Bale Mts, south of Adaba city. The species was collected at an altitude of $3170 \mathrm{~m}$.

Trechus haggei sp. nov. urn:1sid:zoobank.org:act:F38413D7-9ADB-40F7-AF8B-A8B4D96BB384

Figs 103, 107, 111, 124

\section{Diagnosis}

Within the Trechus fauna of the study area, this new species is unique due to the combination of the following characters: medium body length (approx. 4.4-4.7 mm); meshes of microsculpture on head, pronotum and elytra almost uniformly engraved, large and deeply impressed, isodiametric or very slightly transverse; pronotal base laterally markedly bent anteriorly towards very obtuse hind angles; elytra with lateral margin almost parallel in second quarter; pores of elytral discal setae dimple-like, deepened; aedeagal median lobe markedly long and slender.

\section{Etymology}

This remarkable new species is dedicated to the coleopterologist Jonas Hagge, Munich, for his contributions to the biogeography of high-altitude ground beetles of Ethiopia and High Asia.

\section{Material examined}

\section{Holotype}

ETHIOPIA: ${ }^{\wedge}$, Oromia, Bale Mts Finchaya Habera, 3400-3500 m, 0700' N, 39 $43^{\prime}$ E, 20-21 Feb. 2013 (CSCHM, registration number ZSM_COL_2018_026).

\section{Paratypes}

ETHIOPIA: $2 \hat{\jmath} \widehat{\partial}, 2$ 우, same data as for holotype (CSCHM).

\section{Description}

Body LENGTH. 4.4-4.7 mm (Ø $=4.58 \mathrm{~mm}, \mathrm{n}=5)$.

Proportions $(\mathrm{n}=5) . \mathrm{PW} / \mathrm{HW}=1.48-1.54(\varnothing=1.50) ; \mathrm{PW} / \mathrm{PL}=1.33-1.39(\varnothing=1.35) ; \mathrm{PW} / \mathrm{PBW}=$ $1.29-1.33(\varnothing=1.31) ; \mathrm{EW} / \mathrm{PW}=1.39-1.46(\varnothing=1.43) ; \mathrm{EL} / \mathrm{EW}=1.39-1.45(\varnothing=1.42)$.

Colour. Head, pronotum and elytra dark or blackish brown, silk-shiny. Lateral margins of labrum and elytra reddish brown, lightened. Palpi, antennal base and legs light brown; antennae distally slightly darkened beginning from third antennomere.

Microsculpture. Same in males and females. Head, pronotum and elytra with rather large and deeply engraved, almost isodiametric or slightly transverse meshes. 


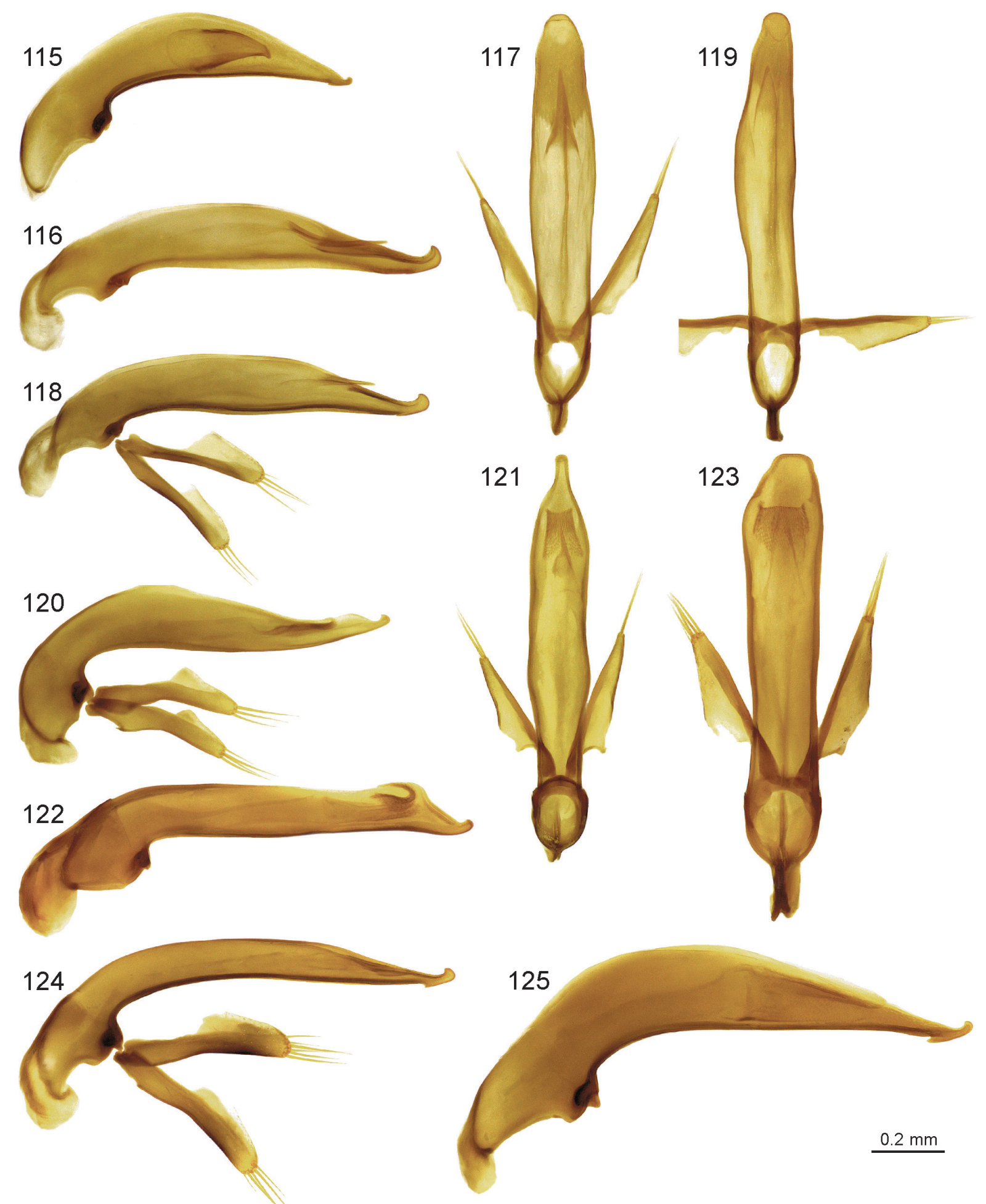

Figs 115-125. Trechus spp., aedeagal median lobe, left lateral view (115-116, 118, 120, 122, 124-125) and dorsal view $(117,119,121,123)$. 115. T. depressipennis sp. nov., holotype. 116-117. T. mekbibi sp. nov., paratypes. 118-119. T. hagenia sp. nov., paratypes. 120-121. T. colobus sp. nov., paratypes. 122-123. T. wiersbowskyi sp. nov., paratypes. 124. T. haggei sp. nov., paratype. 125. T. grandipennis sp. nov., holotype. 


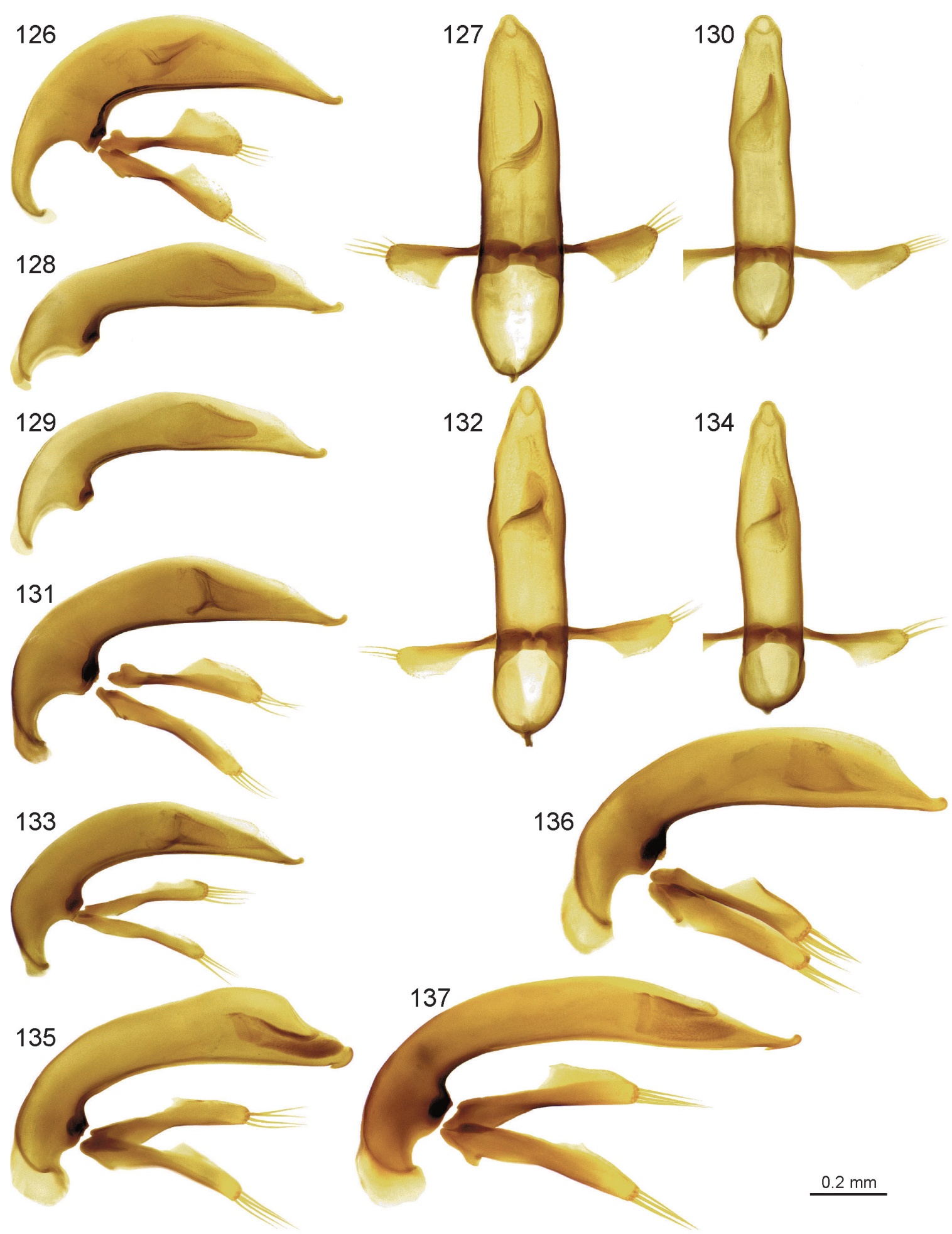

Figs 126-137. Trechus spp., aedeagal median lobe, left lateral view (126, 128-129, 131, 133, 135-137) and dorsal view $(127,130,132,134)$. 126-127. T. sanettii sp. nov., paratypes. 128. T. angavoensis sp. nov., holotype. 129-130. T. batuensis Magrini \& Sciaky, 2006, specimens from Wasama Valley. 131-132. T. abalkhasimi sp. nov., paratypes. 133-134. T. fisehai sp. nov., paratypes. 135. T. tragelaphus sp. nov., holotype. 136. T. nigrifemoralis sp. nov., holotype. 137. T. balesilvestris sp. nov., holotype. 
HeAD. Size normal for Trechus. Mandibles moderately short. Labrum with apical margin widely emarginated. Eyes large, convexly protruded. Tempora moderately short, convex, markedly wrinkled to the neck, approx. 0.7 times as long as eyes, smooth. Frons and supraorbital area strongly convex, with supraorbital furrows almost uniformly bent on disc, deep throughout. Length of antennae average for Trechus, proportions of the first four antennomeres as follows: 1/0.85/1.05/0.9.

Prothorax. Pronotum moderately large and transverse, broadest portion distinctly before middle, base slightly wider than apical margin. Disc moderately convex. Anterior margin moderately concave with anterior angles distinctly protruded, shortly rounded. Sides almost evenly rounded until laterobasal angles; latter very obtuse, very slightly protruded laterally. Marginal gutter narrow in anterior $2 / 3$, very slightly widened towards base. Base straight in middle, with lateral quarters markedly bent anteriorly. Median longitudinal impression very fine, not deepened near base, disappearing at apex; anterior transverse impression indistinct, smooth; posterior transverse impression indistinct in middle with laterobasal foveae very shallow, roundish, smooth. Pronotum with laterobasal setae present.

Pterothorax. Elytra convex on disc, slightly flattened if viewed from behind, in dorsal view rather slender oval with sides almost parallel in second quarter, broadest in mid-length; shoulders and apex broadly rounded. Striae impunctate or suggestively punctate, parascutellar stria moderately long, deep, internal 1-2 striae deeply impressed, 3 very fine, 4-5 indistinct, 6-7 absent, 8 deeply impressed from level of the middle group of the marginal umbilicate pores towards apex. Internal 1-2 intervals slightly convex. Recurrent preapical stria deep, short, slightly curved in front, directed to the seventh stria. Third stria with two setiferous dorsal pores, the anterior one near the end of the anterior elytral quarter, the posterior one in middle, and with preapical seta which is situated at the apical anastomosis of second and third striae, approx. as close to the elytral apex as to the suture; pores of discal setae dimple-like, deepened. Number and positions of the setae of the marginal umbilicate series as in Trechus s. str.

Legs. Moderately short and thin; protibia slightly dilated towards apex, almost straight, distinctly grooved on external surface. Two basal protarsomeres of male dilated.

Male Genitalia. EL/AL $=2.28-2.34(\varnothing=2.31, \mathrm{n}=3)$. Aedeagal median lobe markedly long and slender, in lateral view more markedly bent behind basal bulb, straight in middle, and very slightly bent upward towards apex; apical lamella rather long with apex button-like pointed, latter in lateral view with its upper margin hook-like bent backwards; basal bulb average, sagittal aileron large. Endophallus poorly sclerotized throughout with copulatory piece hardly visible, spine-like.

\section{Distribution}

Endemic to the northern slope of the Bale Mts; known only from the type locality, along a brook valley (place Finchaya Habera) at altitudes of 3400-3500 m.

\section{Trechus rotundicollis (Basilewsky, 1974)}

Cothresia rotundicollis Basilewsky, 1974: 151; locus typicus: Bale Province, Ridge of Mt Batu, Deekasura Pass, ca. 36 km S of Dinshu, Bale Mts, alt. 4150 m, 655' N, 394 $46^{\prime}$ E.

Trechus rotundicollis - Geginat 2008: 124.

\section{Type material}

Not studied. This species was revised by Geginat (2008: 125) with presentation of a photo of the male genitalia. Identification is also based on additional material from the type locality. 


\section{Material examined}

ETHIOPIA: $3 \widehat{\partial}^{\lambda} \widehat{O}^{\lambda}, 2$ 우, Oromia, env. Wasama Camp, alt. 3900-4150 m, 23-25 Feb. 2013, 06 ${ }^{\circ} 55^{\prime} \mathrm{N}$, $39^{\circ} 46^{\prime} \mathrm{E}$ (= type locality) (CSCHM).

\section{Identification}

The largest species of the study area, with body length 5.9-6.6 mm. Externally, most similar to the sympatric T. baleensis (and its allopatric sister species T. chillalicus from Mt Chillalo), however, easy to distinguish due to the markedly elongated median lobe of aedeagus (Geginat 2008: 125). In addition, this is the only species of the study area with additional setae of the marginal umbilicate series.

\section{Distribution}

Endemic to the northern slope of the Bale Mts; up to today only known from the Wasama Valley south of Dinsho. The species has been found at altitudes of approximately $3900-4150 \mathrm{~m}$.

Trechus baleensis (Basilewsky, 1974)

Cothresia baleensis Basilewsky, 1974: 155; locus typicus: Bale Province, Ridge of Mt Batu, Deekasura Pass, ca. 36 km S of Dinshu, Bale Mts, alt. 4150 m, 6 ${ }^{\circ} 55^{\prime} \mathrm{N}, 39^{\circ} 46^{\prime} \mathrm{E}$.

Trechus baleensis - Geginat 2008: 123.

\section{Type material}

Not studied. The species was revised by Geginat (2008: 125) with presentation of a photo of the male genitalia. Identification is also based on additional material collected at the type locality.

\section{Material examined}

ETHIOPIA: $3 \partial^{\lambda}$, Bale Mts, Finchaya Habera Camp, river valley, alt. $3400-3500 \mathrm{~m}, 07^{\circ} 00^{\prime} \mathrm{N}, 39^{\circ} 43^{\prime}$ E, 20-21 Feb. 2013 (CSCHM); 3 우, same data as for preceding, $3470 \mathrm{~m}, 07^{\circ} 00^{\prime} 32^{\prime \prime} \mathrm{N}, 39^{\circ} 43^{\prime} 26^{\prime \prime} \mathrm{E}$,

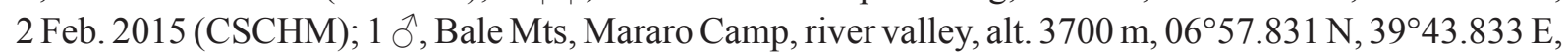

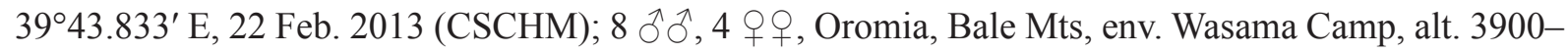
$4150 \mathrm{~m}, 06^{\circ} 55^{\prime} \mathrm{N}, 39^{\circ} 46^{\prime} \mathrm{E}, 23-25$ Feb. 2013 (= type locality) (CAF, CSCHM); 2 우, Bale Mts, river

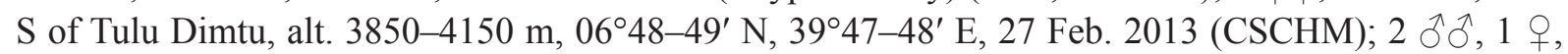
N slope Bale Mts, Kaficha Valley, alt. 3960 m, 27 Feb. 2015, 06 59'12" N, 3951'53" E (CSCHM); 1 ㅇ,

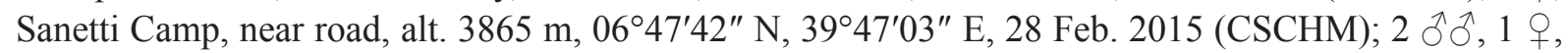
Bale Mts, brook valley above Goba, alt. 3750-3800 m, 06 54'42" N, 3954'38" E, 19 Feb. 2017 (CAF,

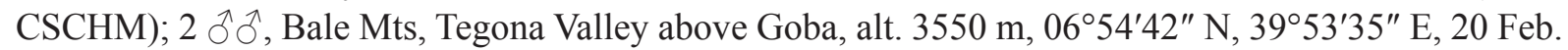

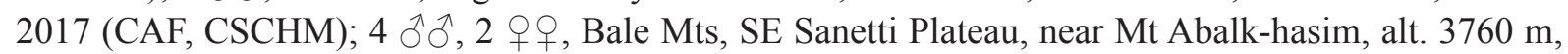

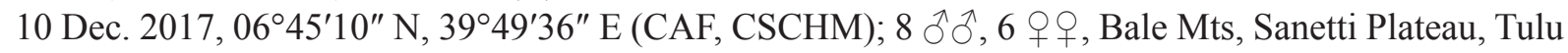

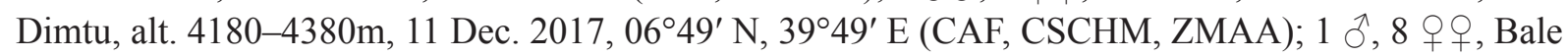
Mts, SE Sanetti Plateau, SW of Tulu Dimtu, alt. 3800-3820 m, 06 $46^{\prime} 43^{\prime \prime}$ N, 3946'47" E, 11 Dec. 2007

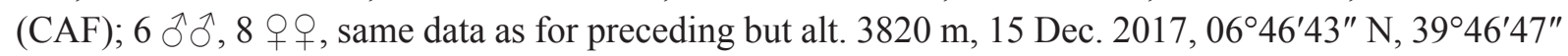
$\mathrm{E}(\mathrm{CSCHM})$.

\section{Identification}

This species is very similar to the sympatric T. rotundicollis, but smaller on average (body length 5.2-6.2 mm), colour of dorsal surface darker and shinier with elytra distinctly iridescent, elytral microsculpture with meshes narrower, more finely engraved, and aedeagal median lobe much shorter 
(see Geginat 2008: 125). For comparison with its allopatric sister species, T. chillalicus from Mt Chillalo, see Diagnosis chapter of the latter, below.

\section{Distribution}

Endemic to the northern slope of the Bale Mts and the high river valleys of the Sanetti Plateau. The species has been found at altitudes of $3400-4150 \mathrm{~m}$.

Trechus chillalicus Jeannel, 1936

Trechus (s. str.) chillalicus Jeannel, 1936: 210; locus typicus: Mt Chillalo, alt. approx. $4000 \mathrm{~m}$.

Cothresia robini Basilewsky, 1974: 156, syn. nov.; locus typicus: Arussi Province, Arussi Mts, just above Mt Titchio, ca $18 \mathrm{~km}$ E of Dighallu, alt. 3500-3700 m, 7 $46^{\prime} \mathrm{N}, 39^{\circ} 21^{\prime}$ E. Remark: in his original description Basilewsky (1974) accidentally noted wrong longitude data $\left(37^{\circ} 21^{\prime} \mathrm{E}\right)$ for the type locality.

Trechus robini [nec Trechus robinii Laboulbène, 1849] - Geginat 2008: 124.

Trechus chillalicus - Ortuño \& Novoa 2011: 137.

\section{Type material}

Not studied. Identification of the distinctive species T. chillalicus is based on its detailed description including figures of habitus and genital characters, and on additional material collected at the type locality. Cothresia robini was revised by Geginat (2008: 125) with presentation of a photo of the male genitalia.

\section{Material examined}

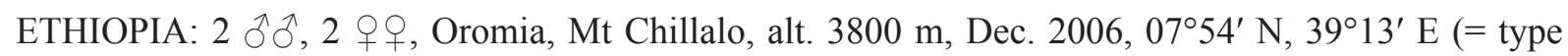
locality) (CAF, CSCHM).

\section{Identification}

Externally very similar to its allopatric sister species, $T$. baleensis, from the Bale Mts, but elytra with humerus more evenly rounded, striae 1-4 much more finely impressed and intervals flat, and aedeagal median lobe in lateral view with ventral margin slightly but distinctly convex (Geginat 2008: 125, fig. 5C). Within the Trechus fauna of Mt Chillalo this species is easy to recognize due to its large size and the markedly robust aedeagal median lobe.

\section{Remarks on synonymy}

Basilewsky (1974) described his species within the genus Cothresia Jeannel, 1964, and thus did not compare it with the numerous Trechus species already described by Jeannel (1936) from the same volcanic system. Comparison of male genital characters of specimens from the type locality of $T$. chillalicus with the holotype of Cothresia robini based on the aedeagus photo presented by Geginat (2008) clearly shows that both taxa refer to the same species.

\section{Distribution}

Endemic to Mt Chillalo and the larger and immediately easterly adjacent Mt Badda. The species was found at altitudes of approximately $3500-3800 \mathrm{~m}$. 


\section{Key to the species of Trechus from the Arussi and Bale Provinces of Ethiopia}

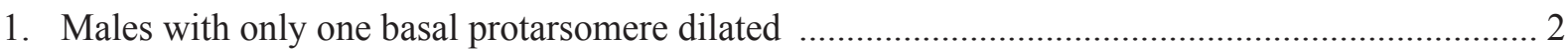

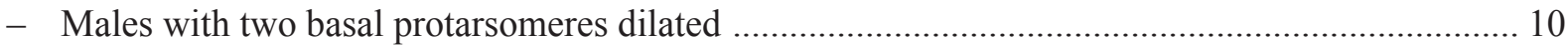

2. Disc of elytra with at least 4-5 internal striae distinctly engraved. Antennae slenderer with antennomeres 7-9 1.6-1.8 times as long as wide. Species from southern slope of Bale Mts ...3

- Elytral discal striae very finely engraved, usually indistinct with first stria often absent. Antennae short with antennomeres 7-9 1.2-1.4 times as long as wide

3. Each elytron with a single dorsal seta (both posterior discal seta on third stria and preapical seta are absent). Pronotum with laterobasal angles very obtuse, blunt at tip, and with laterobasal impressions indistinct; lateral gutter of pronotum not widened near base

T. transversicollis sp. nov.

- Two elytral discal setae present. Pronotum with laterobasal angles slightly obtuse, sharp at tip, and with laterobasal impressions broad; lateral gutter of pronotum distinctly widened towards base

T. mattisi sp. nov.

4. Elytra with preapical seta absent. Species of Mt Enkuolo with body colour of mature specimens light brown

- Elytra with preapical seta present (situated at the apical anastomosis of second and third striae). Species of the Bale Mts; body colour of mature specimens usually brown to dark brown

5. Each elytron with two dorsal setae on third stria in normal position

T. gypaeti Vigna Taglianti \& Magrini, 2010

- The posterior elytral dorsal seta is lacking T. minitrechus sp. nov.

6. Apex of terminal lamella of aedeagal median lobe simply tapered or with a small globose apical capitulum

- Median lobe of aedeagus with a distinct button-like apical capitulum (Figs 45, 47, 48) ............... 8

7. Eyes slightly larger than tempora. Aedeagal median lobe stouter (Fig 43)

T. nanulus sp. nov.

- Eyes slightly smaller than tempora. Aedeagal median lobe more elongated (Fig 44)

T. rira sp. nov.

8. Aedeagal median lobe in lateral view with ventral margin sinusoidal (Fig 47)

T. relictus Magrini, Quéinnec \& Vigna Taglianti, 2012

- Aedeagal median lobe in lateral view with ventral margin concave or straight

9. Aedeagal median lobe robust in view from laterad and dorsad (Figs 48-49) ....T. oppositus sp. nov.

- Aedeagal median lobe slender in view from laterad and dorsad (Figs 45-46) ..T. iridescens sp. nov.

10. Body length $<3.5 \mathrm{~mm}$ and eyes rather small, tempora at least 0.7 times as long as eyes, first stria of elytra indistinctly impressed or absent, microsculpture of elytra with very finely engraved very transverse meshes

- Either body length $\geq 3.5 \mathrm{~mm}$, or eyes rather large, tempora at maximum 0.5 times as long as eyes, first stria of elytra distinctly impressed, microsculpture of elytra with distinctly engraved isodiametric or slightly transverse meshes

11. Body length approximately $3.2-3.3 \mathrm{~mm}$. Aedeagal median lobe slenderer, with terminal lamella long, markedly bent upward at tip (Fig. 56)

- Body length below $3.0 \mathrm{~mm}$. Aedeagal median lobe rather stout, with terminal lamella moderately short, at most slightly bent upward at tip 
12. Endophallus very slightly sclerotized throughout, without suggestion of a copulatory piece even in view from laterad (Fig. 53). Species from northern slope of western Bale Mts above the city of Adaba

T. adaba sp. nov.

- Endophallus with a more markedly sclerotized part near dorsoapical ostium which is easily recognizable in lateral view

13. Aedeagal median lobe in lateral view suggestively sinusoidal with ventral margin slightly convex in apical half (Fig. 55). Species from southeastern slope of Bale Mts

T. harenna sp. nov.

- Median lobe in lateral view with ventral margin evenly curved throughout or straight in apical half

14. Aedeagal median lobe markedly short $(E L / A L=3.96-4.16)$, in lateral view almost evenly bent throughout (Fig. 52). Species from northern slope of western Bale Mts above the city of Dodola .....

T. dodola sp. nov.

- Aedeagal median lobe more elongated $(\mathrm{EL} / \mathrm{AL}=3.03-3.22)$, in lateral view with ventral margin straight in apical half (Fig. 50). Species from southern slope of eastern Bale Mts, near the village of Rira

T. harryi sp. nov.

15. Each elytron with a single discal seta which inserts near the end of the anterior elytral quarter ... 16

- Each elytron with two discal setae, the anterior one near the end of the anterior elytral quarter, the posterior one near elytral middle

16. Pronotum with laterobasal setae absent. Species from Mt Chillalo

T. patrizii Jeannel, 1960

- Pronotum with laterobasal setae present. Species from Mt Chillalo, Mt Enkuolo, and northern slope of Bale Mts T. oromiensis Magrini, Quéinnec \& Vigna Taglianti, 2012

17. Eyes flat and very small, tempora as long as or longer than eyes 18

- Eyes moderately large and convexly protruded laterally, tempora distinctly shorter than eyes ..... 19

18. Aedeagal median lobe markedly funnel-shaped, widened near apex (Jeannel 1936: 209). Species from Mt Chillalo

T. scotti Jeannel, 1936

- Aedeagal median lobe simply narrowed towards apex (Geginat 2008: 125). Species from the Bale Mts

T. clarkeianus (Basilewsky, 1974)

19. Body length $>5.1 \mathrm{~mm}$ (usually $>5.5 \mathrm{~mm}$ ) and endophallus extensively sclerotized with total length of sclerotized portions more than half of length of aedeagal median lobe (Geginat 2008: 125, fig. 5A-C)

- Either body length $<5.1 \mathrm{~mm}$, or endophallus moderately sclerotized with total length of sclerotized portions approx. one third of length of aedeagal median lobe

20. Colour of dorsal surface mid-brown, elytra silk-matt, not iridescent; elytral microsculpture with meshes larger, more deeply engraved; aedeagal median lobe markedly elongated (Geginat 2008: 125, fig. 5A). Species from the Bale Mts

T. rotundicollis (Basilewsky, 1974)

- Colour of dorsal surface dark or blackish brown, elytra markedly shiny, iridescent; elytral microsculpture with meshes narrower, more slightly engraved; aedeagal median lobe markedly robust (Geginat 2008: 125, fig. 5B-C) 
21. Elytra with striae 1-4 very finely impressed and intervals flat; aedeagal median lobe in lateral view with ventral margin slightly but distinctly convex (Geginat 2008: 125, fig. 5C). Species from Mt Chillalo T. chillalicus Jeannel, 1936

- Elytra with striae 1-4 rather deeply impressed and intervals moderately convex; aedeagal median lobe in lateral view with ventral margin nearly straight (Geginat 2008: 125, fig. 5B). Species from the Bale Mts

T. baleensis (Basilewsky, 1974)

22. Species from Mt Chillalo

- Species from the Bale Mts

23. Elytra shinier with meshes of microsculpture more finely engraved, narrower, more transverse; aedeagal median lobe with apex hook-like bent upward (Jeannel 1936: 207, fig. 2)

T. gallorites Jeannel, 1936

- Elytra silk-like matt with meshes of microsculpture more deeply engraved, larger, almost isodiametric; aedeagal median lobe with apex simple (Jeannel 1936: 208, fig. 5) ....T. culminicola Jeannel, 1936

24. Pronotum with basal margin slightly but distinctly concave at outer quarters, and with laterobasal angles large, acute, posteriorly and laterally protruded (Fig. 72). Species from the southern slope and the western part of the Bale Mts.

T. mekbibi sp. nov.

- Pronotum with basal margin straight or convexly rounded at outer quarters; laterobasal angles not protruded posteriad

25. Pronotum with basal margin straight or very slightly bent anteriorly at outer quarters, and with laterobasal angles acute or rectangular or formed as a rather large, +/- sharp tooth (Figs 71, 7374)

- Pronotum with basal margin distinctly bent anteriorly at outer quarters, and with laterobasal angles rounded or formed as a small blunt tooth (Figs 83-86, 95-98, 108-110)

26. Pronotum with laterobasal angles comparatively large and acute (Fig. 71). Elytra markedly depressed on disc; meshes of elytral microsculpture rather large, as wide as long or very slightly transverse. Species from northern slope of Bale Mts

T. depressipennis sp. nov.

- Laterobasal angles of pronotum smaller. Elytra more convex, at most slightly depressed on disc, with micro-meshes very narrow, distinctly transverse

27. Aedeagal median lobe in lateral view distinctly sinusoidal, markedly bent behind basal bulb and markedly convex in middle (Fig. 120). Species from the western Bale Mts ........ T. colobus sp. nov.

- Aedeagal median lobe in lateral view markedly elongated, slightly bent behind basal bulb and slightly convex or straight in middle (Fig. 118; Magrini \& Sciaky 2006: 185, fig. 9). Species from the northern and southern slopes of the eastern Bale Mts

28. Aedeagal median lobe in dorsal view distinctly widened before apex (Magrini \& Sciaky, 2006: 185, fig. 10), and with endophallic copulatory piece short, triangular. Species from northeastern slope of Bale Mts T. bastianinii Magrini \& Sciaky, 2006

- Aedeagal median lobe in dorsal view parallel before apex and with endophallic copulatory daggerlike (Fig. 119). Species from southeastern slope of Bale Mts

T. hagenia sp. nov.

29. Microsculpture of elytra consists of rather large almost isodiametric meshes; elytra silk-shiny, not iridescent

- Microsculpture with sculpticells narrow and transverse; elytra markedly shiny, iridescent .......... 32 
30. Elytra with pores of discal setae conspicuously dimple-like, deepened T. haggei sp. nov.

- Elytral discal pores slightly impressed, normal for Trechus 31

31. Endophallus with sclerotized portions located in centre of aedeagal median lobe (Figs 126127)

T. sanettii sp. nov.

- Endophallus with sclerotized portions located in anterior half of aedeagal median lobe (Figs 129130)

T. batuensis Magrini \& Sciaky, 2006

32. Pronotum comparatively large, elytra slenderer oval (proportion EW/PW below 1.45) ............... 33

- Markedly broad oval elytra contrasting with a rather small pronotum (proportion EW/PW above 1.5)

33. Aedeagal median lobe slenderer, proportion EL/AL distinctly below 2.5 (Fig. 137)

T. balesilvestris sp. nov.

- Proportion EL/AL distinctly above 2.5

34. Legs yellowish brown, femora not distinctly darkened; aedeagal median lobe in lateral view markedly widened near apical ostium (Fig. 135) T. tragelaphus sp. nov.

- Basal three quarter of femora distinctly darkened; aedeagal median lobe in lateral view not widened near apical ostium (Fig. 136) T. nigrifemoralis sp. nov.

35. Aedeagal median lobe markedly elongated with middle portion tube-like, in lateral and dorsal views with side margins straight and parallel in middle (Figs 122-123) T. wiersbowskyi sp. nov.

- Aedeagal median lobe not tube-like, in lateral view with side margins not parallel, and with dorsal margin distinctly convex 36

36. Aedeagal median lobe larger with total length about $1.4 \mathrm{~mm}$ T. grandipennis sp. nov.

- Maximum length of aedeagal median lobe not above $1 \mathrm{~mm}$ 37

37. Aedeagal median lobe robust in lateral and dorsal view, with large basal bulb contrasting with markedly small sagittal aileron; endophallus more markedly sclerotized, with sclerotized portions distinctly longer than one third of total length of aedeagal median lobe (Magrini et al. 2013: 22, figs 2-4) ….......................................................T. ericalis Magrini, Quéinnec \& Vigna Taglianti, 2013

- Aedeagal median lobe slenderer, with basal bulb and sagittal aileron average; endophallus less markedly sclerotized, with maximum length of sclerotized portions one third of total length of aedeagal median lobe

38. Aedeagal median lobe less markedly bent in basal portion, straight from the end of the basal third towards apex (Fig. 128)

T. angavoensis sp. nov.

- Aedeagal median lobe more markedly bent in basal portion, straight after beginning of the second third

39. Aedeagal median lobe larger, total length $0.85-0.90 \mathrm{~mm}$, with button-like apex more markedly bent upward at tip (Fig. 131)

T. abalkhasimi sp. nov.

- Aedeagal median lobe smaller, total length $0.70-0.80 \mathrm{~mm}$, with button-like apex slightly bent upward at tip (Fig. 133)

T. fisehai sp. nov.

\section{Discussion}

The Ethiopian Highlands are characterized by a very high rate of local endemism in the ground beetle genus Trechus. This is not only true for the large massif of the Bale Mts, which represent the remains of an Oligocene shield volcano, but also for the much smaller Late Pliocene-Early Quaternary volcanos like 
Mt Chillalo and Mt Enkuolo. Based on current data, 31 endemic Trechus species are known for the Bale Mts, four for Mt Chillalo, and two for Mt Enkuolo. Only one species, T. oromiensis, was found to occur in relict habitats of each of these volcanos. Trechus chillalicus is known from Mt Chillalo and the nearby Mt Badda. Most of the Trechus species are known from a single locality, or from a few neighbouring localities along a valley of a mountain slope. Only three species are known to have a wider distribution in the Bale Mts: T. mekbibi sp. nov. was found in the Rira Valley on the southern escarpment and along slopes of the western portion of the Bale Mts; T. batuensis and T. baleensis are widely distributed on the Sanetti Plateau and in the uppermost portions of the brooks along plateau margins.

Wide parts of the Bale Mts and the adjacent volcanos are still to be investigated. Consequently, the occurrence of additional local endemics is expected. An in-depth investigation of the ground beetle fauna of the Ethiopian Highlands as a model group would therefore be very helpful to understand the patterns and causes of biodiversity and, last but not least, the particular needs to ensure its protection.

This paper also supports results from previous studies whereby certain morphological features, which are generally rare in the megadiverse Trechus, are much more common in the fauna of Ethiopia (Pawłowski 2003; Ortuño \& Novoa 2011). E.g., dilatation of only one protarsomere in males is a character state found in nine of the 38 species known from the Bale Mts and the adjacent volcanos. Due to the lack of a phylogenetic analysis it remains open whether this character evolved repeatedly or only once in the evolution of Ethiopian Trechus. Interestingly, in Ethiopian Trechus this character state is always associated with remarkable small body size. However, several markedly small species known from the same area have two male protarsomeres dilated (e.g., T. adaba sp. nov., T. dodola sp. nov., T. harenna sp. nov., T. harryi sp. nov.). Other striking characters which are known from species occurring in the volcanic systems of northern Ethiopia, such as pilosity of the dorsal surface and displacement of elytral discal setae towards the fourth stria, are, however, not observed in species of the study area. A possible cause for this pattern might be that development of those characters was restricted to terminal clades which evolved distinctly after the colonization of eastern central Africa by boreal Trechus, and thus a result of subsequent radiation of the lineages in the course of the local mountain development and climate changes.

Herewith arise the closely connected questions of whether the occurrence of the highly diverse Trechus in the Ethiopian Highlands is based on single or multiple immigrations from the Cenozoic Boreal, and in which geological period immigration occured. Ortuño \& Novoa (2011: 137) believe that the Ethiopian Trechus represent "a relict fauna of a group that once had a more contiguous distribution". Jeannel (1954: 181) hypothesized that "migration de lignées paléarctiques vers le sud, sur l'Afrique orientale, doit dater de la période fraîche et très humide du Plio-pléistocène". This opinion was subsequently followed by Mani (1968) and Ortuño \& Novoa (2011). If so, evolution of the mega-diverse Ethiopian Trechus takes place in a rather short period and was very probably based on the immigration of several species that are ancestors of the different endemic lineages occurring in this area today. This hypothesis seems, however, contrasting with the rather low number of palaearctic ground beetle lineages occurring in the Ethiopian Highlands (Basilewsky 1962). Moreover, the appropriate climatic conditions, which would allow for dispersal of cold-adapted mesophilous or hygrophilous beetles in the lowlands of eastern Africa, seem to have never existed. In the Late Cenozoic, periods of higher cooling were connected with aridity and thus, the spread of flightless beetle taxa between the mountains was strongly restricted (summary in Brühl 1997). Long-distance dispersal of individuals of fully winged species originating from warm temperate areas of the Cenozoic Boreal and the subsequent evolution of winglessness, coupled with geographical radiation in the course of the geomorphological development of the Ethiopian Highlands could be another explanation of the current distributional patterns of Trechus. Following this scenario the immigration of northern faunal elements into the Ethiopian Highlands would have been possible during much longer periods. E.g., wide areas characterized by temperate or cooler climatic conditions 
existed in Ethiopia since the Oligocene when the very large and high-rising shield volcanos of Simien and Bale were formed (Williams 2016). Therefore, it is also possible that the evolution of Ethiopian Trechus dates back to 30 Million years ago or even slightly more. If so, it also seems possible that the evolution of Trechus in the Ethiopian Highlands is based on a single immigration event, which resulted in a high taxonomical and morphological diversity. We aim to corroborate this hypothesis in future studies by performing a phylogenetic analysis of Trechus in the widest sense, including a sufficient number of Ethiopian lineages.

\section{Acknowledgments}

We are very grateful to all entomologists who provided specimens of Trechus for study. We thank the Department of Plant Biology and Biodiversity Management, University of Addis Ababa, the Ethiopia Biodiversity Institute, the Ethiopian Wildlife Conservation Authority, and the managements of the Bale Mountain and Arsi Mountain National Parks, for the possibility of carrying out field work in the Ethiopian Highlands. Mekbib Fekadu, Fiseha Getachew, Daniel Wiersbowsky, Yeshitla Merene Abebe, and Yitbarek Wolde-hawariat (Addis Ababa), Robert Beck (Munich), Katinka Thielsen, David Hauth, Georg Miehe, Thomas Nauss and Lars Opgenoorth (Marburg), and Mattis Berndt (Rostock) gave comprehensive support for the field work of JS in Ethiopia. We would like to thank Max Barclay (NHMUK), Achille Casale (Torino) and an anonymous reviewer for critical reading of the MS, and Thierry Deuve (MNHN) for allowing us access to the material of African Trechus at the MNHN. The study was supported by the German Research Council (FOR 2358 OP-5-1).

\section{References}

Basilewsky P. 1962. Mission Zoologique de l'I.R.S.A.C. en Afrique orientale (P. Basilewsky et N. Leleup, 1957). LX. Coleoptera Carabidae. Annales Musée Royal de l'Afrique centrale 8 (107): 48-337.

Basilewsky P. 1974. Les Placomotrechina d'Ethiopie (Col. Carabidae Trechinae). Revue de Zoologie africaine 88 (1): 148-158.

Basilewsky P. 1975. Coléoptères Carabidae africains nouveaux XIX. Revue de Zoologie africaine 89 (1): 96-112.

Brühl C.A. 1997. Flightless insects: a test case for historical relationships of African mountains. Journal of Biogeography 24: 233-250. https://doi.org/10.1046/j.1365-2699.1997.00073.x

Casale A. 2011. Two new subterranean, microphthalmous trechine beetles from the Mediterranean area, and a synonymic note (Coleoptera: Carabidae: Trechini). Contributions to Natural History 16: 1-16.

Faille A., Casale A. \& Ribera I. 2010 Phylogenetic relationships of west Mediterranean troglobitic Trechini ground beetles (Coleoptera: Carabidae). Zoologica Scripta 40: 282-295.

Faille A., Casale A., Balke M. \& Ribera I. 2013. A molecular phylogeny of alpine subterranean Trechini (Coleoptera: Carabidae). BMC Evolutionary Biology 13: 248. https://doi.org/10.1186/1471-2148-13-248

Geginat G. 2008. Revision of the genus Cothresia Jeannel, 1964 (Coleoptera: Carabidae: Trechinae: Trechodina). Annals of the Transvaal Museum 45: 115-126.

Jeannel R. 1936. Sur des Trechinae recueillis par M. Hugh Scott en Abyssinie. Revue française d'Entomologie 2 (4) (1935): 205-212.

Jeannel R. 1954. Les Trechus du Simiène récoltés par le Dr H. Scott en 1952, (Coleoptera Trechidae) avec les planches I et II. Revue française d'Entomologie 21 (3): 171-183 + 2 plates.

Jeannel R. 1960. Un nouveau Trechus de l'Abyssinie. Revue française d'Entomologie 27 (4): 265-266. 
Knapp R. 1973. The Vegetation of Africa with References to Environment, Development, Economy, Agriculuture and Forestry Geography. Gustav Fischer, Stuttgart.

Magrini P., Quéinnec E. \& Vigna Taglianti A. 2012. A new subgenus and two new species of Trechus from Ethiopia (Coleoptera, Carabidae). Fragmenta entomologica 44 (1): 19-32.

https://doi.org/10.4081/fe.2012.30

Magrini P., Quéinnec E. \& Vigna Taglianti A. 2013. A new species of Trechus from the Ethiopian Plateau (Coleoptera, Carabidae). Fragmenta entomologica 45 (1-2): 17-24. https://doi.org/10.4081/fe.2013.13

Magrini P. \& Sciaky R. 2006. Cinque nuove specie di Trechus dell'Ethiopia (Coleoptera, Carabidae). Fragmenta entomologica 38 (2): 173-190. https://doi.org/10.4081/fe.2006.4

Mani M.S. 1968. Ecology and Biogeography of High Altitude Insects. Junk Publishers, The Hague.

Ortuño V.M. \& Novoa F. 2011. A new species of Trechus from the Ethiopian Highlands (Coleoptera: Carabidae: Trechinae) and key to the Trechus species of Ethiopia. Annals of the Entomological Society of America 104 (2): 132-140. https://doi.org/10.1603/AN10122

Pawłowski J. 2001. Le genre Trechus Clairville, 1806 (Coleoptera: Carabidae: Trechini) dans la collection Èthiopienne du Musée Royal de l'Afrique Centrale. I. Groupe du T. chokiensis. Elytron 15: 97-108.

Pawłowski J. 2003. Preliminary report on Ethiopian species of the genus Trechus Clairville, 1806 (Coleoptera: Carabidae). Baltic Journal of Coleopterology 3 (2): 157-160.

Williams F.M. 2016. Understanding Ethiopia. Geology and Scenery. Springer International Publishing, Switzerland. https://doi.org/10.1007/978-3-319-02180-5

Vigna Taglianti A. \& Magrini P. 2010. A new subgenus and a new species of Trechus from Ethiopia (Coleoptera, Carabidae). Fragmenta entomologica 41 (1): 69-76. https://doi.org/10.4081/fe.2009.82

Manuscript received: 18 October 2017

Manuscript accepted: 2 March 2018

Published on: 21 June 2018

Topic editor: Gavin Broad

Desk editor: Eva-Maria Levermann

Printed versions of all papers are also deposited in the libraries of the institutes that are members of the EJT consortium: Muséum national d'Histoire naturelle, Paris, France; Botanic Garden Meise, Belgium; Royal Museum for Central Africa, Tervuren, Belgium; Natural History Museum, London, United Kingdom; Royal Belgian Institute of Natural Sciences, Brussels, Belgium; Natural History Museum of Denmark, Copenhagen, Denmark; Naturalis Biodiversity Center, Leiden, the Netherlands; Museo Nacional de Ciencias Naturales-CSIC, Madrid, Spain; Real Jardín Botánico de Madrid CSIC, Spain; Zoological Research Museum Alexander Koenig, Bonn, Germany. 